\title{
3 "Wie lebt es sich als Türke in Deutschland?" Der Ausländer und sein Volk oder das Recht auf Repräsentation. Literatur, Film und Politik in den 1980er Jahren
}

\subsection{Das Recht auf Repräsentation}

\begin{abstract}
Sie sollen wissen, dass ich nicht in ihr Land gekommen bin, um von ihnen zu leben, dass ich nicht erst hier gelernt habe, was Zivilisation ist, dass ich nicht dumm bin, dass ich nicht von einem Mann abhängig bin, ja, dass ich sogar Französisch kann ... Dies alles möchte ich ihnen aufzählen, um mich von dem Bild einer türkischen Frau in ihren Köpfen zu befreien. Gleichzeitig finde ich mich und diesen Gedanken lächerlich. ${ }^{1}$
\end{abstract}

Diese Zeilen sind einem längeren Monolog der Ich-Erzählerin aus Aysel Özakıns autobiografischem Roman Die Leidenschaft der Anderen (1983) entnommen. Sie sind eine Antwort auf die Frage einer unbekannten, namentlich nicht genannten deutschen Dame an die Protagonistin des Romans, ob sie eine Französin sei. Bei einer Zugfahrt in Deutschland sitzen sich beide in einem Abteil gegenüber. Sie sei keine Französin, antwortet die Ich-Erzählerin. Die ältere deutsche Frau fragt nicht weiter nach, und es folgt ein längerer innerer Monolog über mehrere Seiten, aus dem die zitierte Passage stammt. In ihr reflektiert die Ich-Erzählerin, dass sie doch »handeln« und sagen müsse, dass sie Türkin sei, auch wenn es lächerlich erscheinen möchte - allein um den Vorstellungen der Deutschen zu widersprechen, dass türkische Frauen ungebildet und unterdrückt seien. Ihre kurze Antwort am Ende der Szene, dass sie Türkin sei, quittiert die alte Dame mit der Aussage, dass es ja selbstverständlich Ausnahmen gebe. ${ }^{2}$

Auch in anderen literarischen Gattungen der 1980er Jahre, beispielsweise in der Satire, bleibt vieles in der Begegnung, in Frage und Antwort, unerwähnt und wird nicht ausbuchstabiert. In Şinasi Dikmens Satiresammlung Der andere Türke von 1986 stehen in den ebenso alltagsnahen Szenen die Vorstellungen der Deutschen bei einer vergleichbaren Zugfahrt-Episode mitten im Raum. Dort betritt im eröffnenden Stück Wer ist ein Türke der Ich-Erzähler ein Abteil, in dem nur ein älteres deutsches Ehepaar sitzt. Er fragt höflich, ob ein Platz frei sei und bekommt eine bejahende höfliche Antwort. Er setzt sich, schlägt die Wochenzeitung Die Zeit auf und macht, was in Deutschland nach Ansicht des Erzählers »bei einer

1 ÖzAKIN, Aysel (1983): Die Leidenschaft der Anderen, Hamburg: Luchterhand, S. 29.

2 Ebd. 
solchen Fahrt verlangt wird: nämlich »schweigen, schweigen, schweigen, nie etwas fragen, solange du selbst nicht gefragt wirst «. ${ }^{3}$ Als in Fulda ein »richtiger Türke« in den Zug steigt, "physiognomisch klein, gedrungen, mit handgestrickter Weste, [...] in beiden Händen Plastiktüten« und im Abteil nach einem Platz fragt, schreit die Dame schon, »bevor er ausgesprochen hat«, dass nichts frei sei, obwohl noch drei Plätze frei sind. ${ }^{4}$ Als sich der Ich-Erzähler selbst als Türke zu erkennen gibt und ihr seinen türkischen Pass zeigen möchte, antwortet sie, dass er das nicht brauche, weil er kein Türke sein könne. Er fragt sie, warum. »Weil, hmm, weil, sie soll ich sagen, hmm, weil Sie Die Zeit lesen. ${ }^{5}$

Ebenso abrupt wie Özakıns Dialog im Zug endet auch dieser, und auch hier beginnt die erzählende Figur einen inneren Monolog, indem sie ausrechnet, wie viele Deutsche es eigentlich in Deutschland gibt, wenn nur die dazugehörten, die Die Zeit lesen. Ob sie dabei dem deutschen Ehepaar noch in die Augen blickt oder aus dem Fenster schaut, macht die satirische Erzählung selbst nicht mehr kenntlich. Wie bei Aysel Özakın ist der Erzähler auch hier eine Ausnahme; eine Ausnahme, die selbstredend ohne die Regel, ohne das Kollektiv, nicht bestimmt werden kann. Özakın und Dikmen werden so zu sanderen Türken erklärt, nicht aber zu Zivilen, zu Teilhabern des öffentlichen Raums oder zu Angekommenen. Dass diese besondere und neue Form der Begegnung zwischen alteingesessenen und eingewanderten Menschen in den 1980er Jahren keineswegs nur in der Öffentlichkeit stattfindet, sondern in der Regel in geschlossenen Räumen und besonders in den Wohnungen der Türken, zeigt die titelgebende Satire Der andere Türke. Ohne Vorankündigung steht eines Tages eine Dame vom Elternbeirat der Schule seines Sohnes vor der Wohnungstür des Ich-Erzählers. Sie möchte die Familie des Jungen kennenlernen, der gemeinsam mit ihrem Kind die Schule besucht. Die Frau des Erzählers ist irritiert. Nicht weil eine ungeladene Frau mitten in der Wohnung steht, sondern weil zum ersten Mal eine deutsche Frau bei ihnen zu Gast ist. Doch mehr als die türkische Frau ist die deutsche Dame irritiert, als sie in der Wohnung der Türken einen Schreibtisch entdeckt. Sie freut sich darüber, und sie habe es ja geahnt, weil ihre Kinder dieselbe Schulklasse besuchten, dass sie ganz anders seien als die anderen Türken in Deutschland. Auf die Frage des Erzählers, ob sie schon bei anderen Türken gewesen sei, erwidert die Dame vom Elternbeirat, dass das nicht nötig sei. »Ich brauche doch nicht viel Phantasie, um mir vorzustellen,

3 Dikmen, Şinasi (1986): „Wer ist ein Türke«. In: ders.: Der andere Türke, Berlin: Express-Edition, S. 7-12, hier S. 9.

4 Ebd., S. 10.

5 Dikmen (1986): S. 11. 
daß Sie der einzige Türke sind, der einen Schreibtisch hat. ${ }^{6}$ Auch hier endet das Gespräch abrupt und der Erzähler spricht zu sich selbst weiter, dass ihm diese deutsche Frau gefalle, nicht so, wie man es sich denkt, sondern weil sie einen »scharfen Blick« habe. ${ }^{7}$ Wie in Özakıns und Dikmens Begegnungen im Zug wird das plötzlich abgebrochene Gespräch in Form eines inneren Monologs fortgeführt. Und dass der türkische Erzähler explizit darauf aufmerksam macht, dass ihm die deutsche Frau nicht sexuell, sondern ironisch wegen ihres »scharfen « Blicks gefalle, deutet zweierlei an. Auf den ersten Blick sollen damit wohl die Vorstellungen der Deutschen von den Türken als »lächerliche« bloßgestellt werden. Auf den zweiten Blick geht es auch darum, das Stereotyp des promiskuitiven Ausländers zu konterkarieren. Tatsächlich ist es in den Produktionen der 1980er Jahre so, dass die Sexualität allgemeinen moralischen Vorstellungen weicht und der begehrende und bedürftige Körper im Unterschied zu den Produktionen der 1960er und 1970er Jahre, wie wir noch sehen werden, nicht mehr dargestellt wird. Insgesamt tritt an die Stelle der körperlichen Bedürftigkeit entweder die geäußerte Artikulation oder der innere Monolog.

Allein in diesen kurzen Passagen zeigt sich eine Begegnungsstruktur, eine narrative Reaktion auf Milton Gordons integrationsspezifische Frage, »what happens, when peoples meet«, die sich von der Antwort der 1960er und 1970er Jahre auf vielen Ebenen unterscheidet. Die Frage der Zivilisation ist geklärt. Und wie man sich als ein Teil von ihr definieren kann, auch: indem man nämlich französisch aussieht, Französisch spricht, Die Zeit liest oder zu Hause einen Schreibtisch hat. Diese neue Struktur macht aber auch auf eine neue Form einer gestörten Kommunikation aufmerksam, die die Bewegungen der Akteurinnen und Akteure im öffentlichen und im privaten Raum über das Sprechen und Schweigen in einen Stillstand versetzt; ein Stillstand, der sich integrationstheoretisch im Fehlen einer sozialstrukturellen Mobilität widerspiegelt. Denn kein Akteur und keine Akteurin in Literatur, Film und Dokumentation haben in den 1980er Jahren einen sicheren Job oder gehen einer geregelten Arbeit nach. Selbst wenn dies der Fall ist, werden sie von den >Deutschen $`$ nicht in dieser Hinsicht wahrgenommen. Insgesamt sind Kontakte zu Deutschen rar, und wenn es sie gibt, dann sind sie in der Regel von Diskriminierungen bestimmt. So zumindest antworten viele Migranten in den wichtigen und bekannten Dokumentationen von Dursun Akçam, Günter Wallraff, Jeanine Meerapfel und Metin Gür auf deren Frage, wie sie die Deutschen sähen. ${ }^{8}$

Diese immobile Rahmung von Mobilität und Begegnung als eine neue Dimension der Folgen von Migration in der Bundesrepublik hält auch Aras Ören

6 DikmEN, Şinasi (1986): »Der andere Türke«. In: ders.: Der andere Türke, Berlin: Express-Edition,

S. 71-76, hier S. 73.

7 Ebd.

8 Siehe hierzu: AкÇAM, Dursun (1983): Deutsches Heim - Glück allein, Göttingen: Lamuv. 
im dritten Band seiner Poem-Trilogie Die Fremde ist auch ein Haus von 1980 fest. Sechs, sieben Jahre nach den ersten beiden Bänden ist auch hier eine markante narrative Verschiebung zu erkennen. Wenn beispielsweise in den ersten beiden Bänden die Gastarbeiter und die Alteingesessenen von Straße zu Straße, von Wohnungen zu Gaststätten sich bewegen oder von Wohnung zu Wohnung umziehen, hält Emine, die Tochter des Gastarbeiters Süleyman im dritten Band der Trilogie fest, dass in ihr fremdartig »ein Berg“ zwischen Haus und Naunynstraße getreten sei. ${ }^{9}$ Im Unterschied zu Özakıns und Dikmens Texten liegt es hier nicht allein an den Vorurteilen der Deutschen, sondern dieses Ding zwischen Haus und Straße, zwischen privatem und öffentlichem Raum, ist entstanden, weil so manche Gastarbeiterin und so mancher Gastarbeiter jetzt nach »Anatolien Ausschau hält« und sich deshalb nun »in der Fremde « fühlt. ${ }^{10}$

Eindrücklich zeigt sich diese Verschiebung der Orientierung als Kommunikations- und Bewegungsstörung im öffentlichen Raum in den beiden bekannten türkischen Filmen der 1980er Jahre, in Kartal Tibets GuRBETCIŞABAN (Der Ausländer Şaban) von 1985 und in Şerif Görens zweiter Arbeit nach ACI VATAN ALMANYA zu den Folgen der türkischen Migration nach Deutschland, in dem Film PoLIzEI von $1988 .{ }^{11}$ Im zuletzt genannten wird der Protagonist Ali Ekber, der vom äußerst bekannten türkischen Schauspieler Kemal Sunal (1944-2000) gespielt wird, zu Beginn des Films mit »Hallo Müllmann« morgens von jugendlichen deutschen Obdachlosen und Punks bei seiner Arbeit in Berlin-Kreuzberg begrüßt. Ali grüßt auf Türkisch

9 ÖREN, Aras (1980): Die Fremde ist auch ein Haus, Berlin: Rotbuch, S. 12.

10 Ebd.

11 Wichtig im Zusammenhang der türkei-türkischen Filmproduktionen ist zu erwähnen, dass Mitte der 1980er Jahre über 300000 türkische Filme als Videokassetten über Import- und Exportgeschäfte in der Bundesrepublik im Umlauf waren. $35 \%$ aller türkischen Haushalte in Deutschland besitzen zu dieser Zeit bereits einen Videorekorder; dreimal mehr als die deutschen Haushalte. Nach einer Umfrage von 1986 leiht sich jede türkische Familie bis zu zehn Kassetten pro Wochenende aus. Ein Großteil dieser Filme sind Melodramen und Komödien. Seit den 1970er Jahren gehört die türkische Film- und Kinoproduktion zu den größten der Welt. In ihrer Hochzeit in den 1970er Jahren werden im Jahr bis zu 300 Filme gedreht. Nach dem Militärputsch (1980-1983) geht die Produktion wieder auf 100 Filme pro Jahre zurück. In den 1970er Jahren werden in der Türkei auch viele Softsexfilme gedreht, die aber den Weg in die Bundesrepublik besonders nach dem Militärputsch nicht finden und auch nicht in andere Länder exportiert werden. Der hohe Konsum türkei-türkischer Filme in türkischen Haushalten ist von Tragödien und Komödien, letztlich von Moral und Unterhaltung geprägt. Siehe hierzu: KaYA, Cem (2016): Remake. Remix. Ripoff. Kopierkultur und türkisches Popkino, Dokumentation, ZDF (Das kleine Fernsehspiel), Deutschland. Den Konsum türkei-türkischer Filme thematisieren Film und Literatur erst in den 2000er Jahren. Siehe hierzu: WACKER, Thorsten (2004): Süperseks, Spielfilm, Warner Home Video, Deutschland. Und siehe auch: ÖzDoǦAN, Selim (2011): Heimstraße 52, Berlin: Aufbau, S. 175-182. 
»Merhaba gençler« (»Hallo, ihr jungen Leute«) zurück und zieht mit seinem Müllwagen weiter, die Straßen und Kreuzungen in Berlin säubern. Er wirkt gut gelaunt, wird von zwei Türken herzlich gegrüßt und schaut sich im Schaufenster eines Gemüseladens selbst spiegelnd erfreut an. Ein türkischer Freund ruft ihm von Weitem zu, dass er wie ein Schauspieler aussehe (»artist gibisin«). Bei seiner nächsten Station - wir sehen Ali Ekber auf seinem fahrenden Müllwagen - wird es plötzlich ernst. Neben den ziemlich lauten Straßengeräuschen hören wir zunächst aus dem Off türkische Sprache. Ali Ekber bewegt sich in die Richtung, aus der gesprochen wird. Zwei Türken, die zwischen zwei Geschäften sitzen, lesen laut aus einer türkischen Zeitung vor. Ali stellt sich hinter sie und hört konzentriert, bewegungs- und lautlos zu. Die Lesenden bemerken Ali gar nicht - auch, weil sie so sehr in den Zeitungstext vertieft sind. Sie lesen den Artikel laut vor, warum eine in Deutschland lebende türkische Jugendliche aus ihrem Elternhaus geflohen ist.

\begin{abstract}
Sie sind aus der Türkei nach Deutschland gekommen und haben immer noch nichts gelernt. Sie alle sind so unendlich zurückgeblieben. Mein Bruder durfte frei leben und ich nicht. Ich habe angefangen, die Männer zu hassen. Wegen der Männer wurde meine Freiheit eingeschränkt. Selbst wenn sie meine Freiheit nicht eingeschränkt hätten, hätte ich das Haus verlassen. Denn ich will mein eigenes Leben selbst gestalten. ${ }^{12}$
\end{abstract}

Der Leser kommentiert den von ihm gelesenen Zeitungsbericht mit den Worten, dass es sich bei diesem türkischen Mädchen um die Tochter von Hafize handeln müsse und deutet damit an, dass er und sein Kollege das Mädchen aus der Zeitung kennen. Die wievielte Türkin das eigentlich schon sei, die von zu Hause flieht, fragt er weiter. Von einer anderen namens Ayşe beginnt der andere zu sprechen. Sie arbeite nun abends, und bei einem »Uçuş « ${ }^{13}$ würde sie 150 Deutsche Mark verdienen, bemerkt der zweite in einem anerkennenden Ton. Doch der Zeitungsleser lässt eine solche positive Einschätzung gar nicht zu und sagt seinem Kollegen, dass diese Angelegenheit doch die Ehre von allen Türken

12 GöREN, Şerif (1988): Polizei, Spielfilm, Penta Film, Türkei. Im Film wird ausschließlich Türkisch gesprochen. Einen ähnlichen Konflikt wie in Görens PoLIzEI zeichnet auch Yüksel Pazarkaya in der ersten Fernsehserie zur türkischen Migration nach Deutschland nach. In UNSERE NACHBARN, DIE BALTAS von 1983, die aus zehn Folgen besteht und im WDR ausgestrahlt wurde, steht die Familie Balta im Zentrum des Geschehens. In der neunten Folge »Ohrfeigen« zieht die 17-jährige Tochter Inci aus dem Elternhaus aus und trägt offen einen Konflikt um Emanzipation mit ihrem Vater aus. Ein Konflikt, der sich schon seit der zweiten Folge »Verbotenes« ankündigt. Yüksel Pazarkaya hat das Drehbuch zu dieser Serie verfasst. Siehe hierzu: PAZARKaYA, Yüksel (1983): Unsere Nachbarn, die Baltas, hg. v. Adolf-Grimme-Institut: Begleitheft zur Fernsehserie im Medienverbund AUSLÄNDER - INLÄNDER, Marl: Deutscher Volkshochschul-Verband e.V.

13 »Uçuş« bedeutet übersetzt eigentlich »Flug«, ist in diesem Gesprächszusammenhang jedoch als sexueller Akt gemeint. Der Begriff deutet an, dass Ayşe nun als Prostituierte arbeitet. 
betreffe: Gibt es denn niemanden, der diese verteidigt oder wiederherstellt? ${ }^{14}$ Nun schwenkt die Kamera auf Ali, der hinter den beiden sitzenden Türken steht und noch immer nicht beachtet wird. Es wirkt so, als ob er sich angesprochen fühlt, wobei er zugleich nachdenklich nach innen gekehrt aus der Perspektive der Kamera herausblickt. Obwohl die Frage der Ehre nicht im Zentrum dieses Films steht - es handelt sich bei PoLIzEI um eine »Köpenikiade « ${ }^{15}$-, erweist sich die Spannung zwischen einer türkischen moralischen Ordnung und der sie gefährdenden Sexualität als ein wiederkehrendes Motiv in der eigentlichen Komödie. Denn das Komödiantische wird im Laufe des Films noch mehrmals gebrochen. Wie in Özakıns autobiografischem Roman und Dikmens Satirestück kommt es genau dann zu Unterbrechungen von Mobilität und Kommunikation, wenn >das Türkische` oder `das Deutsche`sich plötzlich im Raum auftut und zum stummen Weitersprechen auf einer der beiden Seiten zwingt. So wird der eigentlich sympathische Ali Ekber zweimal im Film versuchen, die Tochter Hafizes, die er selber gar nicht kennt, vom falschen Weg abzubringen: einmal mit Worten als machomäßige Darstellung vor den anderen Türken, ein anderes Mal abends mit körperlicher Gewalt. In diesen Szenen scheint bei Ali etwas von außen einzubrechen, das zum liebenswürdigen Charakter seiner Figur gar nicht passt.

Auch in diesem Fall zwängt sich ein abstrakt-fremdes Ding des Türkisch- oder Deutsch-Seins zwischen Haus, Wohnung und Straße oder in ein Zugabteil, mit dem sich die ästhetischen und dokumentarischen Reflexionen der 1980er Jahre in Form von Bestätigung oder Kritik auseinandersetzen. Dieses Ding verwandelt die Beweglichkeit der Akteurinnen und Akteure im öffentlichen wie im privaten Raum in Immobilitäten. Dies ist auch erkennbar in der realen Figur Abdullah Yakupoğlu: Nachdem zwei seiner drei Töchter von zu Hause zu ihren deutschen männlichen Freunden geflohen sind, hat er sein »Gesicht« verloren, kann nicht mehr in die Türkei, meidet aber auch den öffentlichen Raum in Andernach. Er besucht nur noch türkische Cafés in einer anderen rheinlandpfälzischen Stadt,

14 Siehe hierzu: GöREN (1988). Im dramatischen Dokumentarfilm AbdullaH YAKUPoǦLU. WARUM HABE ICH MEINE TOCHTER GETÖTET? (1986) des deutschen Dokumentarfilmers Hans-Dieter Grabe, in dem die Tötung von Perihan Yakupoğlu am 22. März 1983 durch ihren Vater Abdullah Yakupoğlu anhand von Interviews mit dem Täter und anderen Betroffenen nacherzählt wird, verweist der Vater zu Beginn des Films auch auf Zeitungsberichte, die vom Kulturverfall der Türkinnen in der Fremde berichten. Siehe hierzu: GRABE, Hans-Dieter (2012): »Abdullah Yakupoğlu. Warum habe ich meine Tochter getötet«. In: Hans-Dieter Grabe. Dokumentarist im Fernsehen: 13 Filme 1970-2008, hg. v. Deutsche Kinemathek. Museum für Film und Fernsehen.

15 Siehe hierzu: GöKтÜRK, Deniz (2000): „Subnationale Mitleidskultur oder transnationale Rollenspiele?«. In: Interkulturelle Literatur in Deutschland. Ein Handbuch, Stuttgart: Metzler, S. 329-347, S. 337. 
wo man die Geschichte seiner Töchter nicht kennt. ${ }^{16}$ Dieser Zusammenbruch des Verhältnisses von Innen und Außen, von Person und Öffentlichkeit, steht auch im Zentrum des bekanntesten und erfolgreichsten Films zur türkischen Migration nach Deutschland, in Tevfik Başers 40 QM DEUTSCHLAND von 1986. Dort sperrt der Gastarbeiter Dursun seine Frau, die er aus dem türkischen Dorf nach Deutschland nachziehen lässt, in die Hamburger Hinterhofwohnung ein. Im Unterschied zu Bekir Yıldız' autobiografischem Roman Türkler Almanyada (Türken in Deutschland) aus den 1960er Jahren sagt er seiner gerade in Deutschland angekommenen Frau nicht, dass es hier für alle gleich schwer sei, für Deutsche wie für Türken, und er lässt sie im Gegensatz zu Bekir Yıldız auch nicht arbeiten, weil sie das Geld brauchen. Stattdessen sperrt er sie ein, weil die Deutschen im Unterschied zu den Türken keinen Anstand und keine Moral hätten. ${ }^{17}$ Deshalb steht im Zentrum von Tevfik Başers Film, wie er es selbst auch konstatiert, die vermeintlich einfache Idee und Vorstellung einer alltäglichen Praxis, nämlich eine türkische Frau aus einer engen Hamburger Hinterhofwohnung auf die Straße zu schicken. ${ }^{18}$

Auch wenn im Unterschied zum Spielfilm 40 QM DEUTSCHLAND der Protagonistin, Melek Tez, in Jeanine Meerapfels interessantem Dokumentarfilm DIE KÜMMELTÜRKIN GEHT kein türkischer Mann vorsteht, weil sie 1971 alleine nach Deutschland gekommen ist und sich von ihrem Mann getrennt hat, beginnt auch dieses filmische »Portrait einer unüblichen Frau « ${ }^{19}$ mit einem Gang auf die Straße in Berlin-Kreuzberg. Am Ende des Films wird sie auf der Straße der Kamera entgegenlaufen. ${ }^{20}$ Melek Tez ist zum Schluss aber nicht mehr in Deutschland, sondern in der Türkei. Doch zwischen diesen beiden Bewegungssequenzen, zwischen Anfang und Ende dieser Dokumentation, werden wir in DIE KüMMELTÜRKIN GEHT

16 Siehe hierzu: GraBe (2012).

17 Auch in Metin Gürs Dokumentation über die Türken in Bergkamen spielt die Berufstätigkeit der Frauen eine ausschlaggebende Rolle: Laut der männlichen Interviewpartner Gürs kränkten arbeitende Frauen deren Ehre. Die Frauen hingegen beklagen sich, dass Frauen, die nicht arbeiten, nur »halbe Menschen« seien. Die meisten Frauen, die Gür befragt, würden lieber arbeiten gehen. Denn den berufstätigen Frauen "geht es besser als uns. Sie benehmen sich anders, sie unterhalten sich anders. Sie haben mehr Selbstvertrauen«. Wenn ihr Mann krank sei, konstatiert eine andere gegenüber Gür, die nicht arbeitet, kann sie kein Geld abheben oder die familiären Geschäfte regeln. Siehe hierzu: GÜR (1987): Meine fremde Heimat. Türkische Arbeiterfamilien in der BRD, Essen: Neuer Weg, S. 41-43.

18 Siehe: PüTz, Anke/Scholten, Frank (1988): $40 \mathrm{~m}^{2}$ Deutschland. Materialien für einen Film von Tevfik Baser, Begleitheft zum Film, Duisburg: Atlas Film, S. 18.

19 Edition DER FilmEMACHER (2016): Jeanine Meerapfel. Begleitheft, Neue Visionen Medien, S. 18. 20 Siehe: MeERAPFEL, Jeanine (1985): Die Kümmeltürkin geht, Dokumentation, Deutsche Kinemathek - Museum für Film und Fernsehen, Goethe-Institut, Deutschland. Siehe auch: Roth, Wilhelm (1985): »Die Kümmeltürkin geht«. In: epd Film, Juni 1985 (http://www.filmportal.de/ node/25393/material/642144) (20.07.2016). 
sehen, dass diese selbstverständlichen Bewegungen im öffentlichen Raum auf keiner selbstverständlichen Grundlage basieren. Sie geht, verlässt die Bundesrepublik nach 14 Jahren, nutzt das Rückkehrförderungsgesetz aus dem Herbst 1983, weil sie die Diskriminierungen von deutscher Seite nicht mehr aushält. Obwohl sie körperlich gesund ist, sagt sie in der Mitte der Dokumentation, sie gehe, weil sie »nur eine Gesundheit« habe. ${ }^{21}$ Der Zuschauer teilt diesen Befund, allein weil zwischen dem Gehen zu Anfang und zu Ende des Films Talking-Head-Aufnahmen, Aufnahmen von geschlossenen Zimmern und Wohnungen, von Hinterhöfen, die von Mauern umgeben sind, schließlich die Bilddramaturgie des Films bestimmen. Melek Tez bezeichnet sich selbst dabei ironisch-bitter als »Kümmeltürkin« und fragt sich zugleich, woher diese Diskriminierung und der Ausländerhass in Deutschland kommen. Während des Drehs lautete der Arbeitstitel noch »Melek geht «. Dass dieses Gehen aber kein einfaches Gehen ist, wird Jeanine Meerapfel während der Dreharbeiten bewusst, weshalb sie den Filmtitel ändert.

Günter Wallraff beginnt seine international erfolgreiche Dokumentation Ganz Unten von 1985 ebenfalls mit dem Befund, dass »fast die Hälfte der ausländischen Jugendlichen psychisch erkrankt ist«. Seiner Ansicht und den Ergebnissen und Erfahrungen seiner verdeckten Rolle als türkischer Leiharbeiter Ali Siǧirlioğlu, gemäß können sie »die zahllosen Zumutungen nicht mehr verdauen «"2 ${ }^{2}$ Im Unterschied zu den 1960er und 1970er Jahren scheinen weder die Sexualität noch der Konsum oder Besitz von Dingen eine entlastende, befriedigende oder die »innere Unruhe« stillende Funktion zu erfüllen. Außerdem geht es hier nicht mehr um eine heterogene Gruppe von Ausländern oder Einwanderern, sondern im Vordergrund stehen vermeintliche Einheiten in Form einzelner türkischer Personen oder türkischer Familien, die jeweils als Repräsentationen für viele verstanden werden sollen. Auch Abdullah Yakupoǧlu aus Grabes Dokumentation, der in der Türkei nur eine Koranschule und ein paar Jahre lang die staatliche Grundschule besuchte, ist sich seiner kulturellen Verortung sicher. Ihn würde es sehr freuen, wenn seine Familie und er frei leben könnten, sagt er. Denn die deutsche Gesellschaft ist für ihn der türkischen »zwei hundert Jahre« voraus. Aber das türkische Volk lasse das nicht zu. National-völkische Kategorien fungieren hier als substantielle Entitäten, die es zu bestätigen oder mit denen es sich auseinanderzusetzen gilt. Als Abdullah Yakupoğlu seinen Wunsch äußert, war er schon über fünf Jahre nicht mehr in der Türkei und hat seit Jahren auch keinen Kontakt mehr zu Türken in Deutschland. Zudem hat Grabe in seiner äußerst intensiven und darin sehr

21 Ebd.

22 WaLLRAFF, Günter (1985): Ganz Unten. Mit einer Dokumentation der Folgen, Köln: Kiepenheuer \& Witsch, S. 11. 
gelungenen Dokumentation auch keinen anderen Türken als Abdullah selbst zum tragischen Fall, der Ermordung seiner eigenen Tochter, interviewt. ${ }^{23}$

Nicht nur in Spiel- und Dokumentarfilm, sondern auch in der Prosa der deutsch-türkischen Literatur finden wir das Motiv der türkischen Frau, die auf die Straße geht. So endet etwa auch der bekannteste deutschsprachige Roman der 1980er Jahre, Die Blaue Maske von Aysel Özakın, mit einer solchen Szene. ${ }^{24}$ Derartige Textpassagen und Filmsequenzen markieren an entscheidenden Stellen in den Werken einen tiefergehenden narrativen Wandel von der sozialen Frage zur psychischen Disposition ihrer Akteure. Eindrücklich lässt sich dies an einem Vergleich der Erzählungen aus den 1970er und 1980er Jahren derselben Autorin zeigen. Özakıns zentrales Thema war immer die Emanzipation der türkischen Frau mit unterschiedlichen ästhetischen Rahmungen. In ihren ersten Erzählungen und Romanen wie Gurbet Yavrum (1975, Die Fremde, mein Kleines) ${ }^{25}$ und Genc Kız ve Ölüm (1979, Das junge Mädchen und der Tod) ${ }^{26}$ werden zwar auch Folgen von Migration thematisiert, allerdings als Sozialgeschichten. Gurbet Yavrum erzählt die Suche einer Tochter nach ihrem Vater, der nach Kanada migrierte, als transkulturelle Vater-Tochter-Geschichte, nicht als eine, in der eine türkische Familie im Zentrum steht. In Genc Kız ve Ölüm geht es um die Emanzipation der türkischen Frau in der türkischen Gesellschaft als ein Prozess, der sich über mehrere Generationen von Frauen erstreckt. Ihre Erzählungen und Romane, die sie während ihres Exils in der Bundesrepublik von 1980 bis in die 1990er Jahre schreibt, behandeln zwar noch immer die zentrale Thematik der Emanzipation. Nur sind sie seit den 1980er Jahren in Deutschland von interkulturellen und psychischen Auseinandersetzungen geprägt, die die Autorin nicht mehr an einer bestimmten Gruppe erprobt, sondern nur noch an einer Person: sich selbst. ${ }^{27}$ Ihre Studien umkrei-

23 Siehe hierzu: Grabe (2012).

24 ÖZAKIn, Aysel (1989): Die Blaue Maske, Frankfurt a. M: Luchterhand.

25 ÖzAKIn, Aysel (1975): Gurbet Yavrum, Istanbul: Can Yayinevi; deutsche Ausgabe: ÖzAKIN, Aysel (1988): Der fliegende Teppich. Auf der Spur meines Vaters, Hamburg: Rowohlt.

26 ÖZAKIN, Aysel (1979): Genc Kız ve Ölüm, Istanbul: Yordam Kitap; deutsche Ausgabe: ÖzAKIN, Aysel (1989): Die Preisvergabe, Frankfurt a. M.: Luchterhand.

27 Interessant in diesem Zusammenhang ist, dass die irakische Autorin Ālīya Mamdūh 1985 mit Habat an-Naftalin (»Mottenkugeln«) eine Autobiografie vorlegt, die die 1950er und 1960er Jahre der irakischen Gesellschaft nicht allein anhand ihrer eigenen Biografie, sondern anhand derer vieler Mädchen und Frauen widerspiegelt. Die Emanzipation ist darin ebenfalls das zentrale Thema. Siehe hierzu: EzLI, Özkan (2005): »Grenzenlose Psyche oder die Kollektivautobiografie von 'Āliya Mamdūh. In: Vom Individuum zur Person. Neue Konzepte im Spannungsfeld von Autobiographietheorie und Selbstzeugnisforschung. Querelles. Jahrbuch für Frauen- und Geschlechterforschung, hg. v. Claudia Ulbrich, Gabrielle Jancke, Göttingen: Wallstein, S. 53-66. 
sen das Thema »der Emanzipation in einer multikulturellen Gesellschaft ${ }^{28}$ und rücken an die Stelle sozialer Praktiken verstärkt individuelle, mitunter kulturell codierte, Reflexionen und Gedanken über nationale Zugehörigkeiten. Dieses zweite und künstliche Bewusstsein geht nach Karl Marx mit dem Verbot einher, nach dem natürlichen Vater, nach der eigenen Genealogie zu suchen. ${ }^{29}$ Dieses Verbot zeigt sich eindrücklich in den Emanzipationsnarrativen der Türkinnen auch in den Dokumentationen von Hans-Dieter Grabe, Paul Geiersbachs Bruder, muß zusammen Zwiebel und Wasser essen! (1982), Jeanine Meerapfels DIE KüMMELTÜRKIN GEHT sowie in der bekannt gewordenen populären Schrift Ayşe und Devrim. Wo gehören wir hin? Zwei türkische Mädchen erzählen (1982), der Interviews der Journalisten Michael Kuhlmann und Alwin Mayer mit zwei türkischen 16- und 17-jährigen Mädchen in West-Berlin zugrunde liegen. Darin steht Ayşes Leitsatz und Maxime im Zentrum, dass sie gegen die eigenen Eltern kämpfen müsse, „was dir nur gelingt, wenn du genug Haß in dir hast, auch wenn du sie [die Eltern, Ö.E.] liebst «. ${ }^{30}$ Diese besondere Form der Emanzipation ist mitunter deshalb von Interesse, weil ihr in der letzten Phase der vorliegenden Kulturgeschichte, beispielsweise in den Filmen Auf DER ANDEREN SEITE (2006) von Fatih Akın, MEIN VATER, DER TÜRKE (2006) von Marcus Vetter, AlMANYA. WiLlKOMMEN In Deutschland (2011) der Şamdereli-Schwestern und im Roman Die Tochter des Schmieds (2005) von Selim Özdoğan die Suche nach den leiblichen Eltern entgegengesetzt ist. Im Zusammenhang der Produktionen der 1980er wird es in den Film- und Literaturanalysen in diesem Kapitel äußerst interessant zu sehen sein, dass fast in jedem Text und Spielfilm die Figur des Begründers der modernen Türkei, Mustafa Kemal Atatürk auftaucht: entweder beschreibend als eine familiale Identifikationsfigur in Die Leidenschaft der Anderen oder in Die blaue Maske (Özakın), als Gegenfigur zu Adolf Hitler und Schutzpatron der türkischen Arbeiterschaft in Köln in Kartal Tibets GuRBETçI ŞABAN, oder visuell als Wandbild in 40 QM DEuTSCHLAND (Başer) bzw. als Büste im Zimmer der türkischen Tochter in YASEMIN (Bohm) als Gegenfigur zur traditionellen dörflichen Türkei. ${ }^{31}$

Ein vergleichbarer Wandel in der Bewusstseinsstruktur der Akteure als geteilte Subjekte zeigt sich in den Genesen der prosaischen Texte Güney Dals,

28 Rösch, Heidi (1992): Migrationsliteratur im interkulturellen Kontext. Eine didaktische Studie, Frankfurt a. M.: Verlag für interkulturelle Kommunikation, S. 123.

29 SPIVAK, Gayatri (2007): Postkolonialität und subalterne Artikulation, Wien: Turia+Kant, S. 36. 30 Ayşe/DeVRim (1982): Wo gehören wir hin? Zwei türkische Mädchen erzählen, hg. v. Michael Kuhlmann, Alwin Meyer, Göttingen: Lamuv, S. 2.

31 Bezeichnenderweise bedeutet »Atatürk« übersetzt »Vater der Türken«. Mustafa Kemal erhielt diesen Beinamen nach der Republiksgründung in den 1920er Jahren. Siehe: KREISER, Klaus (2008): »Vater einer jungen Nation«. In: ders.: Atatürk. Eine Biographie, München: Beck, S. 174-218. 
Habib Bektaşs und Bekir Yıldız' ${ }^{32}$ An die Stelle der sozialen Frage tritt auch in ihren Romanen und Erzählungen der 1980er Jahre verstärkt die Verhandlung psychischer Dispositionen, die sich mit kulturellen Codes, Zuschreibungen und Selbstbeschreibungen ironisch oder dramatisch wie bei den bereits genannten Autorinnen, Autoren und Dokumentaristen auseinandersetzen. Wenn Dal in seinem ersten Roman Wenn Ali die Glocken läuten hört (1978) den »Wilden Streik« bei Ford von 1973 der türkischen Gastarbeiter mit vielen Protagonisten als einer Gruppe aus unterschiedlichen Schichten humoristisch und zum Teil surrealistisch thematisiert und die Frage nach türkischer Identität, trotz des Titels, keine Rolle spielt, arbeitet sich in Dals zehn Jahre später erschienenem Roman Der enthaarte Affe (1988) sein einziger Protagonist an einer zugeschriebenen türkischen Identität im wahrsten Sinne des Wortes ab. ${ }^{33}$ Denn er gründet für sich und seine Familie eine Wandzeitung, in die er jeden Tag seine eigenen Nachrichten einträgt. Er wird an dieser Arbeit in den vermeintlich eigenen vier Wänden nicht körperlich, sondern psychisch zugrunde gehen. ${ }^{34}$ Wie in den bisher eingeführten Werken steht auch hier ein Einzelner im Vordergrund, der im Einfluss von Zeitungsnachrichten und Artikeln zugleich für andere steht. Ähnlich wie in den anderen genannten Produktionen der 1980er ist das Aus-der-Wohnung-Treten auch in Dals Roman von 1988 ein unglaublich schwieriger Akt. Der Zugang zum öffentlichen Raum oder das sich Wohlfühlen darin stellt sich als ein äußerst komplizierter Prozess heraus.

In den rechercheintensiven und auch sonst aufwendigen Dokumentationen Deutsches Heim - Glück allein und Meine fremde Heimat von Dursun Akçam und Metin Gür aus den Jahren 1983 und 1987 haben wir es zwar auf den ersten Blick mit Publikationen zu tun, in denen sehr viele Personen interviewt wurden. Bei Gürs Buch sind es allein über 100 Interviewpartner aus Bergkamen, die größtenteils unter Tage gearbeitet haben oder zum Zeitpunkt der Veröffentlichung noch arbeiteten. Doch sind seine und Akçams Darstellungen sehr davon geprägt, ein einheitliches Bild vom Leben der Türken in Deutschland zu vermitteln. Allein die sieben, acht Akteure, die Yıldız oder Ören in den 1960er und 1970er Jahren jeweils in ihren Werken zeigen und darstellen, fallen weitaus heterogener aus als die Türken bei Akçam und Dursun. Das liegt mitunter auch daran, dass beispiels-

32 Siehe hierzu: BeKTaş, Habib (1981): Belagerung des Lebens. Yaşamı kuşatmak. Gedichte und Geschichten, Stuttgart: Ararat, S. 43-49; ÖzAKIN, Aysel (1982): Soll ich hier alt werden? Türkin in Deutschland, Hamburg: Buntbuch, S. 6f. Siehe zu Tekinay auch: RöscH (1992): S. 121.

33 Siehe hierzu: Willms, Weertje (2010): »Probleme der Identitätskonstitution im interkulturellen Spannungsfeld am Beispiel von Güney Dals Der enthaarte Affe«. In: Zeitschrift für interkulturelle Germanistik, Band 1, Heft 2, S. 63-78, 71-75.

34 DAL, Güney (1988): Der enthaarte Affe, München: Piper. 
weise Metin Gürs Arbeit zum Teil im Austausch mit den Ausländerbeauftragten von Bergkamen entstand und er auch am Ende seiner Dokumentation hofft, dass diese ein wenig dazu beiträgt, für »die brennenden Probleme der türkischen Arbeiter eine Lösung « zu finden. ${ }^{35}$ Dieser Zugang schwächt die Leistung dieser Bücher keineswegs, weil es ihnen gelingt, die Diskriminierungserfahrungen der türkischen Arbeiter, der Hausfrauen und der Jugendlichen eindrücklich darzustellen. Ihr Fokus liegt nicht auf sozialen Interaktionen, sondern in der Darstellung von Verletzungen und der Artikulation von Gefühlen, die auf Diskriminierungen zurückgehen oder auf einfache körperliche Beschwerden. Als Metin Gür Mitte der 1980er in Bergkamen ein Arbeiterwohnheim aufsucht und sich nach dem Gesundheitszustand der Bewohner erkundigt, glaubt er sich nach den ersten Reaktionen in einem Krankenhaus. Die Arbeiter sagen, »sie seien >so kaputt, dass

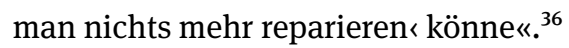

Und auch Melek Tez in Meerapfels Dokumentarfilm hält halb ironisch und halb ernst fest, dass sie es gut fände, wenn die Deutschen wie zu Beginn der Arbeitsmigration auch bei ihrer Rückkehr in die Türkei eine Gesundheitskontrolle durchführen würden - damit sie sähen, wie sich ihr Körper in Deutschland für Deutschland verbraucht habe. So ist auch in Jeanine Meerapfels Dokumentarfilm die Körperlichkeit mit Diskriminierungserfahrungen doppelt codiert und steht im Zentrum der filmischen Erzählung. Auf Meerapfels Frage, was Melek am meisten in Deutschland vermisse, antwortet sie, dass es die Gefühle seien. Doch diese Befunde der Protagonistin in DIE KüMMELTÜRKIN GEHT werden teilweise entkräftet, wenn sie beispielsweise in der ersten Talking-Head-Aufnahme des Films den Schlagersong »Feierabend« von Peter Alexander pfeift. Allein diese Themen, Auseinandersetzungen und Artikulationen erschweren einen rein soziologischen Zugang zum Leben der Türken in der Bundesrepublik der 1980er Jahre. Vergleichbares konstatiert der Soziologe Paul Geiersbach in seiner Analyse Bruder, muß zusammen Zwiebel und Wasser essen! von 1982. Bevor er das Ergebnis seiner vielen Interviews mit Angehörigen einer türkischen Familie, die er zwischen Mai und Oktober 1981 führte, festhielt, hatte er sich ursprünglich mit einem »'streng` wissenschaftlichen Konzept (repräsentatives Untersuchungssample, Fragebogen-Erhebung, Ermittlung sharter Daten` usw.)« dem Leben der Türken in der Bundesrepublik angenähert. Da er aber schon über Jahre in engem persönlichen Kontakt $\mathrm{zu}$ türkischen Arbeiterfamilien stand und $\mathrm{zu}$ den "Forschungsadressaten ein vertrauensvolles Verhältnis herzustellen begann«, hat er davon

35 GÜR (1987): S. 196.

36 Ebd., S. 121. 
wieder abgelassen. ${ }^{37}$ Sein Forschungsinteresse galt von da an der "ganzheitlichen Erfassung von Problemen, die im Leben der ausländischen Arbeiterfamilien in der Bundesrepublik eine zentrale Rolle spielen«. In Bruder, muß zusammen Zwiebel und Wasser essen! unternimmt er den Versuch, den »Druck von außen« und die innerfamiliären Konflikte einer türkischen Familie in Deutschland darzustellen. ${ }^{38}$ Seinen Text beschreibt er als eine hybride Form zwischen Reportage, wissenschaftlicher Studie und Roman. ${ }^{39}$

Die literatur- und kulturwissenschaftliche Forschung spricht an dieser Stelle gerne von einer »Literatur der Betroffenheit« und handelt sie als eine ab, die der Pflicht nachkommt, dem deutschen Zuschauer und Leser den Migranten als Opfer zu zeigen. ${ }^{40}$ Als Gegenentwürfe dienen die Arbeiten von Feridun Zaimoğlu, Zafer Şenocak, Emine Sevgi Özdamar oder von Fatih Akın in den 1990er Jahren, die die deutsche Mehrheitsgesellschaft nicht in ihren Vorstellungen bestätigen, sondern sie kritisieren würden. ${ }^{41}$ Tatsächlich setzt sich Zaimoğlu in der programmatischen Einleitung zur Kanak Sprak auch bewusst von der Gastarbeiter-, der Ausländerliteratur, von der »Müllkutscher-Prosa«, wie er sie bezeichnet, ab. ${ }^{42}$ Aber auch ein zeitgenössischer Autor der 1980er wie Şinasi Dikmen distanziert sich explizit von der seiner Ansicht nach »jammernden Literatur« der Türken. »Die ausländischen Autoren haben, glaube ich, am Anfang viele Fehler gemacht, indem sie über alles gejammert haben. « Nach Dikmen erreichen die »Lachmuskeln mehr im Menschen als [Tränen] «. ${ }^{43}$

Doch wenn wir weniger von pejorativen Begriffen wie »jammern« und »Tränen « ausgehen und die genannte Literatur mehr auf die Reichweite, auf ihre

37 Jeanine Meerapfel ist mit Melek Tez auch in die Türkei geflogen, um sie dort noch für eine Woche zu begleiten. Von dieser Woche gibt es wenige Aufnahmen im Film selbst, aber die >freundschaftliche` Aussage von Meerapfel, dass sie glaubt, Melek habe sich immer stärker in ein Ideal der Türkei hineingeredet, je mehr sie sich umgekehrt in Berlin diskriminiert gefühlt habe. Siehe hierzu: MEERAPFEL (1985).

38 GÜR (1987): S. 9.

39 Ebd.

40 Siehe hierzu: GöKTÜRK (2000); SEYHAN, Azade (2001): Writing outside the Nation, Princeton: Princeton University Press. AdELson, Leslie (2004): The Turkish Turn in Contemporary German Literature, New York: Palgrave Macmillan; BuRns, Rob (2006): »Turkish-German Cinema. From Cultural Resistance to Transnational Cinema? «. In: German Cinema since Unification, hg. v. David Clarke, London: CONTINUUM, S. 127-149. CheEseman, Tom (2006): Novels of Turkish German Settlement, Rochester, New York: Camden House.

41 Siehe hierzu: Gür (1987).

42 ZAIMoĞLU (1995): Kanak Sprak. 24 Mißtöne vom Rande der Gesellschaft, Berlin: Rotbuch, S. 11. 43 Zitiert nach: BoRAN, Erol (2004): Eine Geschichte des türkisch-deutschen Theaters und Kabaretts, unveröffentlichte Dissertation, Ohio State University, S. 210. Siehe auch: http://publikationen.ub.uni-frankfurt.de/frontdoor/index/index/docId/12320 (zuletzt 17.12.2017). 
Mechanismen und Wirkmächtigkeit der Diskriminierung und auf ihre Topografien hin prüfen, erscheint die vermeintliche »Literatur der Betroffenheit « als eine ergiebige Quelle kulturwissenschaftlicher und kulturpolitischer Analyse. Besonders, wenn in Betracht gezogen wird, dass der Begriff der Diskriminierung auch heute wieder häufig Verwendung findet, allerdings mit den Praktiken, Folgen und der rechtlichen Konstellation der 1980er Jahre nicht $\mathrm{zu}$ vergleichen ist. ${ }^{44}$ Wie zu Anfang dieses Buchs festgehalten, legte 2016 eine Münsteraner Studie das Ergebnis vor, dass sich aktuell ein Großteil der türkeistämmigen Menschen in Deutschland in Arbeit und Alltag gerecht behandelt, aber diesem Befund entgegengesetzt, der gleiche Anteil sich zugleich diskriminiert und nicht anerkannt fühlte. Wenn heute die Diskriminierungserfahrungen eine neue Reflexion über die Wahrnehmung, Erklärung und Beschreibung von Diskriminierung und Rassismus verlangen ${ }^{45}$, sind sie in den 1980er Jahren unübersehbar real vorhanden. Das sieht man schon daran, dass etwa in allen bisher genannten Produktionen die Aussage »Türken raus« an Wänden im öffentlichen Raum oder in öffentlichen Toiletten zu lesen ist. Sie ist auch ein zentrales Thema im ersten Kabarettstück Vorsicht, frisch integriert von Muhsin Omurca und Şinasi Dikmen, das sie zwischen den Jahren 1985 und 1988 mehrere hundert Mal in Deutschland bundesweit aufführten. ${ }^{46}$ Darin werden die oben genannte Aussage und das Rückkehrförderungsgesetz in einen losen Zusammenhang gebracht. In der Mitte des Stücks möchte der Straßenkehrer Ahmet (gespielt von Omurca) dem hyperintegrierten Türken Şinasi (gespielt von Dikmen) an einem Beispiel demonstrieren, wie deutsche Gerichte die Diskriminierung von Türken in Deutschland bewerten. ${ }^{47}$

44 Siehe hierzu: Pollack, Detlef/Müller, Olaf/Rosta, Gergely/Dieler, Anna (2016): Integration und Religion aus der Sicht von Türkeistämmigen in Deutschland, Repräsentative Erhebung von TNS Emnid im Auftrag des Exzellenzclusters „Religion und Politik“ der Universität Münster. Siehe hierzu: https://www.uni-muenster.de/imperia/md/content/religion_und_politik/aktuelles/2016/06_2016/studie_integration_und_religion_aus_sicht_t_rkeist_mmiger.pdf.

45 Siehehierzu für viele: BRockschmidt, Lisa (2020): Was darfmannoch? Rassismus und dieweiße Zerbrechlichkeit, In: https://www.hr-inforadio.de/programm/themen/was-darf-man-noch-rassis mus-und-die-weisse-zerbrechlichkeit,rassismus-debatte-100.html. Unbewusster Rassismus. In: https://www.br.de/nachrichten/wissen/unbewusster-rassismus,S5kJDjJ.

46 Der künstlerische Regisseur und Berater des Kabarett-Duos Knobi-Bonbon mit Şinasi Dikmen und Muhsin Omurca konstatiert zu ihrem Erfolg von Mitte bis Ende der 1980er, dass sie in einer Zeit massiver Ausländerfeindlichkeit und Gewalttaten die Funktion eines »sozialen Gewissens" eingenommen hätten: »Für jede Volkshochschule war es ein Muss, die Knobis zu engagieren. Das galt für jede Kulturverwaltung, die irgendeinen Beitrag gegen Ausländerfeindlichkeit leisten wollte«. BORAN (2004): S. 217.

47 Im Sommer 2013 veröffentlichte das britische Nationalarchiv eine Geheimakte nach 30-jähriger Sperrzeit. In der Akte PREM 19/1036 ist ein Treffen zwischen Margaret Thatcher und Helmut Kohl vom 28. Oktober 1982 dokumentiert, in dem Kohl der britischen Premierministerin kurz 
Volksverhetzung ist in Deutschland verboten, es sei denn, daß es gerichtlich erlaubt ist. Der 5. Strafsenat des Oberlandgerichts Frankfurt findet in dem Spruch „TÜRKEN RAUS“ und in anderen Türkenbeleidigungen keine Straftat, weil das keine ausreichende Volksverhetzung ist, sondern eine bloße Diskriminierung der in der BRD lebenden Türken. Sprachlos, gell? ${ }^{48}$

Am Ende des Stücks zwingen die beiden Kabarettisten das Publikum, endlich nach Hause zu gehen und nie wieder zurückzukommen. Diejenigen Gäste, die dies sehr schnell tun, erhalten eine Prämie von 10,50 DM. Tatsächlich lag der höchstmögliche Betrag für Ausländer, die in ihre »Heimat« zurückkehrten, bei 10500 DM. ${ }^{49}$ In dieser Hinsicht stehen Dikmens satirische Texte keineswegs im Gegensatz zur Literatur der »Betroffenen«. Dies verdeutlicht auch eine Aussage Dikmens selbst, in der es um die Motivation seines Schreibens geht, in deren Zentrum ebenfalls Diskriminierungserfahrungen stehen.

Meine Motivation, warum ich Satire schreibe, ist nicht Idealismus, sondern ist meine innere Befriedigung, Zorn, Ausweglosigkeit, Suche. Nachdem ich einen Text geschrieben habe, der mir gelungen erscheint, lehne ich mich zurück, und lese den Text mit Wonne und Genuß laut, und ... ich freue mich darauf, daß ich den Deutschen eins ausgewischt habe. Eine Woche lang habe ich keinen Zorn mehr, ich mag die Deutschen sogar; die Ausweglosigkeit habe ich überwunden, ich sehe wieder für mich eine Zukunft in Deutschland. [...] Das dauert aber nur eine Woche, dann sehe ich wieder alles klar, warum mein Nachbar mich wieder beschuldigt hat, daß ich gestern abend so laut gewesen sei. ${ }^{50}$

nach seiner Ernennung zum Bundeskanzler, seinen Plan unterbreitet, in den kommenden vier Jahren die Zahl der Türken in Deutschland zu halbieren. In der Akte steht, »Kanzler Kohl sagte, [...] über die nächsten vier Jahre werde es notwendig sein, die Zahl der Türken um 50 Prozent zu reduzieren - aber er könne dies noch nicht öffentlich sagen. [...] Es sei unmöglich für Deutschland, die Türken in ihrer gegenwärtigen Zahl zu assimilieren.« HECKING, Claus (2013): »Kohl wollte offenbar jeden zweiten Türken loswerden«. In: DER SPIEGEL, 01.08.2013. Siehe auch: Deutsche-Presse Agentur (2013): »Als Kohl die Hälfte der Türken loswerden wollte«. In: Die Welt, 01.08.2013.

48 Dikmen/Omurca (1985): „Vorsicht, frisch integriert«. In: Dikmen, Şinasi: Der andere Türke, Berlin: Express-Edition, S. 92.

49 Im Stück selbst ist zudem noch die politische Debatte um die Reduzierung des Nachzugsalters der Kinder von Ausländer von 16 auf 6 Jahre Thema. Siehe Hierzu: Dikmen (1986): S. 104.

50 TANTOW, Lutz (1986): »Nachwort«. In: DikmEN, Şinasi: Der andere Türke, Berlin: Express-Edition, S. 113-120, hier S. 117f. Im türkei-türkischen Film GuRBETÇI ŞABAN von Kartal Tibet aus dem Jahre 1985 ist der Zorn auf die diskriminierenden Aussagen und die Benachteiligungen türkischer Gastarbeiter durch Deutsche ein explizit konstitutiver Bestandteil der filmischen Erzählung. Wie in Günter Wallraffs Ganz Unten geht es in dieser ernsten und zugleich überzogenen Komödie um das ausbeuterische System der Leiharbeit illegal eingestellter Gastarbeiter. Der Film endet damit, wie es dem Protagonisten Şaban (Kemal Sunal) gelingt, über Kindergeld und den Milchverkauf selbst reich zu werden und die Deutschen, den Subunternehmer und den Chef der Fabrik, am Ende des Films für sich im eigenen Haus in Deutschland arbeiten zu lassen. Siehe hierzu: TiBET, Kartal (1985): Gurbetci Şaban, Spielfilm, Fanatik, Türkei. 
Die in Satire, Prosa, Spielfilm und Dokumentation entdeckte Zunahme an Abstraktion, psychischer Autokommunikation und der Unterbrechung sozialer Interaktionen als Reaktion auf Diskriminierungserfahrungen ist auch in der Lyrik festzustellen. Während in Gedichten - wie auch in Literatur und Film der Zeit bis Ende der 1970er Jahre die Beschreibung konkreter Transiträume wie Bahnhöfe und Wohnheime im Vordergrund steht, ${ }^{51}$ geht es Mitte der 1980er Jahre um "getrennte Zungen« und "getrennte Welten «.52 Dieser Zusammenhang von Welt und Sprache, der aus dem Gedicht »Doppelmann« von Zafer Şenocak stammt, gehört zu den meistzitierten im Forschungskontext der deutsch-türkischen Literatur der 1980er Jahre. Andere häufig zitierte Verse jener Zeit stammen von Alev Tekinay, die ebenfalls Mitte der 1980er Jahre neben Gedichten vor allem mit Erzählungen auf sich aufmerksam machte ${ }^{53}$ und den von uns festgehaltenen narrativen Wandel für diese Dekade noch einmal bestätigt. In ihrem Gedicht »Dazwischen« von 1985 hält sie fest: »Und jeden Tag fahre ich / zweitausend Kilometer / in einem imaginären Zug / hin und her, / unentschlossen zwischen / dem Kleiderschrank / und dem Koffer, und dazwischen meine Welt «. ${ }^{54}$ Auch in bis heute kaum bekannten Lyrikbänden ist die Trennung zwischen deutscher und türkischer Welt konstitutiv, wie in Das Lachen bewahren von Nevfel Cumart, der sein Leben in Deutschland als eine "Bürde zweier Welten « dichterisch beschreibt. ${ }^{55}$ Tatsächlich meint Diskriminierung, abgeleitet vom lateinischen Begriff discriminare, zunächst ein Unterscheiden und Trennen. Nach George Theodorson hängt das Faktum der Diskriminierung, sprich eine Unterscheidung oder Trennung moralisch oder gesetzlich negativ zu markieren, »von der jeweiligen Gesellschaft und ihren Werten $a b{ }^{56}{ }^{56}$ Die Diskriminierung ist sozusagen erst dann negativ oder positiv (»Sie können aber gut Deutsch sprechen«), wenn sie mit gesetzlichen und gesellschaftlichen Vorannahmen und Vorstellungen korreliert. Wie ich an anderer Stelle in diesem Buch festgehalten habe, ist die Praxis der Diskriminierung voraussetzungsreich. Sie beruht auf Unterscheidungen, die artikuliert

51 ÇAKIR, Sabri (1984): „Was ich nicht verstehen kann«. In: Türken deutscher Sprache. Berichte, Erzählungen, Gedichte, hg. v. Irmgard Ackermann, München: dtv, S. 91f.

52 Vgl. ŞENOCAK, Zafer (1985): »Doppelmann«. In: Türken deutscher Sprache, S. 39. Siehe auch: BeKTAŞ (1981); BAHADINLI, Yusuf Ziya (1982): Zwischen zwei Welten, Berlin: Ararat.

53 Siehe: Tekinay, Alev (1986): Über alle Grenzen. Erzählungen, Hamburg: Buntbuch. Siehe auch: TekinaY, Alev (1988): Die Deutschprüfung, Frankfurt a. M.: Brandes \& Apsel.

54 TEKINAY (1988): S. 9.

55 Cumart, Nevfel (1993): Das Lachen bewahren. Gedichte aus den Jahren 1983-1993, Düsseldorf: Grupello, S. 10.

56 Aus: Kiмmich, Dorothee/SchaHADAT, Schamma (2016): »Diskriminierung. Versuch einer Begriffsbestimmung«. In: Diskriminierungen, Zeitschrift für Kulturwissenschaften 2/2016, Bielefeld: transcript, S. 9-22, hier S. 11. 
und in Ungleichheiten umgewandelt werden. Dieser Prozess geht von »vorurteilsbehafteten Sichtweisen « aus und kann über darauffolgende »herabsetzende Äußerungen« bis zu »benachteiligenden Handlungen« führen. Diskriminierung ist voraussetzungsreich, weil sie Sehen, Sprechen und Handeln in eine vorentschiedene Richtung lenkt. Es müssen also Vorannahmen und Abstrakta im Spiel sein, die über das Gezeigte, über das Sichtbare hinaus verweisen und gegenwärtige Handlungsabläufe blockieren und unterbrechen. Aussagen wie »Sie können aber gut Deutsch« oder »wo kommen Sie ursprünglich/eigentlich her« sind in den 1980er Jahren im Gegensatz zu heute Dialogöffner. Sie sind die Reaktion und die Gegenwehr auf den rassistischen Slogan »Türken raus « der 1980er Jahre. ${ }^{57}$

Jedoch nimmt trotz dieser Gesprächskultur, die vom Affekt des Interesses geleitet ist, in den 1980ern die Abstraktion in öffentlicher Debatte, Prosa und Lyrik auf unterschiedlichsten Komplexitätsebenen ebenfalls zu, wenn von Migration und ihren Folgen die Rede ist. Sie steht dabei in engem Zusammenhang mit der nun einsetzenden Bearbeitung von Diskriminierung, vom Sprechen über Kultur und der Entstehung ihrer Bilder. In diesem epistemischen Zusammenhang ist auch die explizite Bitte der Organisatoren des ersten großen Literaturkolloquiums zur Ausländerliteratur zu verstehen, dass die deutschen Teilnehmer »sich mit eigenen Äußerungen und Deutungen« zurückhalten sollten. Sie sollten zuhören und für die ausländischen Autoren, die schon alle über eine Dekade in der Bundesrepublik leben, eine »sympathische Resonanz« schaffen. ${ }^{58}$ Im Unterschied zu den 1960er und 1970er Jahren sind nicht die körperlichen Bedürfnisse, nicht das Aufzeigen gesellschaftlicher Mechanismen, nicht der Fokus auf Verhaltensweisen, auf spezifisch-funktionale Orte und auch nicht die Arbeit die großen Themen, die die Begegnung zwischen alteingesessenen Deutschen und Türken bestimmen. Selbst in Wallraffs Reportage Ganz Unten und im dazu entstandenen gleichnamigen Dokumentarfilm von Jörg Gförer, in denen es eigentlich um Missbrauch und die Ausbeutung von Leiharbeitern durch Subunternehmer geht, stehen die kulturelle Diskriminierung der Leiharbeiter, und besonders die von Ali Siğirlioğlu, im Vordergrund - nicht die soziale Ungleichheit. Wir begegnen

57 Siehe zu heute: Vu, Vanessa (2019): »Alltag Rassismus: Herkunft. Keine Antwort schuldig«. In: Zeit Campus, 27.02.2019, https://www.zeit.de/campus/2019-02/herkunft-identitaet-diskriminierung-rassismus-selbstbestimmung (zuletzt 29.03.2019). KAZIM, Hasnain (2018): »\#MeTwo. ,Wo kommst du eigentlich her ? Viele Menschen mit dunklerer Hautfarbe beschweren sich, dass sie oft gefragt werden: ১Wo kommst du eigentlich richtig her? « Ist das Rassismus? Und darf man das fragen? «. In: DER SPIEGEL, 11.08.2018, http://www.spiegel.de/kultur/gesellschaft/metwowo-kommst-du-eigentlich-her-darf-man-das-fragen-a-1222620.html (zuletzt 29.03.2019).

58 ACKERMANN/WEINRICH (1986): Eine nicht nur deutsche Literatur. Zur Standortbestimmung der »Ausländerliteratur«, München: Piper, S. 9f. 
auch hier nicht einer Gruppe von Menschen. Im Zentrum stehen Bilder und Vorstellungen darüber, wie jemand aussieht, wofür er steht, und damit verbunden geht es oft um nationale Zu- und Selbstbestimmungen, die sich durch Sprechen oder Schweigen konstituieren. Sie verdichten sich in einzelnen Personen. Genau genommen verschiebt sich die Logik der Repräsentation vom Zeigen mittels darstellen in den 1960er und 1970er Jahren zu einem Vertreten und Fürsprechen mittels darstellen. Auch Gayatri Spivak beschreibt die Praxis der Repräsentation in ihrer äußerst wirkmächtigen theoretischen Abhandlung Can the Subaltern Speak (1985) nicht als eine Praxis zwischen Zeigen und Darstellen, sondern als eine zwischen Darstellen und Vertreten. ${ }^{59}$ Diese Form der Repräsentation, die im Prozess der Darstellung in unterschiedlichen Graden nach einem Vertreter und Fürsprecher fragt, ist immer doppelt codiert. ${ }^{60}$ Die innere Dynamik der Vertretung steht für Spivak in einem explizit "politischen Zusammenhang «, die der Darstellung eher in einem ökonomischen. ${ }^{61}$ Nach Spivak besteht der eigentliche Konnex zwischen Individuum und Kollektiv. Gruppen und Ökonomien spielen bei ihr keine ausschlaggebende Rolle mehr. Dieser narrative Wandel, der den Ausländer von deutscher und auch von türkischer Seite nicht mehr als Arbeiter sieht, sondern mehr als Vertreter, steht in Beziehung zu einem bevölkerungspolitischen Wandel, zu einer gesellschaftspolitischen Neuausrichtung, zu Debatten und Theorien der Integration und zu neuen philosophischen und kulturwissenschaftlichen Reflexionen der 1980er Jahre. Er ist zugleich die Grundlage für Diskriminierungen und Diskriminierungserfahrungen, die im Zentrum aller Produktionen der 1980er Jahre steht.

Bevölkerungspolitisch kommt es nach dem Gastarbeiteranwerbestopp von 1973 bis zum Ende der 1970er Jahre - besonders bei türkischen Gastarbeitern - zu den bekannten Familienzusammenführungen in Deutschland, die zum Großteil zwischen 1974 und 1979 erfolgen. Die Gastarbeiterpolitik der Bundesregierung nach dem Anwerbestopp ist eine der gleichzeitigen »Zuzugsbegrenzung und Integrationsförderung «; das berüchtigte Doppelkonzept, das die Medien »rückkehrorientierte Integration « nennen. Der Bundesregierung werfen auch sie »Konzeptionslosigkeit « vor. ${ }^{62}$ Da der Begriff »Einwanderungsgesellschaft « Anfang der 1970er Jahre keine breite politische Akzeptanz findet, obwohl sich Hans Dietrich Genscher 1972 kurzzeitig dafür einsetzt, wird der »eingegliederte« Gastarbeiter

59 Siehe hierzu: SPIVAK (2007): S. 38.

60 Ebd., S. 30.

61 Ebd., S. 36.

62 Aus: SCHÖNwÄLDER, Karin (2001): Einwanderung und ethnische Pluralität. Politische Entscheidungen und öffentliche Debatten in Großbritannien und der Bundesrepublik von den 1950er bis zu den 1970er Jahren, Essen: Klartext, S. 627. 
als ein »Mitbürger auf Zeit« begriffen, der in der Zeit, die er in Deutschland verbringt, sich einfügen und wohlfühlen, aber auch ohne Probleme wieder zurückkehren soll. ${ }^{63}$ Es gibt, wie in der Literatur und in den Filmen dieser Zeit, keinen wesensfremden Unterschied zwischen Herkunft und Ankunft. Auswirkungen der Einwanderungsgesellschaft auf die türkischen Migranten und andere, die über zwölf, dreizehn Jahre im Land sind, haben hier keinen Platz. Tatsächlich machen Gastarbeiter in den 1980ern überall auf die zeitliche Dauer ihres Lebens aufmerksam: in allen bisher genannten Werken, ob Dokumentation, Literatur oder Spielfilm. In den Arbeiten von Dursun Akcam, Metin Gür und Jeanine Meerapfel ist es beispielsweise immer die erste Information, die der Zuschauer oder Leser erhält: »N. Genc Ordu ist seit 13 Jahren in der BRD. « Oder: »A. Güneş arbeitet seit 14 Jahren unter Tage ${ }^{64}$ Zeitnah beschreibt die Soziologin Verena Macrae in ihrer Arbeit Die Gastarbeiter: Daten. Fakten. Problem das Konzept der Förderung einer »temporären Integration« als eines, das aufgrund seiner »Widersprüchlichkeit und Ambivalenz [...] die mit der Ausländerbeschäftigung verbundenen Probleme auf Dauer nicht lösen « wird. ${ }^{65}$

Doch trotz Anwerbestopp und der unentschlossenen Gastarbeiterpolitik der Bundesregierung wächst die türkische Bevölkerung in dieser Zeit um 240000 Personen »auf rund 1,27 Millionen «. Auf der anderen Seite sinkt die Zahl der »anderen Gastarbeiter-Nationalitäten [...] um rund 335000 auf 1,8 Millionen « ab. ${ }^{66}$ Anfang der 1980er Jahre leben 1,5 Millionen Türken in Deutschland. ${ }^{67}$ In diesem Zeitraum ziehen sehr viele Gastarbeiter aus den Arbeiterwohnheimen in günstige und "sanierungsreife« Stadtwohnungen. ${ }^{68}$ Ein Großteil dieser Wohnungen hat zwar eine Innentoilette, doch muss das Bad in der Regel mit anderen Wohnparteien geteilt werden. ${ }^{69}$ Der Anteil der nicht-arbeitenden migrantischen Bevölkerung steigt. Wenn zuvor 80 \% Gastarbeiter tatsächlich einer Arbeit nachgingen, ist es Anfang der 1980er Jahre wegen Arbeitslosigkeit und Familienzusammenführung

63 Ebd., S. 506.

64 GÜR (1987): S. 12, S. 35. Siehe auch: AKÇAM (1983): S. 38, S. 276.

65 MCRAE, Verena (1980): Die Gastarbeiter: Daten. Fakten. Probleme, München: Beck, S. 121.

66 HunN, Karin (2005): "Nächstes Jahr kehren wir zurück ..." Die Geschichte der türkischen „Gastarbeiter« in der Bundesrepublik, Göttingen: Wallstein, S. 343.

67 Siehe: LAURIEN, Hanna-Renate (1983): »Möglichkeiten und Grenzen kultureller Integration«. In: Die fremden Mitbürger. Möglichkeiten und Grenzen der Integration von Ausländern, hg. v. Hartmut Esser, Düsseldorf: Patmos, S. 39-51, S. 39.

68 HeRBERT, Ulrich (2001): Geschichte der Ausländerpolitik in Deutschland. Saisonarbeiter, Zwangsarbeiter, Gastarbeiter, Flüchtlinge, München: Beck, S. 235. Siehe auch MCRAE (1980): S. 41. 69 Siehe hierzu: MCRAE (1980): S. 41f. In Kartal Tibets Film GuRBETÇI ŞABAN von 1985 zieht der Protagonist in ebensolche Wohnverhältnisse, als er mit einem Touristenvisum zu seinem Bruder nach Köln zieht. Von Anfang an ist es aber seine Absicht, in Deutschland zu arbeiten. 
noch knapp die Hälfte. Wesentlich mehr türkische Kinder beginnen in dieser Zeit Kindergärten und Schulen zu besuchen. ${ }^{70}$ Zugleich bemühen sich die Gastarbeiter darum, ihren Kindern auch einen türkischen Unterricht in Deutschland zu ermöglichen. ${ }^{71} 1979$ setzen die deutsche und türkische Regierung ein Memorandum auf, das einen einheitlichen Türkisch-Unterricht für Kinder türkischer Gastarbeiter in deutschen Schulen ermöglichen soll. ${ }^{72}$ Das Erscheinungsbild und die Zusammensetzung der Migration in Deutschland ändern sich. So stehen auch nicht mehr die Fragen nach den Wohnverhältnissen der Arbeiter, nach ihrer Arbeitskraft oder nach der Solidarität mit ihnen im Vordergrund; die allgemeine politische und wirtschaftliche Ebene wird in dieser Hinsicht verlassen. Stattdessen entsteht eine Verhandlungsebene, die die Kultur im alltäglichen Handeln verstärkt in den Fokus rückt. ${ }^{73}$ Der Titel einer Dokumentation von Irene Hübner zum Leben der türkischen Frauen in Deutschland drückt diese Veränderung so aus: Sie hätten neben ihrer natürlichen, buchstäblichen Haut nun eine »zweite Haut «. ${ }^{74}$

Im 1982 entstandenen Kompendium Ausländer unter uns von Kurzfilmen, längeren Dokumentarfilmen und Spielfilmen zu Ausländern in Deutschland - bis Anfang der 1980er Jahre zählen die Autoren über 250 Titel - wird festgehalten, dass das Ziel der Sammlung darin bestehe, »die Fremden besser kennenzuler-

70 Siehe LAURIEN (1983): S. 43f.

71 Siehe: MAIER, Ulrich (2012): »Türkische >Gastarbeiterkinder in den 1970er-Jahren. Verein türkischer Arbeitnehmer in Heilbronn fordert Schulklassen für türkische Gastarbeiterkinder«, http://www.landesarchiv-bw.de/sixcms/media.php/120/53803/Archivnachrichten_44_Quellen_43.pdf (19.07.2016).

72 Siehe hierzu: ÜNvER, Osman Can (1983): »Probleme der Integration von Türken in Deutschland aus türkischer Sicht«. In: Die fremden Mitbürger. Möglichkeiten und Grenzen der Integration von Ausländern, hg. v. Hartmut Esser, Düsseldorf: Patmos, S. 52-59, hier S. 58. Der Türkisch-Unterricht an deutschen Schulen, der vom türkischen Bildungsministerium und den türkischen Konsulaten in Deutschland organisiert wird, findet in der Regel nachmittags nach dem deutschen Schulunterricht statt. Das türkische Bildungsministerium entsendete und entsendet bis heute Türkischlehrer - insbesondere für den Grundschulunterricht - nach Deutschland.

73 Siehe hierzu: EsSER, Hartmut (1983): »Die fremden Mitbürger. Möglichkeiten und Grenzen der Integration von Ausländern«. In: Die fremden Mitbürger. Möglichkeiten und Grenzen der Integration von Ausländern, hg. v. Hartmut Esser, Düsseldorf: Patmos, S. 7.

74 HÜBNER, Irene (1985): „... wie eine zweite Haut«. Ausländerinnen in Deutschland, Weinheim: Beltz. Wenn Hübners Publikation sich vor allem auf die erste Generation fokussiert, fragen Hanne Straube und Karin König in Zuhause bin ich »die aus Deutschland«. Ausländerinnen erzählen auch die zweite Generation. Wie in Hübners Untersuchung sind es hier auch 13 Frauen, die davon berichten, irgendwann zurückkehren zu wollen, nur dass sich im Unterschied zur ersten Generation für sie auch »eine zweite Haut« in der Türkei gebildet hat. Sie werden in ihren Urlaubsaufenthalten dort immer als »die aus Deutschland« angesehen. Siehe hierzu: STRAUBE, Hanne/KöNIG, Karin (1982): Zuhause bin ich »die aus Deutschland«. Ausländerinnen erzählen, Ravensburg: Mayer. 
nen, sie zu verstehen und zu akzeptieren . $^{75}$ Dieser Leitspruch der Dokumentation setzt sich durch, obwohl in den mit je halb- bis ganzseitigen Beschreibungen sehr verkürzt zusammengefassten Materialien der 1970er Jahre nicht das Verstehen des Anderen im Zentrum steht, sondern ihre sozialen und materiellen Umstände. ${ }^{76}$ In öffentlichen Debatten und auf institutioneller Ebene (Kirche, Vereinsgründungen, Verlage und Universität [DaF, Ausländerpädagogik]) ${ }^{77}$ wird die Verwendung des national gerahmten Begriffs >Kultur` im Themenfeld der deutsch-türkischen Migration im integrierenden wie auch im desintegrierenden Sinn äußerst virulent. ${ }^{78}$ Unterstützt wird diese neue Sichtbarkeit der Migration in Deutschland zudem dadurch, dass muslimisch-religiöse Vereine, politische Bewegungen und Vertretungen wie Milli Görüş, der Verband islamischer Kulturzentren (VIKZ) und die DITIB in Deutschland bis Anfang der 1980er Jahre entstehen und wirksam werden. ${ }^{79}$ Alle genannten Organisationen begreifen sich als provisorische Einrichtungen, da das Ziel der Migranten die Rückkehr in die Türkei ist. Mit anderen Worten: Anfang der 1980er Jahre ist die Bundesrepublik aufgrund der neuen sozialen Konstellation faktisch ein Einwanderungsland, auch wenn die neuen völkisch-nationalen Orientierungen diesem Faktum widersprechen. ${ }^{80}$ Die türkeispezifische Perspektive der genannten Einrichtungen sowie die deutsche Ausländerpolitik der 1980er Jahre führen dazu, dass die Bundesrepublik hinsichtlich des Sprechens über Migration und Integration und der Imagination ein geteiltes Land ist. Das bindende Narrativ dieses Dilemmas lautet »Wie lebt es sich als Türke in Deutschland?«.

Deshalb folgt in den anbrechenden 1980ern trotz faktischer Einwanderungssituation auch keine Projektion einer Integration, die einen Ist-Zustand kritisiert und einen Soll-Zustand anvisiert. Im Gegenteil zeigt die Verwendung des Begriffs >Integration ` in dieser Dekade, dass nun selbst der Ist-Zustand (etwa das Sprechen-Können und die Sprache), der in den Kulturproduktionen der 1960er und 1970er eindrücklich geschildert wurde, nun zur Kontroverse wird. Denn

75 FReUnde DER DEUTSCHEN KinEMATHEK E.V. BerLin (1982): Ausländer unter uns. Ein Filmkata$\log$, hg. v. Senator für Arbeit und Betriebe Berlin, S. 7.

76 Ebd. Die meisten der aufgelisteten Filme sind kurze bis halblange Dokumentarfilme, in denen im Besonderen die Arbeits- und Familienverhältnisse der Gastarbeiter gezeigt werden.

77 Das Institut für Deutsch als Fremdsprache (DaF) wird in München 1978 gegründet. Die Forschungsrichtung der Ausländerpädagogik beginnt Ende der 1970er und Anfang der 1980er sich zu etablieren. Siehe hierzu: MECHERIL, Paul (2010): Migrationspädagogik, Oldenbourg: Beltz, S. 56.

78 Vgl. Deniz GöKtüRk/David GramLIng/Anton KaEs/Andreas LANGEnohl (Hg.) (2011): Transit Deutschland. Debatten zu Nation und Migration, Konstanz: Konstanz University Press, S. 361-365. 79 SCHIFFAUER (2004): S. 356.

80 Siehe: BADE, Klaus (1983): Vom Auswanderungsland zum Einwanderungsland? Deutschland 1880-1980, Berlin: Colloquium, S. 123. 
Deutschland ist von den 1980ern bis Ende der 1990er in politischer Diktion nun weitaus entschiedener als in den 1970ern entgegen jeder sozialen Realität »kein Einwanderungsland «. ${ }^{81}$ Damit geht erneut eine Veränderung der politischen Epistemologie einher. Politisch etabliert sich in den 1980er Jahren mit einer Logik der »Hinwendung zur Differenz« nun der Begriff der Ausländerpolitik - im Gegensatz zur vorher betriebenen »Gastarbeiterpolitik«. 1979 wird die Gastarbeiterproblematik zum ersten Mal Wahlkampfthema und gilt 1982 im »Dringlichkeitsprogramm « der »Politik der Erneuerung« der Regierung Kohl als eines der vier wichtigsten politischen Aufgaben, die sich jedoch nicht auf die politische Umsetzung von Integrationsmaßnahmen konzentriert, sondern auf die der Begrenzung der Ausländeranzahl in Deutschland. In den 1960er und 1970er Jahren war im Zusammenhang der Gastarbeiter hingegen noch von »europäischer Integration«, vom Übergang der wirtschaftlichen zur sozialen Integration zumindest die Rede. ${ }^{82}$ Mit der Senkung der Zahl der Ausländer durch Sofortmaßnahmen $^{83}$ ist auch eine politische Kompetenzverlagerung vom Arbeitsministerium zum Innenministerium verbunden, die 1982 erfolgt. Mit ihr wird von Seiten der Regierung signalisiert, dass »nicht mehr sozialpolitische, sondern ordnungspolitische Aspekte im Vordergrund der Ausländerpolitik« stehen, wobei nach den Familienzusammenführungen in Deutschland eine sozialpolitisch auf Integration ausgerichtete Politik erforderlich gewesen wäre. ${ }^{84}$ Durch diese neue, ethnisch codierte Grenzziehung in der Politik erfolgt der begriffstechnische Übergang nicht vom Gastarbeiter zum Einwanderer - wie er spätestens in dieser Zeit hätte erfolgen müssen -, sondern zum Ausländer, der seine literarischen

81 Als »sozialschizoid« hinsichtlich Migration und Integration beschreibt Klaus Bade heute die Anfänge der 1980er Jahre. Siehe hierzu: BADE, Klaus J. (2017): Migration. Flucht. Integration. Kritische Politikbegleitung von der >Gastarbeiterfrage` bis zur >Flüchtlingskrise،. Erinnerungen und Beiträge, Karlsruhe: Loeper, S. 27.

82 Vgl. RAUER, Valentin (2013): »Integrationsdebatten in der deutschen Öffentlichkeit (19472012)«. In: Die Integrationsdebatte zwischen Assimilation und Diversität. Grenzziehungen in Theorie, Kunst und Gesellschaft, hg. v. Özkan Ezli, Andreas Langenohl, Valentin Rauer, Claudia Voigtmann, Bielefeld: transcript, S. 51-86, hier S. 57ff.

$83 \mathrm{Zu}$ diesen Sofortmaßnahmen gehörten zum einen das Rückkehrförderungsgesetz von 1983, durch das die rückkehrwilligen Ausländer ihre Arbeitslosen- und Renteneinzahlungen zurückbekamen, wenn sie heimkehrten. Eine weitere Maßnahme bestand darin, das Nachzugsalter ihrer Kinder von 16 auf 6 Jahre zu reduzieren. Dies wurde in den 1980ern zwar nie durchgesetzt, war jedoch eines der zentralen Streitthemen in der Koalition von CDU mit ihrem damaligen Innenminister Friedrich Zimmermann und der FDP mit ihrer Ausländerbeauftragten Liselotte Funke, die sich mit ihrer Partei gegen diese Herabsetzung der Altersgrenze aussprach. Vgl. HeRBERT (2001): S. 252-255. Siehe auch: HunN (2005): S. 451-477.

84 HERBERT (2001): S. 250. Dieses politische Vorhaben ist auch Thema in Dikmens und Omurcas Satirestück Vorsicht, frisch integriert!. Siehe hierzu: DikmEN (1986): S. 104. 
sowie amtlichen Referenzen in den 1980ern hat. ${ }^{85}$ Der Erziehungs- und Kultursoziologe Wolf-Dietrich Bukow versteht diesen Wandel Ende der 1980er Jahre als eine »Politik der Ethnisierung «, als einen politischen Vorgang also, hinter dem eine »bestimmte gesellschaftliche Strategie «steckt ${ }^{86}$ - eine Politik, die er sowohl im »strukturellen « als auch im »alltäglichen Bereich « in der Bundesrepublik der 1980er verortet. ${ }^{87}$

Diese Politik ist auch der Ausgangspunkt für die Rede von der kulturellen Differenz, die die Integrationsdebatten der 1980er Jahre prägt. Der Verhaltensforscher Eibl-Eibelsfeld löst beispielsweise eine folgenreiche Debatte aus mit seiner Aussage, dass Türken auch Menschen seien, aber Menschen mit einer anderen Kultur und deshalb nicht wirklich integrierbar. Die bestimmende Leitkategorie ist im Unterschied zur Debatte Mitte der 1960er Jahre der Begriff >Kultur und nicht die Arbeit. ${ }^{88}$ In der Wochenzeitschrift Die Bunte heißt es am 30 . September 1982 hierzu, den Wortlaut Eibl-Eibesfeld wiedergebend:

»Hier Christen - dort Moslems. Hier Emanzipation der Frau - dort demutsvolle Unterwürfigkeit. Hier fortschreitende Dekadenz des Familienverbandes - dort straffe Sippenordnung.« Außerdem - so Eibl-Eibesfeld weiter - sei »unser Land [...] überbevölkert. Und für gegenseitiges Abstandhalten in Respekt und Freundschaft fehlt es hierzulande - im Gegensatz etwa zu den USA - allein schon am Platz. [...] Wer also immer noch glaubt, dass Türken bei uns so leben können wie Deutsche, vergisst: Türken sind auch nur Menschen. Und zwar Menschen mit einer anderen Kultur ${ }^{89}$

85 So setzt auch Günter Wallraffs Dokumentation Ganz Unten mit dem Wahlabend am 6. März 1983 ein, dem Tag, an dem »die Wende gewählt wurde«. Als verkleideter Türke mischt er sich unter die Wahlfeier im Konrad-Adenauer-Haus der CDU in Bonn. Kurt Biedenkopf stellt er sich als Abgesandter von Alparslan Türkeş, dem Parteiführer der nationalistischen türkei-türkischen Partei MHP, vor. Er wird dort als dessen Vertreter willkommen geheißen. Siehe hierzu: WALLRAFF (1985): S. 14f. Auch Zafer Şenocak beschreibt 13 Jahre später in seinem bekannten Roman Gefährliche Verwandtschaft die Wahl der CDU zur regierenden Partei als eine paradigmatische Wende in der Ausländerpolitik Deutschlands. Für ihn war sie der Beginn einer Zeit von »klaren Vorstellungen von Grenzen«. Für Şenocak wussten Helmut Kohl und Şenocaks damaliger Freund Anton, wer nach Deutschland gehörte und wer nicht, und »wo die Mitte in diesem Land war «. Siehe hierzu: ŞENOCAK, Zafer (1998): Gefährliche Verwandtschaft, München: Babel, S. 108.

86 BuKow, Wolf-Dietrich/LlarYoRA, Roberto (1988): Mitbürger aus der Fremde. Soziogenese ethnischer Minoritäten, Opladen: Westdeutscher Verlag, S. 2.

87 Siehe hierzu: ebd., S. 82-110.

88 Vgl. Herbert (2001): S. 259. Siehe auch: HunN (2005): S. 494; EzLI, Özkan (2013): »Narrative der Integration im Film«. In: Die Integrationsdebatte zwischen Assimilation und Diversität, S. 189-212, S. $208 \mathrm{f}$.

89 Aus: HunN (2005): S. 495. 
Helmut Kohl äußerte, wie oben erwähnt, im Herbst 1982 gegenüber Margaret Thatcher genau denselben Befund, was den Paradigmenwechsel zwischen den zwei Dekaden zuvor und den 1980ern eindrücklich untermauert. Nach Kohl habe Deutschland kein Problem mit Portugiesen, mit Italienern, selbst mit den Südostasiaten nicht. »Aber die Türken kämen aus einer sehr andersartigen Kultur... . Deutschland habe 11 Millionen Deutsche aus osteuropäischen Ländern integriert. Aber diese seien Europäer und stellten daher kein Problem dar. « ${ }^{90}$

Was Kohl Thatcher vertraulich mitteilte, zeigte sich im Kern ein Jahr zuvor schon im Heidelberger Manifest vom 17. Juni 1981, das auf große Resonanz stieß und eine öffentliche Debatte auslöste. Das Manifest erschien nach der ersten Veröffentlichung mehrfach leicht modifiziert in unterschiedlichen überregionalen Tagesund Wochenzeitungen bis März 1982. Im Fokus stehen in allen Versionen von allen Ausländern in Deutschland die Türken. Diese würden die deutsche Sprache, die deutsche Kultur überfremden und das deutsche »Volkstum« und seine »geistige Identität « gefährden. ${ }^{91}$ Das türkische Volk sei definitiv ein anderes als das deutsche. >Völker s sind nach der Definition des Heidelberger Kreises, der aus 15 deutschen Professoren besteht, »biologisch und kybernetisch lebende Systeme höherer Ordnung mit voneinander verschiedenen Systemeigenschaften, die genetisch und durch Traditionen weitergegeben werden . $^{92}$ Die Nation geht ihrer Ansicht nach aus einem Volk hervor und nicht aus einer bestimmten Summe von Völkern wie im amerikanischen Modell. Das deutsche Volk sei obendrein noch geteilt und müsse zu einer eigenen Einheit finden, dessen Realisierung gefährdet sei, wenn sich ein Teil des deutschen Volkes mit einem anderen vermischen würde. ${ }^{93}$ Trotz dieses starken Bezugs auf das deutsche Volk verweisen die Verfasser des Manifests explizit darauf, dass sie »auf dem Boden des Grundgesetzes stehend« argumentierten und sich dabei gegen jeden »ideologischen Nationalismus, gegen Rassismus und gegen jeden Rechts- und Linksextremismus « wendeten. ${ }^{94}$

Eine stärkere Bindung zur Bundesrepublik zu entwickeln, steht auch im Zentrum der bekannten Schrift des Politikwissenschaftlers Dolf Sternbergers zum ,Verfassungspatriotismus` von 1982. Ohne Bezug auf die Folgen der Migration in

90 Deutsche-Presse Agentur (2013). Siehe auch: Schmidt, Michael (2013): »Türken waren Kanzler Kohl fremd «. In: DIE ZEIT, 02.10.2013, https://www.zeit.de/politik/deutschland/2013-08/ kohl-gastarbeiter-gespraechsprotokoll (zuletzt 11.05.2021).

91 HeIdelBerger Kreis (1982): »Heidelberger Manifest«. In: Transit Deutschland, S. 155-157, hier S. 155. Diese Ausgabe ist ein Wiederabdruck des Manifests, das am 4. März 1982 in der Frankfurter Rundschau erschienen ist.

92 DiE ZeIT o. V. (1982): »Das Heidelberger Manifest«. In: DIE ZEIT, 05.02.1982, http://www.zeit. de/1982/06/heidelberger-manifest (20.07.2016).

93 Ebd.

94 Siehe hierzu die Versionen aus der Frankfurter RundSCHAu und aus der ZeIt, S. 155. 
der Bundesrepublik ist für ihn die Verfassung die »Patria in diesem geteilten Land und Volk «. ${ }^{95}$ Sternberger distanziert sich ebenfalls von einem mythischen Nationalismus. Zugleich nimmt er aber auch Abstand von den basisdemokratischen Bewegungen der 1960er und 1970er Jahre - in deren Zentrum die soziale Interaktion steht - und verlangt, dass man »etwas weniger von Demokratie«, dafür aber »mehr von der Verfassung reden« sollte. Seinen gesellschaftspolitisch äußerst wirkmächtigen Aufsatz schließt er mit Sätzen, deren imaginärem Anteil wir ebenfalls in der deutsch-türkischen Literatur und im deutsch-türkischen Film begegnen: »Ich wünschte, die Gelegenheit und der Wille fänden sich, dass auch die Verfassungsfreunde einmal auf die Straße gingen und die Demonstrierdemokraten beschämten durch die Macht ihres Patriotismus«. Denn es sei an der Zeit, »die gemeinsame Verfassungsloyalität der Bürger und ihrer Parteien einmal öffentlich sichtbar zu machen «. ${ }^{96}$ So steht also auch im sich neu konstituierenden deutsch-deutschen Verhältnis in den beginnenden 1980er Jahren ein »Berg« zwischen Wohnung und Straße. ${ }^{97}$ Und wenn es auf der einen Seite darum geht, einen Türken auf die Straßen zu schicken, so geht es in den 1980ern auch darum, endlich einen Deutschen auf die Straße zu schicken.

Von dieser Hervorhebung des politischen deutschen Bürgers sind der Migrant und seine Nachfahren in höchstem Maße betroffen. Denn nicht mehr nur die Lohnarbeit steht im Zentrum des Zugangs in die Kerngesellschaft, wie sie dies in frühen kapitalistischen Gesellschaften tat. ${ }^{98}$ In den 1980ern stellt sich anhand der Kategorie des Bürgers die Frage »nach dem Zugang zur und Beteiligung an der

95 STERnBerger, Dolf (1982): »Verfassungspatriotismus«. In: Grundfragen der Demokratie. Schriftenreihe der Niedersächsischen Landeszentrale für Politische Bildung. Folge 3, hg. v. der Niedersächsischen Landeszentrale für Politische Bildung 1982, S. 7.

96 Ebd., S. 17.

97 Anton Kaes beschreibt in seinem Buch Deutschlandbilder. Die Wiederkehr der Geschichte als Film von 1987, wie nach dem Deutschen Herbst 1977 und nach dem großen Erfolg der amerikanischen Serie HoLOcaust von 1978 besonders unter den deutschen Filmschaffenden ein Bewusstseinswandel einsetzt. Wurde die deutsche Geschichte vom Neuen deutschen Film in den 1960er und 1970er Jahren nicht thematisiert, folgen in den 1980er Jahren - beispielsweise mit Edgar Reitz' Anfang der 1980er Jahre einsetzender Heimat-Trilogie - filmische Produktionen, die sich mit den »Bildern Deutschlands« beschäftigen. Als Reaktion auf den immensen Erfolg der amerikanischen Serie setzt ein »Insistieren auf dem Besitz der eigenen Geschichte« bei den Filmschaffenden ein. Nach Reitz haben die Amerikaner mit ihrer Kommerzästhetik den Deutschen ihre Geschichte »aus den Händen gerissen«. Im Zentrum von Kaes’ Arbeit stehen neben Reitz' Heimat, Hitler. Ein Film aus Deutschland von Syberberg und Deutschland. Bleiche MutTER von Sanders-Brahms. Siehe hierzu: KAES, Anton (1987): Deutschlandbilder. Die Wiederkehr der Geschichte als Film, München: Edition text + kritik, S. 41.

98 Siehe hierzu: OfFE, Claus (1984): Arbeitsgesellschaft. Strukturprobleme und Zukunftsperspektiven, Frankfurt a. M.: Campus, S. $13 \mathrm{ff}$. 
Gesellschaftlichkeit « neu. ${ }^{99}$ Bei dieser Umstellung wird der Migrant vom Arbeiter über den Ausländer zum Nicht-Deutschen, zum Nicht-Bürger. Er wird nicht mehr über seine historisch-soziale Existenz - er lebt schon seit den 1960ern in der Bundesrepublik -, sondern durch einen »spezifischen kulturellen Standort« identifiziert. Der alteingesessene Deutsche wird hingegen zum Bürger, dem der öffentliche Raum per se gehört. ${ }^{100}$ Wenn die Bundesrepublik in den 1970er Jahren noch als ein Staat einer Industriegesellschaft gedacht wurde, rücken nun die Kategorien >Bürgerlichkeit` und `Zivilgesellschaft` im Fahrwasser einer restaurativen Politik nach den Folgen des linken Extremismus - Deutscher Herbst ins Zentrum der politischen Erzählung. ${ }^{101}$ Da auch in diesen Zusammenhängen der türkische Einwanderer weder dazugehört noch adressiert wird, beschränkt sich seine soziale Teilhabe darauf, ein Klient der Ausländerpolitik zu sein. ${ }^{102}$ Dieser Aspekt der Diskriminierung unterscheidet sich grundlegend vom politischen Zustand der Türkeistämmigen heute, was auch an den Änderungen des Staatsbürgerschaftsgesetzes 2000 und 2013 sowie der Erlassung des Allgemeinen Gleichbehandlungsgesetzes (AGG) - auch Antidiskriminierungsgesetz genannt von 2006 liegt. $^{103}$

Diese über- bzw. unterdeterminierte Perspektive auf Alteingesessene und Einwanderer geht über die Gruppenperspektive Milton Gordons und der Theorien zur Öffentlichkeit und Privatheit der 1960er und 1970er Jahre hinaus und erfüllt die Voraussetzungen der Essenzialisierung. Essenzialisierungen generieren die Idee eines Wesenskerns, der den Charakter einer Gesellschaft oder einer Epoche unverrückbar bestimmt. Sie reduzieren die Vielschichtigkeit sozialer Phänomene auf ein Merkmal oder auf ein Symbol und führen daher oft zu identitätspolitischen Verhärtungen. ${ }^{104}$ Sie stellen folglich eine Verhärtung dar, die auf gesellschaftlichem Unbehagen und Angst basiert, die über die Debatten hinaus Ende 1970er und Anfang der 1980er auch statistisch erfasst wurde. Eine zentrale

99 BUKOW/LlaRYORA (1988): S. 88.

100 Ebd., S. 2.

101 Siehe hierzu: HACKe, Jens (2009): Die Bundesrepublik als Idee. Zur Legitimationsbedürftigkeit politischer Ordnung, Hamburg: Hamburger Edition, S. 84-113.

102 Bukow/LlaryoRa (1988): S. 93. Siehe hierzu auch: HütTERMAnN, Jörg (2009): »Zur Soziogenese einer kulturalisierten Einwanderungsgesellschaft«. In: Wider den Kulturenzwang. Migration, Kulturalisierung und Weltliteratur, hg. v. Özkan Ezli, Dorothee Kimmich, Annette Werberger, Bielefeld: transcript, S. 95-133, hier S. 105f.

103 Heute ist es umgekehrt. Es wird erwartet, dass man sich von islamistischer Gewalt öffentlich distanziert und kritisch Stellung zur Politik Recep Tayyib Erdoğans bezieht. Integration ist heute gänzlich eine Frage des öffentlichen Raums geworden.

104 Siehe hierzu: EzLI, Özkan (2012): Grenzen der Kultur. Autobiographien und Reisebeschreibungen zwischen Okzident und Orient, Konstanz: Konstanz University Press, S. 11. 
Frage in einer vielzitierten Repräsentativumfrage zu Türken in Deutschland war, ob diese zurückkehren sollten oder man ihnen die Möglichkeit geben sollte, in Deutschland zu bleiben. Die Umfrage erfolgte zwischen den Jahren 1978 und $1983^{105}$ und ergab, dass im November $197839 \%$ der Deutschen die Rückkehr der Türken befürworteten, Anfang 198268 \% und im März 1983 sogar 80 \%. Zugleich gaben dieselben Interviewten an, dass sie die allgemeine Wirtschaftslage in Deutschland als »nicht gut « empfänden. ${ }^{106}$

In dieser gesellschaftspolitischen Stimmung wird im Herbst 1983 das bereits erwähnte Rückkehrförderungsgesetz verabschiedet, das durch finanzielle Anreize Ausländer dazu bewegen soll, in ihre Herkunftsländer zurückzukehren. Neben der ökonomischen Entlastung, die man sich mit diesem Gesetz versprach, war das stützende kulturpolitische Argument dafür, dass man dem türkischen Bevölkerungsanteil - wie Eibl-Eibesfeld und die Verfasser des Manifests zuvor aus kulturellen Gründen die Fähigkeit absprach, sich in die deutsche Kultur integrieren zu können. Mit >deutscher Kultur` war mitunter ein christlich geprägtes westeuropäisches Land gemeint. ${ }^{107}$ Das Rückkehrförderungsgesetz erwies sich in der

105 Im Zusammenhang der Zahlen dieser Studie spricht Klaus Bade Anfang der 1980er Jahre davon, dass sich die deutsche Gesellschaft von einer »sperrigen Aufnahmegesellschaft« in eine »Abwehrgesellschaft« verwandelt habe. Siehe hierzu: BADE (1983): S. 113-115. In vielen bislang erwähnten Filmen und Texten ist der damals populäre Schriftzug »Türken raus« an viele Wände im öffentlichen Raum gesprayt. Mitunter lesen wir in den Filmen von Gförer und Meerapfel auf öffentlichen Toiletten oder am Arbeitsplatz Sprüche wie »Tod den Türken«. Jeanine Meerapfel zeigt in ihrem Dokumentarfilm städtische Mülleimer, auf die »Türken da rein « gesprayt wurde. Diese Türkenfeindlichkeit wird in Kartal Tibets Film GURBETCI ŞABAN äußerst harsch dargestellt. In dieser überzogenen Komödie, die im Kern eine Rachegeschichte ist, erkennt der Protagonist Şaban, wie seine Landsleute in einer Firma beschimpft (»scheiß faule Türken«) und ausgebeutet werden. Sie ertragen und erdulden es, weil viele von ihnen illegal im Land sind oder keine Arbeitserlaubnis mehr haben. Er schwört sich, wiederum in Form eines Monologs, für alle Rache zu nehmen. Am Ende des Films, er wird zu einem Milchfabrikanten, zieht er mit seiner Frau aus der engen Wohnung mit Außenbad und Außentoilette in ein repräsentatives großes bürgerliches Haus. Darin werden am Ende des Films die deutschen Ausbeuter, Subunternehmer und ihre Frauen und Familien für Şaban als Putzkräfte arbeiten. Die Deutschen werden durchweg nur von türkischen, mitunter sehr bekannten Schauspielern aus der Türkei gespielt. Siehe hierzu: TIBET (1985).

106 Siehe hierzu: Herbert (2005): S. 241. Siehe ebenfalls: BAdE (1983): S. 113; MEIER-Braun, Karl-Heinz (1988): Integration und Rückkehr? Zur Ausländerpolitik des Bundes und der Länder, insbesondere Baden-Württembergs, Mainz: Grünewald, S. 41.

107 Siehe: http://www.bpb.de/lernen/grafstat/projekt-integration/134768/glossar?p=all (15.11.2017). Auch Aras Örens Protagonist in Bitte nix Polizei bezeichnet das kalte Wetter morgens in Deutschland auf dem Weg zur Arbeit nicht mehr mit dem Bild der "gefrorenen Straßen« wie in Was will Niyazi in der Naunynstraße von 1973, sondern als »Christenkälte«. Siehe hierzu: ÖREN, Aras (1981): Bitte nix Polizei. Kriminalerzählung, Frankfurt a. M.: Fischer, S. 35. Und im Unterschied zum ersten Poem wird 
Praxis jedoch als folgenlos. Denn trotz finanzieller Anreize verließen kaum mehr als 100000 Türken die Bundesrepublik. ${ }^{108}$ Diese nicht stattfindende Rückkehr ist auch deshalb bemerkenswert, weil innerhalb türkischer Einwandererfamilien in Deutschland das Narrativ >Nächstes Jahr kehren wir zurückı zu dieser Zeit sehr bestimmend war ${ }^{109}$ - obwohl nur die wenigsten wirklich zurückkehrten. Das lag unter anderem selbstredend daran, dass die politische und wirtschaftliche Situation in der Türkei nach dem Militärputsch im Herbst 1980 äußerst prekär war. ${ }^{110}$ Daher ist es auch im Besonderen diese Kluft zwischen Sprechen und Praxis, zwischen Wohnung und Straße, die die Ambivalenz und den kontroversen Charakter der Integration in dieser Zeit auszeichnet und fälschlicherweise viel zu oft als ein Sein zwischen den Kulturen gelesen wurde. ${ }^{111}$ Sicher haben kulturelle Kategorien eine Rolle gespielt, doch waren die Bedingungen, die dieses Sprechen über Kultur erst ermöglichten oder hervorbrachten mitunter materieller Natur und hatten zu tun mit Bewegungsmöglichkeiten und Rechtssicherheiten. Beispielsweise waren die Ausländerbehörden ermächtigt, die Aufenthaltsgenehmigung mit der Arbeitserlaubnis zu verbinden. Verlor man seine Arbeit und bekam kein Arbeitslosengeld mehr, konnte dies zur Ausweisung aus der Bundesrepublik führen. ${ }^{112}$

Der christliche Zusammenhang, der im Rückkehrförderungsgesetz zur Abwehr der türkischen Kultur bemüht wird, ist ebenfalls ambivalent. Im Gegensatz zur kulturellen Legitimierung des Rückkehrförderungsgesetzes ist beispielsweise auf dem Deutschen Evangelischen Kirchentag im September 1980 offensiv von einer multikulturellen Gesellschaft die Rede. Im Kern ihrer Thesen hält die evangelische Kirche fest, dass »für das künftige Zusammenleben eine gegenseitige Integration erforderlich « sei. ${ }^{113}$ In Mit Einwanderern leben. Positionen evange-

in der Erzählung von 1981 die Arbeit kaum noch beschrieben, denn auch hier wurde sie entweder durch »Kultur« oder die Suche nach »Persönlichkeit« ersetzt.

108 Eine dieser Personen ist Melek Tez in Jeanine Meerapfels Dokumentarfilm Die KüMmELtüRKIN GEHT.

109 Siehe hierzu: Hunn (2005): S. 11. Siehe ebenfalls: PAgenstecher, Cord (1996): „Die >Illusion` der Rückkehr. Zur Mentalitätsgeschichte von `Gastarbeit` und `Einwanderung`. In: Soziale Welt 47:2, S. 149-179.

110 Siehe hierzu: ADANIR, Fikret (1995): Geschichte der türkischen Republik, Berlin: Bibliographisches Institut; KREISER, Klaus/Neumann, Christoph (2009): Kleine Geschichte der Türkei, Stuttgart: Reclam.

111 LAURIEN (1983): S. 40.

112 MCRAE (1980): S. 64. Besonders in den türkei-türkischen Filmen GuRBETÇI ŞABAN und PoLIZEI sind die Aufenthaltserlaubnis und die Arbeitserlaubnis zentrale Themen, die den Auftritt der Türken und den Kontakt mit den Deutschen im öffentlichen Raum zentral mitbestimmen.

113 Der ÖKumenische Vorbereitungsausschuss (1980): »Wir leben in der Bundesrepublik in einer multikulturellen Gesellschaft‘. Thesen vom 24. September 1980, Tag des ausländischen Mitbürgers«. In: Transit Deutschland, S. 361-365, hier S. 361. 
lischer Ausländerarbeit bringt der evangelische Theologe und Soziologe Jürgen Micksch Mitte der 1980er Jahre diesen gesellschaftspolitischen Begriff mit dem Argument ins Spiel, dass man den Ausländer in Deutschland nicht mehr durch seinen ökonomischen Mehrwert oder allein durch seine Arbeitskraft für diese Gesellschaft legitimieren dürfe, sondern vielmehr durch seine Kultur, die eine Bereicherung für die deutsche Gesellschaft darstelle. ${ }^{114}$ In der »Anwesenheit von Ausländern « stecke eine »geistesgeschichtliche Herausforderung«. Nach Micksch ist für das Gelingen eines Zusammenlebens eine »ständige Kommunikation zwischen Einwanderern und Einheimischen « erforderlich. ${ }^{115}$ Denn Gott selbst habe sich um den Fremden gekümmert und ihn geliebt. Daher habe das »Eintreten für Ausländer keine politischen, sondern theologische Wurzeln «. ${ }^{116}$ Damit, dass Jesus selbst sich um den Fremden gekümmert habe, argumentiert auch Günter Wallraff in Ganz Unten. ${ }^{117}$

Dass es den Fremden zu akzeptieren gilt, steht auch im Zentrum der integrationstheoretischen Reflexionen des Soziologen Georg Elwert. In seinem bis heute oft zitierten Aufsatz »Probleme der Ausländerintegration. Gesellschaftliche Integration durch Binnenintegration?« von 1982 argumentiert er gegen Hartmut Essers Assimilationstheorie von 1980, dass die Erhaltung der Herkunftskultur des Einwanderers auch positive Effekte auf die Integration der Ausländer haben könne. Sie ermögliche dem Einwanderer, in der Fremde ein Selbstbewusstsein $\mathrm{zu}$ entwickeln, das ihm Sicherheit im Alltag biete und die Kraft spende, auf

114 Siehe hierzu: Micksch, Jürgen (1984): Mit Einwanderern leben. Positionen evangelischer Ausländerarbeit, Frankfurt a. M.: Lembeck, S. 8.

115 Ebd., S. 9.

116 Ebd., S. 14. Auch Wallraff versucht als Ali, der gemäß seiner Fiktion in der Türkei politisch verfolgt wird, die Kirchen um Hilfe zu bitten. Dass in seinem Zugang auch das Faktum der Diskriminierung steht und er diese ebenfalls aufzeigen möchte, zeigt eindrücklich, dass er sich nicht wegen Asyl an die Kirchen wendet, sondern wegen einer Schnelltaufe, einer Konversion, die ihm den weiteren Aufenthalt in Deutschland erleichtern könnte. Er weist sich mit seinem künstlichen Ausländerakzent als versierter Kenner des Christentums aus, erhält aber trotzdem an keiner Stelle die Möglichkeit getauft zu werden. Siehe hierzu WALLRAFF (1985): S. 51-76.

117 WALLRAFF (1985): S. 67. Die Gespräche mit den Geistlichen, die Wallraff wiedergibt, zeigen aber auch seine etwas erzwungene Strategie, Situationen der Diskriminierung zu provozieren. Denn neben dem Wissen, das Ali Siğirlioğlu über das Christentum und die Reformation hat, was ihn für die Taufe zulassen sollte, macht Ali, alias Wallraff, in den Gesprächen auch immer auf die Dringlichkeit der Taufe aufmerksam, da er andernfalls als politischer Flüchtling in die Türkei abgeschoben würde. Diese Dringlichkeit steht dem Ansinnen der Kirchenvertreter zuwider, dass eine Taufe eine Glaubensangelegenheit zu sein habe. Doch ist dieser Einwand am Ende insofern nicht überzeugend, als die originalen Audioaufnahmen von Ganz Unten dokumentieren, wie herablassend die kirchlichen Geistlichen mit Ali Siğirlioğlu umgehen. Siehe hierzu: WALLRAFF, Günter (2006): Ganz Unten. 2 Cds: Mit einer Dokumentation der Folgen, Delta Music. 
Stigmatisierungen seitens Angehöriger der Mehrheitsgesellschaft reagieren zu können. ${ }^{118}$ Nach Elwert finden wir diesen Zugang auch bei Wallraff, Akçam und Gür: Der Ausländer erfährt den Alltag in der Bundesrepublik als inkonsistent und ist durch diese Erfahrung verunsichert. Sicherheit und Selbstbewusstsein kann er dagegen in einer vertrauten Umgebung gewinnen, die ihm einen Zugang in die Mehrheitsgesellschaft ermöglicht. Nicht ein stabiler Gruppenbezug wie bei Gordon ist hier vorrangig, sondern ein individueller Bezug des Einwanderers auf seine Herkunftskultur. Diesen Prozess bezeichnet Elwert als »Binnenintegration«. Darunter versteht er den »Zustand, in dem das Glied einer durch emische (kulturimmanente) Grenzen definierten Subkultur der Zugang zu einem Teil der gesellschaftlichen Güter [...] vermittelt ist «. ${ }^{119}$ Für Hartmut Esser hingegen ist der Einwanderer weniger ein emotionaler als vielmehr ein rationaler Akteur, dessen Integration als Assimilation gelingen wird, wenn auf den Erwerb kognitiver Kompetenzen (Sprache), strukturelle (Beruf) und soziale (Kontakte) folgen. ${ }^{120}$ Die assimilatorische Identifikation mit der Mehrheitsgesellschaft wird sich dann von selbst ergeben. ${ }^{121}$ Jedoch konstatiert er auch für die Ausländerpolitik der Bundesregierung in den 1980er einen paradoxen Zustand, der nicht einen Integrationsprozess als Assimilation, sondern umgekehrt die kulturelle und strukturelle Marginalität der Ausländer fördert. Denn einerseits wird »das Angebot zur Integration gemacht (Weizsäcker)«, andererseits aber auch »die Rückkehrfähigkeit der Ausländer« gefördert. Aber da »der einzelne Ausländer immer nur beide Forderungen gemeinsam sehen kann, wird die Unsicherheit eher noch verstärkt «. ${ }^{122}$

Für Bukow und Llaryora ist das Hauptproblem, das die für sie zuvor bestandene »Gesellschaftlichkeit« der Arbeitsmigranten sich strukturell auflöst. Indem sie durch eine Politik der Ethnisierung Ende und Anfang der 1980er zu Ausländern und Türken werden, geht es nicht mehr um die Frage, welchen wirtschaftlichen oder gesellschaftlichen Wert Migranten haben; sondern vielmehr darum, negativ gewendet - im Alltag oder in Debatten zu konstatieren, dass sie eigentlich gar nicht zur deutschen Gesellschaft gehören. In der entstehenden Diktion der

118 ELWERT, Georg (1982): »Probleme der Ausländerintegration. Gesellschaftliche Integration durch Binnenintegration?«. In: Kölner Zeitschrift für Soziologie und Sozialpsychologie 34:4, S. 717-731, hier S. 721.

119 Ebd., S. 720.

120 Vgl. BuKow/Llaryora (1988): S. 93.

121 Wie bereits in der Einleitung dieses Buchs erwähnt, hat Esser seinen theoretischen Zugang mit den Begriffen `Platzierung`, >Interaktion`, >Kulturation` und `Identifikation` in der 2000er Jahren modifiziert. Siehe hierzu: EsSER (2011). Siehe hierzu auch: Rauer/Schmidtke (2004): S. 279. 122 ESSER, Hartmut (1983): »Multikulturelle Gesellschaft als Alternative zu Isolation und Assimilation«. In: Die fremden Mitbürger. Möglichkeiten und Grenzen der Integration von Ausländern, hg. v. Hartmut Esser, Düsseldorf: Patmos, S. 25-38, S. 28, Hervorhebung im Original. 
multikulturellen Gesellschaft heißt es, dass man sich um sie kümmern müsse. Dass Migranten in den 1980ern entweder nur als Fremde oder nur als Klienten auftreten, ist für Bukow und Llaryora ein aus dieser Konstellation entstehendes Folgeproblem der Integration. ${ }^{123}$ Soziale Teilhabe und Repräsentation auf einer bürgerlichen Ebene durch ein ökonomisches, soziales oder kulturelles Kapital ist unter diesen Bedingungen nicht möglich. ${ }^{124}$ Für die Autoren wird die »Identitätspassage« zwischen Minderheit und Mehrheit nicht nur verweigert, sondern im Vollzug der Ethnisierung sogar abgesprochen. ${ }^{125}$ Denn sie sind nicht gänzlich »ohne einen politischen Ort, sondern in einer bestimmten Weise politisch restriktiv eingebunden «. ${ }^{126}$ Eindrücklich zeigt sich dies darin, wo und wie die Wirkung des Türkischen in der Bundesrepublik in den 1980er Jahren gesehen wird. Denn ähnlich wie Elwert sieht auch Micksch den eigentlichen Raum und Ort der Aktivität der Türken in der Bundesrepublik in deren eigenen vier Wänden. Und so wie die erste Ausländerbeauftragte der Stadt Berlin, Barbara John, den Deutschen vorschlägt, zu den Ausländern zu gehen, weil sie nett seien, schlägt Micksch vor, kulturelle Zentren entstehen zu lassen, »die ihnen ein Leben mit ihren kulturellen Traditionen ermöglichen«. Genau in solchen Zentren »könnte die multikulturelle Zusammenarbeit besonders gepflegt und gefördert werden «. ${ }^{127}$ Daher sollten besonders auf kommunaler Ebene im »deutschsprachigen Angebot Produktionen aus den Herkunftsländern präsentiert und interpretiert werden, die fremdartiges Verhalten verständlich machen können «. ${ }^{128} \mathrm{Zu}$ welch überzogenen und mitunter abstrusen Interpretationen solch ein Zugang führen kann, zeigt äußerst eindrücklich, woran beispielsweise der Ausländerbeauftragte von Bergkamen Mitte der 1980er Jahre die Zerrissenheit zwischen zwei Kulturen bei einem türkisch-kurdischen Mädchen zu erkennen meint. Als er eines Tages fasziniert türkisch-kurdischer Musik lauscht, fragt ihn das Mädchen »stirnrunzelnd «, ob ihm das wirklich gefalle. Wenn ihre Eltern diese Musik, dieses »Gejaule« auflegten, verschwinde sie immer in ihr Zimmer und höre lieber ihre Musik: Rock. Für den Ausländerbeauftragten verdeutlicht diese Episode nicht eine typische Differenz zwischen dem Musikgeschmack der Eltern und der Kinder, sondern einen $»$ Kulturverlust «. ${ }^{129}$

Diese zwischen zwei Subjekten beschriebene gestörte Kommunikation und Interpretation ist nicht nur das Problem der vermeintlich konkreten Theorien $\mathrm{zu}$

123 Bukow/Llaryora (1988): S. 93.

124 Ebd., S. 91.

125 BuKOW/LLARYORA (1988): S. 94.

126 Ebd., S. 93.

127 Zitiert nach: GöKTÜRK et al. (2011): S. 362.

128 Ebd., S. 363.

129 GÜR (1987): S. 7. 
Folgen der Migration, die vom subjektiven Bewusstsein über das ethnologisch Andere, dem rational choice-Ansatz bis zum Migranten als Fremden und Klienten ohne Repräsentationskraft reichen. Sie steht mit allgemeineren theoretischen Narrativen aus der Philosophie, Soziologie und Kulturwissenschaft der 1980er ebenso, wie mit Dolf Sternberger angedeutet, mit den Politikwissenschaften in Verbindung. Mit etwas anderen Referenzrahmen gehören zu ihren zentralen Themen wie Migration und Integration ebenfalls Sprache, Kommunikation, Subjekt, Repräsentation und Nation. Jürgen Habermas hält Anfang der 1980er Jahre für diese neue Dekade im Unterschied zu den 1960er und 1970ern fest, dass sich die politisch »utopischen Akzente vom Begriff der Arbeit auf den der Kommunikation« verschoben hätten. Wenn zuvor »die arbeitsgesellschaftliche Utopie« darin bestanden habe, dass die »Solidarität der Arbeitersubkultur [...] am Arbeitsplatz regeneriert werden kann«, stehe nun die Voraussetzung dieser Utopie in Zweifel, ob man sich nämlich nach dem Ende der großen Erzählungen der Moderne auf sprachlicher und kommunikativer Ebene überhaupt noch verstehe. $^{130}$

Wenn, wie ich oben auch für die Thematisierung von Migration festgehalten habe, Sprache und Kommunikation zuvor vorausgesetzt wurden oder Randbedingungen der Begegnungen darstellten, stehen beide Entitäten nun im Zentrum der Auseinandersetzung und mit ihnen die Integration. Diese Erkenntnis, mit der sich Habermas auch gegen die französische Postmoderne $\mathrm{zu}$ positionieren versucht, ${ }^{131}$ ist zugleich die Grundlage seines Hauptwerks der Theorie des kommunikativen Handelns, die ebenfalls in den 1980er Jahren verfasst und veröffentlicht wird. Im Zentrum dieser Theorie steht - wie in den erwähnten Beispielen aus dem deutsch-türkischen Zusammenhang auch - die intersubjektive Situation als Kommunikation. Allerdings lässt sich die abstrakt-theoretische Kommunikation, die Habermas in Theorie des kommunikativen Handelns entwickelt, nicht auf die Begegnung zwischen dem alteingesessenen Deutschen und dem Einwanderer anwenden. ${ }^{132}$ Sie führt vielmehr die deutsche Westintegration als Dialog mit der

130 HABERMAS, Jürgen (1985): „Die Krise des Wohlfahrtsstaates und die Erschöpfung utopischer Energien«. In: ders.: Die neue Unübersichtlichkeit, Frankfurt a. M.: Suhrkamp, S. 141-166, hier S. 160 .

131 HABERMAS, Jürgen (1985): „Das Zeitbewußstsein der Moderne und ihr Bedürfnis nach Selbstvergewisserung«. In: ders: Der philosophische Diskurs der Moderne. Zwölf Vorlesungen, Frankfurt a. M.: Suhrkamp, S. 9-33.

132 Diese wird er zehn Jahre später in seinem bekannten Kommentartext Anerkennungskämpfe im demokratischen Rechtsstaat zu den Ausführungen des kanadischen Philosophen Multikulturalismus und die Politik der Anerkennung nachliefern. Allerdings werden wir es dann, wie es die Begriffe `Anerkennung Verschiebung zu tun haben, die im nächsten Kapitel im Fokus der Analysen stehen wird. Siehe 
amerikanischen praktischen Philosophie weiter. Die unzähligen Kommunikationssituationen, die es in den ästhetischen Bearbeitungen zur türkischen Migration nach Deutschland in den 1980er Jahren gibt und die wir im Folgenden auch analytisch in Augenschein nehmen werden, sind aber auch nicht einfach als sintersubjektiv zu bezeichnen. Geprägt vom Verlust des Narrativs »Wir wollten alle Amerikaner werden« und bestimmt davon, dass nun »Ausschau nach Anatolien« gehalten wird, kreisen die Begegnungen der Akteure in Literatur, Film, Migrations- und Integrationstheorie um die Entitäten >Nation`, >Herkunft ‘ und >Repräsentation`. Und in den Vordergrund rücken dabei das Sprechen über die Herkunft. Zeitnah entstandene kulturtheoretische Konzepte wie von Benedict Anderson, Spivak Gayatri und von Stuart Hall kreisen ebenfalls um das Verhältnis genannter Entitäten zu Kommunikation, Sprechen und Artikulation.

In Benedict Andersons Ausführungen zur Erfindung des Konstrukts >Nation sind es ebenfalls Sprache und Kommunikation, die im Zentrum der vorgestellten Gemeinschaft als Nation stehen. Sie bilden über die Techniken des Lesens und Schreibens sowie die Medien Zeitung und Roman in einer gemeinsamen Schriftsprache die Grundlagen für die vorgestellte Gemeinschaft. Die dabei entstehenden Gemeinschaften sind »größer [...] als die dörflichen mit ihren Face-to-face-Kontakten«. Allerdings hat diese Expansion einer vorgestellten Zusammengehörigkeit auch seine Grenzen, denn »keine Nation setzt sich mit der Menschheit gleich «. ${ }^{133}$ So geht auch Andersons Theorie über die Nation ein politischer Wandel Ende der 1970er Jahre voraus, und wir finden die Grenzziehung und Definition von Anderson, dass die Nation nicht mit der Menschheit gleichzusetzen ist, auch in der debattenauslösenden Aussage Eibl-Eibelsfelds, dass Türken zwar auch Menschen seien, aber einer anderen Kultur angehörten. Für Anderson ist ab Ende der 1970er Jahre die marxistisch geprägte soziale Frage nicht mehr international, sondern wieder national gerahmt. Die erneute Rückkehr des Nationalen korreliert für ihn mit dem Ende der Wirkkraft eines klassischen Marxismus: »Das Problem einer Theorie des Nationalismus steht für das große Versagen des Marxismus. « ${ }^{134}$ Der erste Schritt für ihn ist daher, dass man >Nation ` begrifflich nicht als eine Ideologie wie »Liberalismus« oder »Faschismus« behandeln dürfe, »sondern wie `Verwandtschaft` oder >Religion « ${ }^{135}$ Hierfür finden wir in

hierzu: HABERMAS, Jürgen (1993): »Anerkennungskämpfe im demokratischen Rechtsstaat«. In: Multikulturalismus und die Politik der Anerkennung, hg. v. Charles Taylor, Frankfurt a. M.: Suhrkamp, S. 147-198.

133 Anderson, Benedict (2005): Die Erfindung der Nation. Zur Karriere eines folgenreichen Konzepts, Frankfurt a. M.: Campus, S. 16.

134 ANDERSON (2005): S. 13.

135 Ebd. 
den Anfangssequenzen von Şerif Görens Film PoLIZEI ein eindrückliches und plastisches Beispiel, als die beiden türkischen Einwanderer durch den türkischsprachigen Zeitungstext sich über das Statement der Türkin der zweiten Generation unterhalten und die Ehre der Gemeinschaft, zu der sie gehören, gefährdet sehen. Sie sind mit dem erwähnten Mädchen zwar überhaupt nicht verwandt, reden aber so, als ob sie es doch wären. Das sozial-geografische Faktum, dass sie und ihre Familie wie sie selbst in Kreuzberg leben, reicht offenbar dafür aus, sie als Teil ihrer eigenen türkischen Ehre zu begreifen. Andersons Definition von >Nation` lautet daher: „Sie ist eine vorgestellte politische Gemeinschaft - vorgestellt als begrenzt und souverän. « ${ }^{136}$ Auch Abdullah Yakupoǧlu bezieht sich gleich zu Beginn von Grabes Dokumentarfilm auf Zeitungsberichte, in denen beschrieben wird, wie junge türkische Mädchen auf »deutschen Bahnhöfen sich herumtreiben und kein wirkliches Zuhause hätten«. Er selbst bringt seine Töchter mit den »türkischen Mädchen aus der Zeitung« in Verbindung und achtet sehr streng darauf, dass sie eben nicht auf solche kulturelle Abwege kommen wie die anderen. Denn das »türkische Volk« erlaube das nicht. In Grabes Film ist er, wie gesagt, der einzige Türke, den wir sehen.

Es sind auch diese neuen Grenzziehungen, die die Grundlage von Spivak Gayatris äußerst bekannter These sind, dass der subalterne Akteur - im Besonderen die Frau aus der Dritten Welt - nicht sprechen kann. Ihr Ausdruck oder das des subalternen Akteurs kann immer nur ein Bemühen um Repräsentation sein, aber niemals die Repräsentation im öffentlichen Raum selbst. So hält sie in der Entstehungszeit ihrer Schrift Can the Subaltern Speak? Anfang der 1980er Jahre fest, dass politisch in den letzten Jahren ein Wandel »vom Sichtbarmachen eines Mechanismus zum Stimmhaftmachen des Individuums « stattgefunden habe. ${ }^{137}$ Dieser Wandel führt zu einer besonderen Form von Identitätspolitik, die auch im Zentrum der Überlegungen Stuart Halls steht. In seinem bekannten Text Neue Zeiten hält er ebenfalls für die 1980er fest, dass es nicht mehr möglich sei, an der ökonomischen Klasse eines Akteurs seine "politischen Verhaltensweisen und objektiven sozialen Interessen und Motivationen [...] ablesen zu können«. Die vom klassischen Marxismus unterstellte »Entsprechung zwischen dem Ökonomischen und dem Politischen « gebe es nicht mehr. ${ }^{138}$ Vielmehr sei nun die »Tatsache « bestimmend, »dass immer mehr Leute (Frauen und Männer) - mit wie wenig Geld auch immer - sich an dem Spiel beteiligen, Dinge zu benutzen, um zu signalisieren wer sie sind « - selbst dann, um Halls Satz mit Özakıns Aussage

136 Ebd., S. 15.

137 SPIVAK (2007): S. 53.

138 HALL, Stuart (2000): »Die Bedeutung der Neuen Zeiten«. In: ders.: Cultural Studies. Ein politisches Theorieprojekt. Ausgewählte Schriften, Hamburg: Argument, S. 78-97, hier S. 83. 
zu komplettieren, wenn man dieses Bemühen um Repräsentation als »lächerlich« empfindet. Am Anfang dieser Erzählungen stehen nicht mehr die materielle Existenz und ihre körperlichen Bedürfnisse, »sondern [...] ihr symbolischer Platz«, ihre »zweite Haut «. ${ }^{139}$ Die »heutigen Güter « und Sichtbarkeiten treten nun immer »doppelt auf «. ${ }^{140}$ Die politische Sprache ist nicht mehr auf der sozialen, sondern verstärkt auf der »kulturellen Seite der Gleichung zu finden «. ${ }^{141}$ In der Logik der Repräsentation ist nun an die Stelle des Zeigens und Darstellens die des Vertretens und Darstellens getreten. Die Theorien selbst sind ebenfalls Teil dieser neuen restriktiven Einbindung, dieser neuen Sichtbarkeit, die zugleich eine neue Unsichtbarkeit bedeutet. Wenn die postkolonialen Theorien nun auf dieser Logik beruhen, dann ist die Wahrscheinlichkeit, dass sie ein aktives politisches Feld politischer Integration werden generieren können, äußerst gering. Denn das wesentliche Anliegen einer gelingenden politischen Integration muss es sein, die Elemente des Kulturellen und Politischen wie Orte, Kontakte, Sprechweisen, Handlungen, Auseinandersetzungen (Kämpfe) in Form unterschiedlicher Gestaltungen in einen Zusammenhang zu bringen. Das Ziel postkolonialer Forschung ist hingegen »die Produktion eines `Außen`, eines Bereichs [...] intelligibler Wirkungen, die dann zurückkehren und verunsichern, die wir voreilig >Identitäten nennen «. ${ }^{142}$ Es ist also die Kritik von Identität, wobei der ausschließliche Fokus auf die Identität, auf das Sprechen davon, den Überschuss nicht mehr aufzufangen vermag, den die Verunsicherung auslöst. Dort, wo es dann um die Arbeit daran gehen würde, dass Kultur auch eine Frage der Umstände, Bedingungen, Materialitäten und Praktiken ist, bleibt die Frage und das Problem im Raum bei den postkolonialen Theoretikern bestehen, weil sie sich ausschließlich auf Diskurse und Artikulationen konzentrieren. Deren Grundlage ist aber wiederum, daß sich ein »Berg« zwischen Haus und Straße gestellt hat.

Die öffentlichen Debatten, Politiken, Theorien und ästhetischen Bearbeitungen der Migration in der Bundesrepublik der 1980er Jahre geben die hier kurz skizzierte theoretische und politische Transformation auf unterschiedlichen Reflexions- und Thematisierungsebenen eindrücklich wieder. Meine Analysen werden aber auch zeigen, dass sie darüber hinausgehend auf eine besondere Form der Identitätspolitik und Subjektivierung aufmerksam machen, die auch mit der heutigen Rückkehr nationaler Kategorien zusammengeführt werden kann. Im Zentrum der Analyse stehen in diesem Kapitel der Film 40 QM DEUTSCHLAND

139 Ebd., S. 93. Siehe ebenfalls: HÜBNER (1985): S. 174-185.

140 HALL (2000): S. 94.

141 Ebd., S. 83.

142 HALL, Stuart (2004): „Wer braucht Identität«. In: ders.: Ideologie, Identität und Repräsentation, Hamburg: Argument, S. 167-187, S. 185. 
von Tevfik Başer, die Romane Die Leidenschaft der Anderen (1982) und Die Blaue Maske (1989) von Aysel Özakın, der Spielfilm YASEMIN (1988) von Hark Bohm, die erste Familienserie UnSERE NACHBARN, Die BALTAS (1983) und schließlich die Dokumentarfilme DIE KÜMMELTÜRKIN GEHT (1985) von Jeanine Meerapfel, GANZ UNTEN (1985) als Buch und Film von Günter Wallraff und von Jörg Gförer, ABDULLAH YAKIPOĞLU. WARUM HABE ICH MEINE TOCHTER GETÖTET? von Hans-Dieter Grabe und die soziologische Dokumentation von Paul Geiersbachs Bruder, muß zusammen Zwiebel und Wasser essen! Eine türkische Familie in Deutschland von 1982. Wir werden in den Analysen nicht nur auf die Integrationstheorien und Debatten, sondern auch zentral auf die theoretischen Aspekte der Arbeiten von Stuart Hall, Gayatri Spivak, Jürgen Habermas und Benedict Anderson eingehen. Dabei werden die Reflexionen zur Postkolonialität und zu den aufkommenden Cultural Studies ${ }^{143}$ Anfang der 1980er Jahre mit den sehr wirkmächtigen Arbeiten von wiederum Spivak und Stuart Hall ebenfalls eine sehr wichtige Rolle spielen. Denn auch sie verhandeln mit Sprechen, Repräsentation und Artikulation die Kommunikation zwischen einem Akteur aus der Mehrheit und einem aus der Minderheit. Bevölkerungs- und gesellschaftspolitisch neue Rahmenbedingungen verändern das Narrativ der Integration und Migration in Deutschland Ende der 1970er und Anfang der 1980er Jahre grundlegend, und sie dominieren es bis Anfang der 1990er Jahre auch.

Das Narrativ »Wie lebt es sich als Türke in Deutschland? « hat in der Geschichte der Migration und Integration in Deutschland ein besonderes und spezifisches Bemühen um Repräsentation in Literatur, Film, Debatte und Theorie erzwungen und ausgelöst. Es ist ein Zwang und ein Bemühen um Repräsentation, das im innerdeutschen Zusammenhang mit der Verwendung der Begriffe ^Volkı und >Nation $>$ ebenfalls seinen Platz hat. Jenseits dieser abstrakten Kategorien - und das ist mein ästhetisch-politischer Zugang - geht es vor allem deshalb um ein Bemühen um Repräsentation, weil zum einen die Begegnungsstruktur zwischen Alteingesessenen und Einwanderern sich grundlegend gewandelt hat und zum anderen weil der einfache Weg von der Wohnung auf die Straße aus mehreren Gründen versperrt ist. Diese Konstellation verlangt eine besondere erzählerische Bearbeitung des Themas >Migration` in den 1980er Jahren, um Gehör zu finden und überhaupt erkannt zu werden. Bis heute wird in der Forschung besonders den künstlerischen Produktionen der 1980er Jahre vorgeworfen, dass ihnen die ästhetische Bearbeitung nicht gelungen sei. Denn sie würden entweder einer Pflicht nachkommen, den Vorurteilen und Erwartungen der Mehrheitsgesell-

143 Siehe hierzu: HALL, Stuart (1990): »The Emergence of Cultural Studies and the Crisis of Humanities«. In: Humanities as Social Technology, October Vol. 53 (Summer 1990), S. 11-23. 
schaften zu genügen oder schlicht an der »burden of representation« scheitern. Auch wenn sie in hohem Maße ästhetisch-konstruktiv seien, blieben sie Filme und Texte eines sozialen Realismus, der die Akteurinnen und Akteure homogenisiere und sie zu Opfern degradiere. ${ }^{144}$ Dieser Befund kennt bislang auch keinen Unterschied zu den Produktionen der 1960er und 1970er Jahre.

Wenn die soziale Frage, allerdings nicht ihre Homogenisierung, tatsächlich im Zentrum der Filme und der Literatur der 1960er und 1970er Jahre steht, dann greift der »Vorwurf» des sozialen Realismus keineswegs bei den Produktionen der 1980er Jahre. Denn es gibt keine Phase in der vorliegenden Kulturgeschichte, in der die sozialen Handlungen, Interaktionen, Kontakte und Mobilitäten so unausgeführt im Raum stehen bleiben wie in den Produktionen der 1980er Jahre. Dies deuten allein schon die Sequenzen an, die dieses Kapitel eingeleitet haben. Das Sprechen wird in ihnen nicht weiter in einem Dialog oder in einer sozialen Interaktion geführt oder übersetzt. Das Weitersprechen ist in den 1980er Jahren vielmehr nach innen gewendet, weil abstrakte Kategorien wie stürkisch >deutsch`das Verhältnis, die Begegnungen rahmen und bestimmen. Daher liegt der besondere kulturwissenschaftliche Reiz und Wert dieser Reflexionen zum »verlorenen Jahrzehnt der Integration ${ }^{145}$ in der Bundesrepublik zum einen in historischer Hinsicht darin, welche Verletzungen und Diskriminierungen sich in die Geschichte der Migration und Integration in der Bundesrepublik eingeschrieben haben - denn weder die erste noch die zweite Generation hat dieses Jahrzehnt vergessen. ${ }^{146}$ Kulturtheoretisch von Interesse ist, was passiert, wenn an die Stelle des Zeigens und Sehens in der Praxis des Re-präsentierens verstärkt das Vertreten tritt. Şinasi Dikmen hat etwa nie den Eindruck verloren, dass die Deutschen durch ihn hindurchschauen würden, weil er der andere Türke ist. ${ }^{147}$ Wenn sie ihn sehen, sehen sie auch die anderen. Günter Wallraffs Erfahrungen als Ali Siǧirlioğlu, den er eineinhalb Jahre lang mimte, haben zu einem ähnlichen Ergebnis geführt, das er allerdings von der gegenüberliegenden Seite aus beschreibt. In Ganz Unten lautet

144 Siehe hierzu: MALIK, Sarita (1996): »Beyond `The Cinema of Duty`? Pleasures of Hybridity: Black British Film of the 1980s and 1990s«. In: Dissolving Views. Key Writings on British Cinema, hg. v. Andrew Higson, London: Cassell, S. 202-215. GöKTÜRK (2000); AdELSON (2004); NeUBAUER, Jochen (2011): Türkische Deutsche, Kanakster und Deutschländer. Identität und Fremdwahrnehmung in Film und Literatur, Würzburg: Königshausen \& Neumann.

145 BADE (2017): S. $27 \mathrm{f}$.

146 Tatsächlich weisen viele Autorinnen und Autoren der zweiten aber vor allem der dritten Generation, die sich heute als People of Color bezeichnen, in Eure Heimat ist unser Albtraum von 2019 auf Diskriminierungserfahrungen ihrer Eltern aus dieser Zeit oder auf Erfahrungen, die sie zeitnah im Kindesalter in deutschen Schulen gemacht haben. Siehe hierzu: AYDEMIR/YAGHooBIFARAH (2019).

147 Dikmen (1986): S. 75. 
der Name des Erzählers »Ich (Ali)«, den Wallraff durchgehend verwendet. Dieses »holprige >Ich (Ali)« « müsse man so lesen, als sei »Ich« der Vorname und »(Ali)« in Klammern der Nachname. »Ich war immer beides. Und das meine ich. Wenn man sich s sagt, muß das immer in Verbindung stehen $\mathrm{zu}$ anderen Schicksalen, Existenzen, Identitäten ... >Ich 〈 ist das Durchgehen von vielen anderen. ${ }^{148}$ Es handelt sich dabei um eine Passage der Identität, um eine epistemische Gewalt im öffentlichen Raum, der Aysel Özakın begegnet und sie sich zugleich vorstellt, als sie auf der Zugfahrt gefragt wird, ob sie Französin sei. Es erscheint ihr lächerlich, darauf zu antworten, aber sie muss dagegen »sprechen«, wobei es ihr am liebsten wäre, sie könnte dagegen »handeln «: ${ }^{149}$ sozusagen mit einem Akt der Antidiskriminierung gegen die Diskriminierung vorgehen. Sie entgegnet der älteren deutschen Frau aber nur, dass sie Türkin sei. Ihre Antwort verweist auf die schon mehrmals genannte »zweite Haut«, die entstanden ist, weil der bedürftige und begehrende Körper der 1960er und 1970er Jahre sich zurückgezogen hat. Sie verweist aber auch auf eine Gesellschaft, die nicht genau weiß, wann wir es mit Diskriminierung zu tun haben und wie genau man dagegen vorgehen kann; eine Gesellschaft, in der das Verhältnis von Gesetz und Werten sich noch in einem Aushandlungs- und Verhandlungsprozess befindet. Nicht zufällig fällt der Begriff des Verfassungspatriotismus in den 1980er Jahren auf fruchtbaren Boden. Bevor wir uns nun Özakıns Texten eingehender zuwenden und danach fragen, woraus neben dem Sprechen das antidiskriminierende Handeln bestehen könnte, werden wir in der ersten Materialanalyse, derjenigen von Tevfik Başers Film 40 QM DEuTschland, sehen, dass der »Berg « zwischen Wohnung und Straße oder die »zweite Haut« in dieser Dekade nicht nur in öffentlichen Räumen aufkommt und Thema ist, sondern an dem Ort, von dem aus der Einwanderer versucht, sich auf die Straße zu begeben.

148 WALLRAFF (1985): S. 428. Wallraff hebt neben der repräsentativen Logik auch hervor, dass es für ihn als Türke ein befreiendes Moment gewesen sei, innerhalb der Rolle zu leben, ein Spiel, das er viel intensiver und authentischer erlebt habe, als einfach nur Deutscher zu sein: »Es ist für mich immer wieder eine Suche nach Identität, eine Möglichkeit, mir meiner selbst bewußt zu werden, und es ist auch meine Neugierde: also neben allem Engagement auch ein egoistisches Prinzip, das ich damit verbinde.« Ebd.

149 ÖZAKIN (1983): S. 29. 


\title{
3.2 Eine epistemische Gewalt steht im Raum
}

\begin{abstract}
Nur zu, geh auf die Straße, geh, geh, nur Scheiße gibt es dort. Zeig Deinen Hintern wie die Huren unter den Deutschen. Du kennst diese Deutschen nicht. Sie sind wie Krankheitskeime, dieses Volk. Sie wissen nicht, was Ehe bedeutet, nicht was Liebe und Ehre bedeuten. Sie zeigen ihre nackten Hintern und ihre bloßen Häupter. Möchtest Du sie etwa nachahmen, ihnen nacheifern, oder was? Ich habe es kürzlich in der Fabrik mitbekommen: Neue Frauen sind aufgetaucht und gekommen, um Frauen von ihren Männern und Kindern zu trennen und sie in Wohn- und in Vereinsheimen unterzubringen. Und sie sind sogar so weit gegangen, die Frauen zu fragen, wie ihre Männer mit ihnen schlafen und ob wir sie schlagen würden. Was geht euch das an? Habt ihr etwa über unseren Anstand zu wachen? Die Regierung ist auch auf ihrer Seite, auch der Staat ist auf ihrer Seite. Wenn es nur die Ehefrauen wären: Aber sie trennen auch die Kinder von ihren Müttern und Vätern. Weißt Du, was der Tochter von Mehmets Familie passiert ist? Sie haben sie von ihrem Vater getrennt. Und warum? Weil er sie geschlagen habe. Natürlich kann er sie schlagen. Was geht das euch an? Nein Weib, nein. Ich bin noch nicht wahnsinnig. Ich lasse mir von den anderen nicht nachsagen, dass er auf die eine Frau, die er hatte, nicht aufpassen und sie an sich binden konnte. Bleib da, wo du bist. Es gibt kein Hinausgehen. ${ }^{150}$
\end{abstract}

Anlass für diese Wutrede des türkischen und in dieser Szene alkoholisierten Gastarbeiters Dursun in der Silvesternacht 1984 in der Mitte des Films 40 QM Deutschland ist die Aussage seiner Ehefrau Turna, dass sie in der Hamburger Zweizimmerhinterhofwohnung, die sie beide bewohnen, wahnsinnig werde und sogar vergessen habe, wie sie heißt. Zuvor kam er mit einer Clownsnase im Gesicht und Lametta im Haar nach Hause, wo er seine Frau verängstigt vor dem Feuerwerk vorfand. Sie glaubt, ein Feuergefecht habe stattgefunden, Bomben seien gefallen. Er schmunzelt und entgegnet: „Was für Bomben? Es ist die Feier zum Beginn des neuen Jahres«. Woher solle sie das wissen, meint sie, sie verliere hier zwischen den Wänden ihren Verstand. Nicht an der fremdartigen Feierlichkeit in einem fremden Land liegt es, dass Turna ihren Verstand verliert, sondern am Eingeschlossen- und Alleinsein in der kleinen Wohnung in Hamburg-Altona. Dursun und Turna haben in der Türkei geheiratet. Seit sie in Deutschland leben, verschließt Dursun jeden Morgen die Wohnungstür, wenn er in die Fabrik zur Arbeit geht. Er macht dies - so suggeriert es zumindest sein Monolog -, aus Angst davor, dass Deutsche ihm seine Frau wegnehmen und dass seine Landsmänner deshalb hinter seinem Rücken schlecht über ihn reden könnten. ${ }^{151}$

$150 \mathrm{Im}$ Film wird ausschließlich türkisch gesprochen. Siehe zur übersetzten Passage: BASER, Tevfik (1986): 40 qm Deutschland, München: Filmverlag der Autoren GmbH \& Co. Vertriebs KG. $151 \mathrm{Im}$ Dokumentarfilm ABdullah YAKUPoĞLU: WARUM HABE ICH MEINE TOCHTER GETÖTET? von Hans-Dieter Grabe ist die üble Nachrede der eigenen »Landsmänner « ebenfalls ausschlaggebend für die Erklärung, warum Abdullah Yakupoğlu seine Tochter tötet. Siehe: GrABE, Hans-Die- 
Auch wenn diese Erklärung womöglich nachvollziehbar macht, warum Dursun seine Frau in der Wohnung einschließt, ist der Film bis dahin keineswegs von Monologen, Dialogen oder explizit von Erklärungen der Situation der Gastarbeiter und ihrer Frauen in Deutschland geprägt. Im Gegensatz zur angesprochenen, fast explosiv wirkenden Silvester-Szene ist 40 QM DEUTSCHLAND insgesamt ein stiller Film, in dem wenig gesprochen und wenig erklärt wird. Die filmische Erzählung steuert strukturell auch zwingend nicht auf eine Erklärung hin. Dennoch gehört die Szene zu denen, die in Forschung und Presse zitiert wird, wenn es darum geht, diesen Film im Positiven wie im Negativen zu charakterisieren. Positiv heißt es in den zeitnahen Besprechungen zum Film, er zeige »die Innenwelt einer fremden Kultur« oder er werbe auf subtile Weise um Verständnis zwischen den Kulturen. ${ }^{152}$ Negativ konstatiert Heike Kühn Mitte der 1990er, dass Dursun sich »inmitten des sittenlosen Deutschland auf die Gesetze seiner Väter, auf Maximen [berufe], deren Einhaltung ihm leicht falle, weil sie für seine Überlegenheit bürgen ${ }^{153}$ Mitte der 2000er hält der Filmkritiker Claus Löser schließlich fest, dass es auch in den zwanzig Jahren von 40 QM DEUTSCHLAND bis zu Fatih Akıns GEgEN DIE WAND keinen Film gegeben habe, dem so eindringlich eine Innensicht der türkischen Community gelungen sei. ${ }^{154}>$ Community< ist in den 1980er und 1990er Jahren noch kein geläufiger Begriff, und im Unterschied zur Rezeption der Filme und Texte von Helma Sanders-Brahms und Aras Ören ist die Interpretation in den 1980er und 1990er Jahren eindeutig: Es geht um die andere Kultur, die als eine andere Welt verstanden wird. Zu fremdartig wirkt auch für die eigene Gesellschaft das Verhalten, seine eigene Frau einzusperren und ihr den Zugang in den öffentlichen Raum zu verwehren. Die Angst jedoch, etwas zu verlieren, das einem ver-

ter (1986): Abdullah Yakupoğlu. Warum habe ich meine Tochter getötet, Dokumentation, ZDF, Deutschland.

152 TIP BERLIN 16/86, S. 37.

153 KüHN, Heike (1995): »Mein Türke ist Gemüsehändler. Zur Einverleibung des Fremden in deutschsprachigen Filmen«. In: ১Getürkte Bilder`: Zur Inszenierung von Fremden im Film, hg. v. Ernst Karpf, Doron Kiesel, Karsten Visarius, Marburg: Schüren, S. 43-62, S. 54.

154 Vgl. LösER, Claus (2004): »Berlin am Bosporus. Zum Erfolg Fatih Akıns und anderer türkischstämmiger Regisseure in der deutschen Filmlandschaft«. In: Apropos: Film. Das Jahrbuch der DEFA-Stiftung, Berlin, S. 129-147, hier S. 142. In jedem Fall ist er neben der vermeintlich gelungenen Innensicht auch bis GEGEN DIE WAND der am meisten beachtete Film zur türkischen Migration nach Deutschland und ihrer Folgen. Er wird im Jahr seiner Erstaufführung in Cannes gezeigt, erhält dort den Unesco-Preis und in Locarno den Silbernen Leoparden. Zudem folgten Einladungen auf Filmfestivals in London und Los Angeles. 1987 erhält 40 QM DEUTSCHLAND den Deutschen Filmpreis. Siehe hierzu: http://www.filmportal.de/film/40-qm-deutschland_4ecff652d8c342299b576c8d59e6f592 (16.11.2017). 
traut ist und die eigene Identität mitbestimmt, ist wiederum verständlich. Insgesamt überwiegt in den Filmkritiken der Tenor, Başers erster abendfüllender Film vermittle auf eine beeindruckende Art Kultur. Im Unterschied zur Filmkritik sieht die Forschung, die erst eine Dekade später einsetzt, den Film problematisch.

Nach Rob Burns haben wir es bei 40 QM DEuTschland mit einem »cinema of the affected « zu tun, einem Betroffenheitskino, in dem der Fokus einfach auf der Andersheit der Türken und in ihrer Opferrolle liegt. ${ }^{155}$ Zudem misslinge es dem Film, wie es des Regisseurs Intention gewesen sei, neben der Frau auch den Mann als Opfer darzustellen. Die Kamera nehme hierfür nur die Perspektive der Frau ein, was problematisch sei. ${ }^{156}$ Diese Perspektive ist für Kühn eine der kulturellen Unterwerfung. Denn Turnas »Erziehung lässt keine Beschwerde zu. Als sie einmal aus ihrem Schweigen fällt, ihre Rundgänge vorbei an verschiedenartig gemusterten Tapeten und abgestoßenen Türen unterbricht, hält man vergeblich den Atem an «, denn für den Protest ist sie zu schwach. ${ }^{157}$ Deniz Göktürk versteht 40 QM Deutschland als einen Film, der das Opfernarrativ besonders für die deutschen Zuschauer und Medien aufbereitet, weil nur Filme, die dieses auch bedienen, in den 1980ern eine Filmförderung erhalten. Der Film nehme anstelle einer transnationalen eine subnationale Position ein, die keine Kritik an bestehenden gesellschaftlichen Strukturen zulasse. ${ }^{158}$

Die Grundlagen dieses Films und ihre filmische Realisierung sind jedoch weitaus komplexer als es die positiven oder negativen Einschätzungen von Presse und Forschung vermuten lassen. Denn die Diktion des Films bestimmen nicht Erklärungen über die Ungeheuerlichkeit, dass ein Mann seine Frau einsperrt oder warum sie aus diesen Verhältnissen nicht einfach flieht, vielmehr besondere Bildkonstellationen (mise-en-scènes), wechselnde Lichtverhältnisse und Geräuschkulissen aus dem Off, Farben, Kameraeinstellungen und Kamerafahrten in einer Wohnung von 40 qm. Auch der Inhalt von Dursuns Wutrede im Film wird nicht gespiegelt, hat keine Referenz. Denn bis zu dieser Szene werden weder die Lebensweisen der Deutschen gezeigt, noch die Fabrik, noch Freunde von Dursun, die er erwähnt, noch der Staat und schließlich auch nicht die anderen, die schlecht über ihn reden könnten, wenn es ihm nicht gelingt, auf seine Frau aufzupassen und sie an sich zu binden. Der Realitätsgehalt von Dursuns Aussage kann im Film selbst nicht geprüft werden. Der Zuschauer ist, wie Turna, nie draußen. Die Trennung der Deutschen von den Türken, wie Dursun sie vornimmt, und die Rede über die Kultur scheinen in der Logik des Films aus dem Nichts zu kommen. Oder

155 BuRNS (2006): S. 133.

156 Ebd., S. 135.

157 KüHN (1995): S. 54.

158 GÖKTÜRK (2000): S. 67. 
ist die Trennung an eine andere Bewegung im Film gekoppelt, die über das Erklären, Zeigen und letztlich über das Darstellen fremdartiger kultureller Phänomene hinausgeht? Wir werden sehen, dass in Başers Film und in anderen ästhetischen Reflexionen der 1980er Jahre zur Migration nach Deutschland und ihren Folgen die Akteurinnen und Akteure in einer »diskursiven Zwickmühle « ${ }^{159}$ stecken, wie bereits der Auszug aus Özakıns Die Leidenschaft der Anderen zu Beginn dieses Kapitels gezeigt hat. Ihre Sprecherpositionen sind weniger als subnational denn als subaltern im Spivak'schen Sinne zu begreifen. Statt um die Assimilierung des Anderen geht es darum, eine »innere Stimme « freizulegen, deren Sprecherin und Sprecher ohne jeglichen Bewegungsradius sie in den öffentlichen Raum einbringen muss. ${ }^{160}$

Die erwähnte Filmsprache suggeriert dies zumindest, und wenn wir uns in die Anfänge der Entwicklung dieses Films begeben, stoßen wir dort auf eine Unstimmigkeit, die 40 QM DEUTSCHLAND eigentlich strukturiert: auf eine Kommunikation disparater Ordnungen, die offensichtlich nicht zusammengehören. Dieser Umstand hat sich folgendermaßen ergeben: Am Anfang des Filmprojekts 40 QM DEUTSCHLAND stehen zwei szenische Ideen, die Tevfik Başer in der Geschichte, die im Film erzählt wird, zusammenführen will. Sie verbinden kulturelle Irritation und Fremdheit mit alltäglicher Normalität. Seine erste szenische Idee ist, eine Person in der Türkei einschlafen zu lassen, die dann in der Bundesrepublik aufwacht. Warum die Fahrt nach Deutschland, die Grenzkontrollen wie in Yildız' Roman von 1966 oder die Gesundheitskontrollen in der Verbindungsstelle in Istanbul in Sanders-Brahms' Film SHIRINs HochzEIT von 1976 für Başer unwichtig sind, liegt vor allem daran, dass er herausfinden und zeigen möchte, »wie jemand reagiert, der so rasch von einer Kultur in die andere verpflanzt wird. ${ }^{161}$ Das war natürlich eine Utopie. Das ging nicht «. ${ }^{162}$ Konkretisieren kann er diese Utopie mit seiner zweiten Idee, seinem Anliegen für Integration, wie er es nennt, auf das der ganze Film am Ende zusteuere: »Ich wollte eine Frau aus der Türkei nach Deutschland, nach Hamburg bringen und ganz alleine auf die Straße lassen «. ${ }^{163}$ Das Zusammenführen, die Verbindung und Darstellung dieser beiden Ideen, auch wenn sie sehr unterschiedliche Codes zwischen Repräsentation, Kul-

159 STEYeRL, Hito (2007): »Die Gegenwart der Subalternen«. In: Gayatri Spivak: Can the Subaltern Speak? Postkolonialität und subalterne Artikulation, Wien, Berlin: Turia+Kant, S. 5-16, S. 12. 160 Siehe hierzu: SPIVAK (2007): S. 106 u. S. 121.

161 Presseheft zum Film 40 QM Deutschland, Filmverlag der Autoren 1985, S. 5. Siehe hierzu ebenfalls den zweiten Band von Aras Örens Poem-Trilogie von 1974. ÖREN, Aras (1974): S. 12.

162 Presseheft zum Film 40 QM Deutschland, Filmverlag der Autoren 1985, S. 5.

163 PÜTZ, Anke/Scholten, Frank (1988): 40 qm Deutschland. Begleitheft zum Film. Duisburg: Atlas, S. 18. 
turalisierung und Praxis bedienen, bestimmt Başers Film. ${ }^{164}$ Wenn die erste Vorstellung die kulturelle Ohnmacht der Protagonistin veranschaulicht, drückt die zweite das Vermögen und den Willen der Frau aus, in Deutschland ankommen zu können und zu wollen. Dass diese beiden Ebenen als Kontroverse in Kommunikation treten, ist in 40 QM DEUTSCHLAND einer besonderen Filmsprache geschuldet, deren Analyse uns zeigen wird, dass die bisherige Rezeption dieses Films nicht weit genug ging. Zuvor möchte ich kurz die Handlung des Films zusammenfassen.

In 40 QM DEUTSCHLAND wird die Geschichte eines türkischen Paares erzählt, das in der Bundesrepublik lebt. Der 40-jährige Gastarbeiter Dursun, gespielt von Yaman Okay, ehelicht nach einem mehrjährigen Arbeitsaufenthalt in Deutschland in der Türkei die Anfang 20-jährige Turna, gespielt von Özay Fecht, die mit ihm nach Hamburg in eine verwahrloste, dunkle und enge Hinterhofwohnung zieht. Trotz der kleinen und baufälligen Wohnung ist Turna anfangs voller Vorfreude, Deutschland nun kennenzulernen. Doch dann sperrt Dursun sie täglich ein, wenn er zur Arbeit geht. Dabei wird Dursun, trotz der oben zitierten Kritik von Burns, insgesamt weder grausam noch brutal dargestellt. Er ist konservativ und von der liberalen Lebensweise der Deutschen abgestoßen und verunsichert. Als Turna bemerkt, dass er sie einschließt, beginnt ein Prozess des stillen Widerstands, der ihre wütende Ohnmacht in langen, stummen Einstellungen, sehr kurzen Dialogen und einem längeren Monolog, den sie allein vor dem Spiegel hält, deutlich macht. Sie bittet Dursun, mit ihr auszugehen. Er verspricht ihr, am Sonntag mit ihr auf den Jahrmarkt zu gehen. Als sich Dursun am Sonntag an den Frühstückstisch setzt, wartet Turna mit "golddurchwirkten Seidenstoffen « und "paillettenbesetzten Schärpen « ${ }^{165}$ äußerst traditionell gekleidet und sehr stark geschminkt darauf, dass sie zusammen ausgehen und die Wohnung verlassen. Diese Doppelung, hinausgehen zu wollen und dies als Türkin tun zu wollen, erfolgt in Jeanine Meerapfels Film in umgekehrter Form ebenfalls. Neben den Anfangs- und Endsequenzen der Dokumentation, den Talking-Head-Aufnahmen in geschlossenen Räumen unternimmt Melek Tez, die sich nicht traditionell kleidet, mitten in der Dokumentation den Versuch, als »echte Türkin« auf die Straße zu gehen, um zu erfahren, wie es sich »anfühlt«, eine »richtige Türkin« zu sein. Dursun ist jedenfalls von Turnas Kleidung und Aufmachung irritiert und kommt ins Grübeln. Er sagt ihr, dass er kurz zum Bahnhof gehen wolle, um eine

164 Der Mangel und der Ausschluss an und von Mobilität für Akteurinnen und Akteure aus der "Dritten Welt«, die Başers Vorstellungen und seinen Film kennzeichnen, stehen ebenfalls im Zentrum von Gayatri Spivaks Reflexionen darüber, warum der subalterne Akteur nicht sprechen kann. Siehe: SPIVAK (2007): S. 129.

165 KÜHN (1995): S. 53. 
türkische Zeitung zu holen und gleich wieder zurück sein werde. Er wird jedoch erst am Abend mit der Ausrede wiederkehren, dass ihn die Freunde im Kaffeehaus beim Kartenspiel nicht hätten gehen lassen und dass sie ja noch an einem anderen Tag nach draußen gehen könnten. ${ }^{166}$

Wir sehen in der Folge einige Sequenzen, in denen Turna sich orientierungslos in der Wohnung bewegt oder die Kamera sie statisch durch Tiefenaufnahmen filmt, die ihren kleinen Bewegungsradius dokumentieren. Sie wird nach diesen Sequenzen irgendwann in Ohnmacht fallen. Daraufhin konsultiert Dursun einen Hoca, der ihr helfen soll. Dieser löst im Beisein Turnas in Tinte verfasste Basmala ${ }^{167}$ in Wasser auf und spritzt dieses Wasser um sie herum. Die Basmala schreibt er anschließend auch über ihren Bauchnabel. Ob Dursun den Hoca in die Wohnung gebracht hat, um sie mit seiner Hilfe vor einer erneuten Ohnmacht $\mathrm{zu}$ bewahren oder um ihre Fruchtbarkeit anzuregen, weil sie noch kein Kind geboren hat, ist nicht klar. Allein aus der Logik der Abfolge der Geschehnisse im Film, ist Dursuns Handlung aus der Sorge um seine Frau heraus zu interpretieren, doch deutet das Einschreiben der Basmala über dem Bauchnabel Turnas auch auf ein Fruchtbarkeitsritual hin.

166 Das türkische Kaffeehaus steht in den 1980er Jahren für eine besondere topografische Verschiebung. Es ist auch die einzige Lokalität in 40 QM DEUTSCHLAND, die neben dem Bahnhof Erwähnung findet. Metin Gür macht ebenfalls auf diesen wichtigen Wandel aufmerksam, den Şerif Gören in der zweiten Hälfte seines Films ACı Vatan ALMANYA schon andeutet. Ein Interview mit einem türkischen Kaffeehausbesitzer gibt Gür in seiner Dokumentation aus dem Jahr 1987 wie folgt wieder: „Ein Cafébesitzer auf die Frage, warum es nach seiner Meinung immer mehr türkische Kaffeehäuser gibt: >Diese Gewohnheit, ins Kaffeehaus zu gehen, ist drei bis vier Jahre alt. Hauptsächlich die Deutschen haben uns dazu gedrängt. Als sie uns nicht in ihre Lokale ließen oder uns dort schlecht behandelten, haben wir uns dazu entschlossen, unsere eigenen Gaststätten zu eröffnen. Sogar in einer Wirtschaft, in der ich jahrelang Stammgast war, wendete sich die Stimmung immer mehr gegen mich. Mit der aufkommenden Ausländerfeindlichkeit haben wir uns zurückgezogen.« GüR (1987): S. 17. In Görens erstem Film zur türkischen Migration nach Deutschland aus einer türkei-türkischen Perspektive von 1979 stehen die deutsche Gaststätte, in der Mahmut seine deutsche Liebschaft kennenlernt, und das türkische Café, in dem nur Männer verkehren, nebeneinander, da beide im Film gleich häufig frequentiert werden. Siehe hierzu: GöREN (1979). Siehe allgemein zur Entstehung und Verbreitung türkischer Kaffeehäuser in Deutschland: CeYlan, Rauf (2006): »Das Café-Milieu. Zwischen Tradition und Wandel«. In: ders: Ethnische Kolonien. Entstehung und Wandel am Beispiel türkischer Moscheen und Cafés, Wiesbaden: Verlag für Sozialwissenschaften, S. 181-244.

167 Die Basmala ist die islamische Anrufungsformel, die bis auf zwei Ausnahmen alle Suren im Koran einleitet. Zugleich spielt sie im Alltag und im Gottesdienst eine zentrale Rolle. Gläubige Muslime beginnen einen Großteil ihrer alltäglichen Handlungen wie Essen, Auto fahren etc. mit der Basmala. Im Wortlaut übersetzt bedeutet sie: »Im Namen Gottes, des Allerbarmers und Barmherzigen«. Siehe hierzu auch: Burns (2007): S. 131; Kühn (1995): S. 54. 
Religion taucht hier als ein traditionelles und vormodernes Phänomen auf. ${ }^{168}$ Turna wird tatsächlich schwanger, und für kurze Zeit hält ein wenig Hoffnung Einzug in diesen Film. Als Dursun davon erfährt, wird er sie das erste Mal wie eine Braut auf den Arm nehmen, kurz darauf die Fenster zum Innenhof öffnen und auf Türkisch und auf Deutsch hinausrufen, dass er Vater werde. Doch selbst die Schwangerschaft tut Turnas Psyche nicht gut, weil Dursun unbedingt einen Sohn haben will. Turna schneidet die Haare einer Mädchenpuppe, die sie aus ihrem Dorf mitgenommen hat, so zurecht, dass sie wie ein Junge aussieht. Diese Szene leitet das letzte Drittel des Films ein. Im ersten Drittel des Films schnitt Turna sich selbst die Zöpfe ab, nachdem sie bemerkt hatte, dass sie eingeschlossen ist und dagegen nichts auszurichten vermag. Wenig später erliegt Dursun unter der Dusche einem Herzinfarkt, den ein epileptischer Anfall ausgelöst hat. In der Dramaturgie des Films erzählt Başer mit Rückblenden von Dursuns Epilepsie, die er mit der sich entwickelnden psychischen Isolation Turnas zusammenschneidet. Dursun fällt am Ende des Films im Sterben auf die Wohnungstür und hält diese dadurch als Toter weiterhin versperrt. Beim Heraustorkeln aus der Dusche zerschlägt er mit seinem Rücken den Spiegel, der in der filmischen Darstellung der Isolation Turnas eine große Rolle spielt. Wir sehen Turna geschockt vom plötzlichen Tod ihres Mannes, nach einer Weile seine Leiche von der Tür wegschieben, den Nachbarn im Treppenhaus auf Türkisch mitteilen, dass ihr Mann verstorben sei, den Hausflur entlang zur Haustür gehen und kurz vor dem Abspann des Films das Haus verlassen.

Auch wenn diese Schlusssequenz des Filmes aus der inhaltlichen Diegese des Films wie eine Befreiung oder gar ein Happy-End wirken mag, war es nicht Başers primäres Anliegen, eine einfache Emanzipationsgeschichte zu erzählen. Denn seiner Ansicht nach drehen sich die Debatten um die Türken in Deutschland in den 1980ern nicht darum, »das Kopftuch oder den Schleier« abzulegen

168 Tatsächlich wird das Thema Religion, respektive Islam, in der Forschung zur Migration nach Deutschland äußerst randständig behandelt. In einer Studie von 1990 zeigt die Sozialwissenschaftlerin Ursula Boos-Nünning auf, dass von 1961, mit dem Beginn der türkischen Migration nach Deutschland, bis 1984 nur insgesamt 15 Bücher zu islamischen Themen im Kontext der Migration veröffentlicht wurden. Siehe hierzu: Boos-NüNNING, Ursula (1990): Die türkische Migration in deutschsprachigen Büchern 1961-1984. Eine annotierte Bibliographie, Wiesbaden: Opladen. Man spricht in der Forschung für die genannte Zeit auch von einer »vorislamischen Phase«, was die türkische Migration und Integration in Deutschland betrifft, die von den 1960er Jahren bis Ende der 1980er reicht. Siehe hierzu: TEzCAN, Levent (2011): „Spielarten der Kulturalisierung«. In: Kulturalisierung. Zeitschrift für Kulturphilosophie 2, S. 357-376, hier S. 360. Wenn Religion doch in der Forschung auftaucht, dann wird sie als ein Teil der Tradition und als Gegenstück zu Säkularisierung und Moderne begriffen. Sie ist sozusagen ein eingebetteter Teil rückschrittlicher Gesellschaften und dörflicher Lebensstrukturen. 
oder die deutsche Sprache zu lernen. »Das sind äußere Zeichen der Assimilation. Die Unterschiede gehen viel tiefer, sind im Menschen drin, als Erbe der eigenen Kultur und Tradition. « ${ }^{169}$ Stattdessen führt die Schlusssequenz des Films auf luzide Weise die zuvor genannten disparaten Ordnungen, Başers erste szenische Ideen zusammen. Eine türkische Frau geht am Ende des Films in Deutschland auf die Straße und der Zuschauer fragt sich, wie es wohl weitergeht. Wie wird eine Frau, die aus einem ganz anderen kulturellen Umfeld kommt, auf die deutsche Kultur reagieren?

Dass Zuschauer, Filmkritik und Forschung hier an Kulturen denken, liegt nicht daran, was der Film zeigt, sondern an dem, was er nicht zeigt. Denn das Umfeld der Akteure in diesem Film ist weder die Türkei, weder das türkische Dorf, noch spezifische kulturelle Praktiken. Dursun und Turna beten kein einziges Mal und reden auch miteinander nicht über die Türkei oder über Deutschland. Als kulturelle Marker dienen lediglich Turnas Kleidung, Dinge in der Wohnung und der Hoca, der einmal im äußersten Notfall Hilfe leistet. Es liegt paradoxerweise an der Enge der Wohnung mit ihrer Fläche von 40 qm, an den Dingen und den Außengeräuschen, die in der Wohnung widerhallen, dass im Film ein beschriebenes Außen entsteht, ein »unmarked space«, auf das das Sprechen über Kultur reagiert. Nach Niklas Luhmann ist aber die Grundlage des Sprechens über Kultur der Vergleich; der Vergleich unterschiedlicher Praktiken, Sichtweisen oder Glaubensformen. ${ }^{170}$ Dieser liegt in 40 QM DEUTSCHLAND nicht vor. Dass der Film trotzdem ein Sprechen über unterschiedliche Kulturen ausgelöst hat, liegt daran, dass Başer, wie gesagt, ein abstraktes Anliegen mit einem konkreten verbunden hat: daran, dass das Hinausgehen einer türkischen Frau auf deutsche Straßen ein kultureller Akt sei. Sprich, es geht dabei keineswegs um die Praxis und das Handeln selbst. Im Zentrum steht, wofür beide stehen. Insgesamt verbinden beide Anliegen als abstrakte und konkrete Bewegungen, nach innen in die eigene Kultur und nach draußen auf die Straße in einem fremden Land, zwei differente Ebenen miteinander. Die Rahmung dieses dilemmatischen Grundverhältnisses zwischen Abstraktion und Konkretion gelingt in Başers Film zum einen durch eine besondere ästhetische Filmsprache, die vorzüglich durch >innere Montagen`, die Dinge, Kleidung, Geräusche, Farben und die Wohnung selbst als Grenzraum mit den Akteuren in den Aufnahmen und Einstellungen ebenbürtig miteinbezieht. Zum anderen schafft die Kamera selbst diese Verbindung, indem mit spezifischen optischen Schärfenverlagerungen im Bild, Geräuschaufnahmen aus dem Off und

169 PÜTZ/SCHOLTEN (1988): S. 18.

170 Vgl. LuhmanN, Niklas (1995): »Kultur als historischer Begriff«. In: ders.: Gesellschaftsstruktur und Semantik. Studien zur Wissenssoziologie der modernen Gesellschaft, Bd. 4, Frankfurt a. M.: Suhrkamp, S. 31-54. Siehe auch: BAECKER, Dirk (2000): Wozu Kultur, Berlin: Kadmos. 
Kamerafahrten in der Wohnung als teilnehmende Beobachter gearbeitet wird. Hinzu kommt, dass Dursuns Wutrede bei genauerer Analyse der Szene auf einen weiteren, dritten Gesprächspartner und Beobachter aufmerksam macht, der die Wohnung eigentlich erst zu dem macht, was sie ist: zu einem öffentlichen Raum. Doch bevor wir auf diesen letzten Punkt zu sprechen kommen, der als epistemische Gewalt im Raum fungiert, die uns auch den analytischen Weg zu Özakıns Romanen der 1980er ebnen wird, möchte ich auf die ästhetische Erzählweise im Film zu sprechen kommen. ${ }^{171}$

Es sind die ersten Einstellungen im Film zusammen mit dem Vorspann, die vor dem Eintritt der Protagonisten in die Wohnung zeigen, dass sie nicht allein im Vordergrund stehen, auch die Wohnung, die Kamera und die Geräusche aus Treppenhaus und Innenhof nehmen entscheidende Funktionen in der Erzählung ein. Der Film beginnt mit einer Kamerafahrt durch eine unaufgeräumte Wohnung, während ein Quarzwecker aus dem Off piepst. Von links nach rechts bewegt sich die Kamera, wir sehen zunächst ein Foto von drei Gastarbeitern, das an einem hellblauen türkischsprachigen Ilmihal-Buch lehnt. ${ }^{172}$ An der Wand erscheint als nächstes, schwächer ausgeleuchtet, ein Plakat mit einem Portrait von Mustafa Kemal Atatürk, dem Begründer der modernen Türkei. Darauf folgen verdunkelte Stellen an der Wand und ein bunter türkischer Wandteppich, auf den die Blaue Moschee gestickt ist. Diese Einstellung dunkelt mit der Bewegung der Kamera wieder leicht ab, und wir sehen, wie der Titel des Films in blauen Großbuchstaben eingeblendet wird. Die Kamera fährt darauf leicht nach unten und wieder nach oben, es wird weiter mit Hell-/Dunkel-Schattierungen gearbeitet, wir

171 Die technisch-ästhetische Ebene des Films ist bislang in der Forschung kaum beachtet worden. Dort, wo kurz auf die Kameraführung eingegangen wird, folgen oft kulturell-essenzialistische Verortungen. Beispielsweise hält Kühn stellvertretend für viele andere für die Schlusseinstellung des Films fest: »Die Kamera bleibt im Treppenhaus zurück, die Kamera hat sich noch nicht befreit: Von den Bildern des Gefangenseins in einer Kultur, die für den türkischen Regisseur in Deutschland eigen und fremd zugleich ist«. KüHN (1995): S. 57.

172 Ilmihal-Bücher sind praxisorientierte Darstellungen und Interpretationen der Grundlagen der islamischen Religion. Sie sind mit Katechismen vergleichbar, wobei die Heterogenität der Interpretationen unterschiedlicher Ilmihal-Bücher größer ist als im katholischen Christentum. Seit den 1980er Jahren haben sie in türkischen Moscheen und Haushalten eine besondere Verbreitung erfahren, die mit der Errichtung der DITIB, dem deutschen Ableger des türkischen Amtes für Religiöse Angelegenheiten in Deutschland, einhergingen. Zur Gründung der DITIB siehe: SCHIFfaUER, Werner (2004): »Vom Exil- zum Diaspora-Islam. Muslimische Identitäten in Europa«. In: Soziale Welt. Zeitschrift für sozialwissenschaftliche Forschung und Praxis 55:4, S. 347-368, S. 352f. Siehe hierzu auch: SEUfERT, Günter (1999): »Die `Türkisch-Islamische Union` (DITIB) der türkischen Religionsbehörde. Zwischen Integration und Isolation«. In: Turkish Islam and Europe. Türkischer Islam in Europa, hg. v. Günter Seufert, Jacques Waardenburg, Istanbul: Orient Institut der DMG, S. 261-294. 
sehen dabei einen Ofen, auf dem eine türkische Teekanne steht, einen Stuhl mit darauf abgeworfener Bekleidung. Es wird wieder ein wenig heller und wir sehen auf einer Kommode den Mantelteil einer türkischen Zeitung, darauf gebrauchte Teelöffel. Auf der Fahrt wieder nach unten sind leere Bierflaschen, Aschenbecher, ausgedrückte Zigarettenstummel und ausgetrunkene türkische Teegläser zu sehen. Regengeräusche und Geräusche aus dem Treppenhaus dringen in einer Lautstärke aus dem Off in die Kamerafahrt durch die Wohnung, als ob Fenster und Wohnungstür weit aufstünden. Die Kamera fährt wieder hoch, dunkel und hell wechseln wieder, und wir sehen ein Sofa, auf dem eine verknitterte dünne Decke liegt. Es folgt eine weitere Kommode mit einem leeren Joghurtbecher und dem Innenteil der Zeitung darauf. In diese Fahrt werden die Namen der Hauptdarsteller, Yaman Okay und Özay Fecht, wieder in blauen Großbuchstaben eingeblendet. An dieser Stelle gesellt sich zum Piepsen des Weckers und zum Regen das deutlich hörbare Aufschließen einer Tür aus dem Off. Die Tür war also gar nicht offen, obwohl die Außengeräusche so nah wirkten. Die Kamera fährt darauf durch und um einen blauen Türrahmen und nimmt das zweite Zimmer der Wohnung, das Schlafzimmer, auf. In diesem sehen wir ein ungemachtes Bett stehen und eine Pyjamahose auf dem Boden liegen. Die Kamera bewegt sich aus dem Zimmer heraus, in dem wir auch den Wecker entdecken und endet mit ihrer Fahrt durch die Wohnung, als zwei Säcke kurz vor der Wohnungstür auf den Boden gestellt werden. Die Kamera macht einen leichten Schwenk nach oben und wir sehen eine mit vielen matt-bunten Kleidungsstücken angezogene Frau in der Wohnung stehen und hinter ihr Dursun, der eine Wolldecke in die Wohnung trägt und sich gleich daran macht, den Wecker auszuschalten.

In dieser ersten Sequenz des Films, die zugleich der Vorspann ist und ohne Schnitt auskommt, treten viele Aspekte auf, die den Film in seiner Struktur bestimmen. Der Fokus liegt auf Bildkonstellationen, auf mise-en-scènes (In-Szene-Setzungen bzw. >innere Montagen`), dem Licht, auf Außengeräuschen, Farben, Dingen, der beweglichen Kamera - eine Ausmessung der kleinen Wohnung, die eine geschlossene Struktur erzeugt. Mit mise-en-scène ist in der Filmsprache eine Form der sinneren Montage، gemeint, die im Unterschied zur gewöhnlichen Montage und zum Schnitt des Films nicht eine zeitliche Anordnung und Abfolge der Bilder, sondern eine räumliche Anordnung der Figuren und Dinge im Bild bestimmt. ${ }^{173}$ Eine Szene wird dabei nicht in einer aufeinander folgenden Reihe von Einstellungen aufgelöst, wie es beispielsweise häufig

173 Siehe hierzu: BordwEll, David/Thompson, Kristin (2010): A Film Introduction, Tenth Edition, New York: McGraw-Hill Inc., S. 113. Siehe zur sinneren Montage ebenfalls: BoRDWELL, David (1997): On the History of Film Style, Cambridge, Mass., London: Harvard University Press. 
im Hollywoodkino geschieht. Bei einer sinneren Montage als mise-en-scène werden alle relevanten Objekte und Akteure einer Szene in einer Einstellung arrangiert.

Neben der Wohnung als Metapher und als geschlossener Raum, der im Film immer mit mittellauten bis lauten Außengeräuschen aus dem Off, Treppenhausgeräuschen, Regen, Musik über den Innenhof aus einer anderen Wohnung, Motorgeräuschen oder Polizei- bzw. Krankenwagensirenen gefüllt wird, zeigt die Kamerafahrt zu Anfang noch drei weitere Aspekte. Dazu zählen gebrauchte und konsumierte Dinge. Wir werden das Paar außerdem dreimal beim Frühstück sehen, dabei wird immer nur Dursun essen und trinken, und wir werden das Paar dreimal beim Sex sehen, den Turna jeweils passiv über sich ergehen lässt. Die Unordnung in der Wohnung ist auffällig. Wir sehen Turna oft Wäsche von Hand waschen oder die Wohnung in Ordnung bringen - solange, bis sie die eigene innere Ordnung verliert. Wir haben es in 40 QM DEUTSCHLAND also nicht einfach mit repräsentativen Akteuren zu tun, sondern mit solchen, die konsumieren, Ordnung schaffen und Ordnung verlieren. Dennoch ist die hier gezeigte Bedürfnisstruktur nicht mit der zu vergleichen, die wir in SHIRINS HochzEIT, in Was will Niyazi in der Naunynstraße und in ANGST ESSEN SEELE AUF gesehen haben. Wenn die Migrantinnen und Migranten dort gewissermaßen noch vor dem Konsum stehen und assimilatorisch durch Konsum noch andere Menschen werden wollen, zeigt der Einstieg in 40 QM DEUTSCHLAND, dass hier schon konsumiert wurde und die Migration und ihre Folgen nicht mehr davon bestimmt sind, wie ein Anderer zu leben oder ein Anderer zu werden. ${ }^{174}$

174 Der türkei-türkische Film KöşEYI DöNEN ADAM (»Plötzlich reich«, 1978) von Atıf Yılmaz beginnt mit einer identischen Kamerafahrt, in dem mit einer Kreiskamerafahrt konsumierte Dinge, Plakate (eines mit Atatürk), gezeigt werden, die am Ende uns den Protagonisten morgens noch im Schlaf von Autos und Frauen reden lassen, bis der Wecker klingelt. Er arbeitet als Portier in einem einfachen Wohnkomplex und wohnt im Untergeschoss in einem Zimmer. Im Laufe des Films wird sein in die USA migrierter Onkel sterben und ihm ein Erbe hinterlassen. Diese Nachricht ändert vollkommen sein Ansehen unter seinen Vorgesetzten, Freunden und der Frau, die er liebt, die selbst aber eine heimliche Liebesbeziehung zu einem anderen Türken hat. Sie nutzt ihn aber aus bis zur Nachricht, dass er nun reich ist. Der Vater seiner Ersehnten ändert auch schlagartig sein Verhalten ihm gegenüber und nimmt ihn sogar als Schwiegersohn in seine Wohnung auf. Das Erbe jedoch, das aus den Vereinigten Staaten eintrifft, ist ein Esel. Der Protagonist Adem verbreitet darauf das Gerücht, dass dieser Esel Gold »scheißen« würde und man nur darauf warten müsste. Dieser Umstand führt zu äußerst amüsanten Szenen im Film, die die Geldgier aller Akteurinnen und Akteure entlarvt, der dabei nicht auf andere Bedürfnisse abzielt, sondern beim Verweis auf eine fehlende moralische Ordnung stehenbleibt. Siehe hierzu: YILMAZ, Atif (1978): Köşeyi dönen Adam, Spielfilm, Çiçek Film, Türkei. 
Auf diesen Ausschluss des Anderen deutet auch die symbolische innertürkische Kommunikation zwischen moderner und vormoderner Türkei hin, die an der symbolpolitischen Anordnung der Dinge zueinander in der Wohnung deutlich wird. Wir sehen zu Anfang und auch im Laufe des Films einige Male das Konterfei Atatürks in Relation zu Symbolen volksreligiöser Praxis wie Katechismen und Teppichen, auf denen eine Moschee abgebildet ist. Auch die Sequenz mit dem Hoca steht für diese Auseinandersetzung. Insgesamt treten an die Stelle von sozialer und ähnlicher Bedürfnisstruktur von Deutschen und Türken in den 1970ern nun Grenzziehungen und neue Bindungen, die die Akteure entweder mit kulturellen Kennzeichen oder mit psychischen Bedürfnissen verbinden. Den fehlenden Vergleich zwischen türkischer und deutscher Lebensweise ersetzt in Başers Film derjenige zwischen Moderne und Tradition, die innertürkisch in der Wohnung und durch die Akteure zur Disposition steht. Dass diese Kontroverse nicht einfach bei den Dingen bleibt oder plakativ wirkt, liegt an der von Başer eingesetzten Filmsprache. Das filmische Stilmittel von 40 QM DEUTSCHLAND ist die sinnere Montage , die das Narrativ der Integration in diesem Film bestimmt. Hamid Naficy beschreibt die Erzählweise in 40 QM DEUTSCHLAND als eine »closed mise-en-scène and closed-form filming «. ${ }^{175}$ Im Folgenden möchte ich eine Szenenfolge aus 40 QM DEUTSCHLAND analysieren, die sehr plastisch aufzeigt, wie Başer die Akteure mit dem Raum und den Dingen in Verbindung bringt.

Nachdem Turna die Wohnung in Ordnung gebracht hat, freut sie sich sichtlich darauf, Deutschland zu entdecken. Den zweiten Versuch, mit Dursun darüber zu sprechen, hat sie zuvor vor dem Spiegel in halb wütendem und halb bittendem Ton eingeübt; er fällt bei Dursun allerdings als zahme Bitte aus und scheitert: Turna muss feststellen, dass es sehr wahrscheinlich nicht mehr als diese 40 qm der Wohnung sein werden, die sie in diesem Land kennenlernen wird, woraufhin ein psychischer Prozess einsetzt, dessen Ausgangspunkt eine der stärksten sinneren Montagen ` des Films ist. Ihm geht eine Rückblende voraus, in der Dursun ebenfalls in einer kleinen Wohnung bei Turnas Vater um ihre Hand anhält. Dursun ist allein gekommen, ohne seine Eltern, wie es üblich wäre, und er stottert beim Vortrag seiner Bitte. Turna hört aus der Küche, wie ihr Vater und Dursun über eine Hochzeit reden. Auf Dursuns Anfrage erwidert Turnas Vater, dass er die Bräuche hier im Dorf kenne: Wenn er das Brautgeld zahle, könne er Turna haben. Auf diesen Verkauf reagiert Turna mit einem besorgten Gesichtsausdruck, während sie türkischen Kaffee für die beiden Männer zubereitet.

175 Naficy, Hamid (2001): An Accented Cinema: Exilic and Diasporic Filmmaking, Princeton: Princeton University Press, S. 193. 
Nach dieser Einstellung sind wir wieder in der Hamburger Hinterhofwohnung. Die Kamera fängt Turna durch eine Tiefenaufnahme im Raum im Schlafzimmer ein. Wir sehen ihr Spiegelbild. In der Mitte des Bildes dieser mise-en-scène trennt und verbindet die offene Tür mit ihrem blauen Türrahmen das Schlaf- vom Wohnzimmer. Auf der linken Seite sehen wir Turna in die Tiefe aufgenommen und auf der rechten Seite die Wand, die die Zimmer trennt. An der Wand hängt eine arabische Kalligrafie mit dem Namen Gottes. Wir beobachten Turna über den Spiegel, über dem ein durchsichtiges blaues Tuch hängt, wie sie ihren Blick in seine, respektive in unsere Richtung wendet. Nach kurzer Zeit läuft sie auf den Spiegel zu. Dabei wird zugleich die Schärfe des Bildes wieder verlagert, bis sie vor dem Spiegel steht. Nun zeigt die Kamera nur noch ihr Spiegelbild. Turna nimmt eine Schere in die Hand und schneidet sich die Zöpfe ab, die sie auf eine türkische Tageszeitung legt. In der nächsten Einstellung hören wir mit ihr aus dem Innenhof heraus ein türkisches Klagelied, das aus einer anderen Wohnung dringt. Die Musik lässt sie das Fenster öffnen, sie wird lauter und ein deutscher Punk, ein Nachbar im Wohnhaus, beschwert sich mit einem Stinkefinger über die Musik. Woher die Musik kommt, ist nicht klar. Turna schließt verängstigt das Fenster und die Musik wird wieder leiser. ${ }^{176}$

Turnas Bewegung zum Spiegel, das Schneiden der Haare, die klagende türkische Musik aus dem Innenhof und das Schließen des Fensters korrespondieren in szenischer Hinsicht miteinander. Sie stehen für einen Schließungsprozess im Film, der sich bis zum psychischen Wahn steigern wird. Er ist diegetisch von Dialogarmut zwischen menschlichen Akteuren und von vielfältigen Grenzziehungen bestimmt. An die Stelle der körperlichen Abtrennung tritt im Laufe des Films die psychische, die etwa das zweite Haareschneiden (der Puppe) dokumentiert.

176 Die besondere Bedeutung der türkischen Volksmusik für die türkischen Ausländer hebt auch Metin Gür in seiner Studie hervor. Als er Mitte der 1980er Jahre in Bergkamen ein Arbeiterwohnheim besucht, sich in der Gemeinschaftsküche mit den Arbeitern aufhält, hören sie das türkische Radioprogramm des WDR. Beim Verlesen der Nachrichten über die politische Situation in der Türkei hört kaum jemand zu, doch als die Volkslieder abgespielt werden, »wird ihre Unterhaltung wie von selbst leiser«. GüR, Metin (1987): S. 103. Dass das »türkische Volk« sich durch seine Lieder ausdrückt, konstatiert auch Robert Anhegger, der in der Fortbildung türkischer Deutschlehrer tätig war. Siehe: ANHEGGER, Robert (1982): »Die Deutschlanderfahrung der Türken im Spiegel ihrer Lieder. Eine `Einstimmung «. In: Gastarbeiterkinder aus der Türkei. Zwischen Eingliederung und Rückkehr, hg. v. Helmut Birkenfeld, München: Beck, S. 9-25. Umgekehrt macht Abdullah Yakupoğlu in Grabes Dokumentarfilm darauf aufmerksam, dass er jeden Abend die türkischen Radionachrichten des WDR gehört habe, und er gibt auch aus dem Stehgreif einen Rat des türkischen Botschafters an die türkische Bevölkerung in der Bundesrepublik wieder. Der Botschafter hat den Türken in Deutschland empfohlen, ihre Kultur nicht zu vergessen und sie in Deutschland auch zu leben. Siehe hierzu: Grabe (2012). 
Turna wird bewusstlos, bekommt Tagesalbträume, wird später am Tisch beim Essen mit Dursun einfach ohne Grund schreien und bis zum Schluss des Films immer mehr verzweifelte Grimassen schneiden. Ihre Gesichtsfarbe wird immer fahler, während die Farben der Dinge kräftig bleiben. Der Körper der Migrantin wird hier zum Austragungsort eines psychischen Konflikts zwischen Kultur und einem Auf-die-Straße-gehen-Wollen. Wie für Emine, der Tochter des Gastarbeiters Kemal aus Aras Örens letztem Band seiner Poem-Trilogie Die Fremde ist auch eine Heimat, hat sich auch für Turna ein Berg zwischen Haus und Straße geschoben.

Überzeugend ist dieser Konflikt in 40 QM DEUTSCHLAND, weil es im Film über das spärliche Sprechen der Akteure hinaus eine durchgehende Innen-Außen-Kommunikation gibt. Diese entspricht weder den soziologischen Vorstellungen Georg Elwerts noch den theologischen von Jürgen Micksch zur Integration der Einwanderer, weil beide sich allein auf die gesprochene Sprache und das damit zusammenhängende Bewusstsein konzentrieren. ${ }^{177}$ Dies beginnt schon bei den Geräuschen aus dem Off, die lauter sind als sie sein dürften. Vom Regen, von Treppenhausgeräuschen bis zur Musik entsteht immer wieder der Eindruck, dass diese Wohnung entgegen den Bildmontagen und Kamerafahrten offenstehen muss. Diese spezifische Verschränkung, durch die im Innen immer auch ein Außen steckt, wird durch eine weitere, die symbolische Kommunikationsebene im Film verstärkt. Die symbolische Kontroverse und Kommunikation besteht zwischen Moderne und Tradition, zwischen Fortschritt und Rückstand, zwischen dem mehrfach dargestellten Mustafa Kemal Atatürk, für den unter anderem die unverschleierte öffentliche Frau die moderne türkische Republik symbolisiert ${ }^{178}$, und dem hier volksreligiös und abergläubisch dargestellten Islam, dem Dursun aus Unwissenheit folgt. Diese weitere Innen/Außen-Kommunikation leitet sich aus der Abfolge der sinneren Montagen ab. So wird die materielle und symbolische Verschränkung, die auf die ersten szenischen Ideen Başers zurückgeht, in 40 QM DEUTSCHLAND nicht gelöst oder synthetisch zusammengeführt. Dafür gibt es zwei Gründe: eine explizit technische und eine weitere, dritte Kommunikationsebene, die jenseits der Sprachlosigkeit von Dursun und Turna, jenseits der Ding- und Audioebene des Films liegt. Sie zeigt sich implizit in Dursuns Wutrede, mit der wir unsere Analyse des Films begonnen haben. Diese Sequenz muss anders gelesen werden, als dies bisher geschehen ist. Denn in ihr sehen wir eine komplexe dialogische Konstellation, der wir auch in den folgenden Film- und

177 ELWERT (1982): S. 3; MiCKSCH (1984): S. 9.

178 Siehe hierzu: KreISER, Klaus (2014): Atatürk. Eine Biographie, München: Beck, S. 261-263. Siehe hierzu auch: Die türkische Frauenrechtsbewegung. Die Geschichte der modernen Frauenrechtsbewegung in der Türkei ist eng verknüpft mit der Gründung der türkischen Republik vor fast einhundert Jahren, In: https://www.bpb.de/internationales/europa/tuerkei/184972/frauenrechte. 
Literaturanalysen zu den 1980ern als einem konstitutiven Aspekt ihrer politischen Epistemologie begegnen werden.

Wir haben gesehen, dass die erwähnten Kritiken am Film, ob positiv oder negativ, insgesamt zu kurz greifen, wenn es darum geht, das Verhältnis zwischen ästhetischem und gesellschaftspolitischem Narrativ genauer zu fassen. Das liegt zum einen daran, dass der Film allein durch seine Materialität und psychische Intensität in seiner Darstellung über die Repräsentation von Kulturen, Tätern und Opfern hinausgeht, zum anderen, dass den kultur- und opferspezifischen Interpretationen das Narrativ »Wie lebt es sich als Türke in Deutschland? «schon als Kritik oder Bestätigung vorausgeht. Dieses Narrativ wird auf seiner Gegenseite weder in diesem noch in anderen Filmen und literarischen Texten der 1980er von einem stabilen deutschen sozialpolitischen Narrativ gestützt, so dass auch eine subnationale Etikettierung für diesen Film nicht greift. ${ }^{179}$ Die Innenperspektive durch die geschlossene Wohnung als Metapher betrifft nicht nur die Audio- und Dingebene, sondern auch die kommunikative. Denn Dursun spricht in seiner Wutrede nicht nur mit seiner Ehefrau. Es ist ein dritter Akteur im Spiel, dessen Beobachterposition nicht einfach mit der Perspektive der Kamera oder der Zuschauer identifiziert werden kann. Im Unterschied zu Fassbinders beobachtenden Figuren des internationalen Paares in ANGST ESSEN SEele AUf (1973) und dem Großgrundbesitzer in Türkan Şorays Film DöNÜŞ (Rückkehr, 1972), der ebenfalls im Bild ist, sehen wir den für die Kommunikation hier konstitutiven Partner nicht. Er nimmt nicht an der Kommunikation teil.

Als Turna sich nach ihrer Aussage, dass sie in den eigenen vier Wänden wahnsinnig werde, ins Bett legt, setzt sich Dursun mit dem Rücken zu ihr ans Bettenende. Er blickt nach vorne rechts aus der Kameraeinstellung heraus. Seine Frau liegt hinter seinem Rücken und hat sich zugedeckt. Ihre Positionen sind diametral. Bevor er mit seiner Wutrede beginnt, ändert sich zudem das Lichtverhältnis im Zimmer und die Bildschärfe wird bei gleichbleibender Kameraeinstellung auf Dursun verlagert. Hinter ihm wird es dunkel, nur seine Statur, sein Gesicht und sein Blick sind aus der Einstellung heraus ausgeleuchtet. Hinter ihm sind die Schlafzimmerwand und die zugedeckte Turna kaum noch zu sehen. Dursun wird seinen Kopf ein-, zweimal kurz während seiner Rede leicht in Turnas Richtung wenden, in den Momenten, als er sie fragt, ob sie den westlichen Frauen nacheifern möchte oder ob sie die Geschichte der Familie von Mehmet nicht kenne. Ansonsten adressiert er mit seinem Monolog, wenn man von seiner Körperhaltung ausgeht, jemand anderen, der in diesem Raum physisch nicht zugegen ist. Und beide Male, wenn er sich von Turna wieder abwendet, wird er nicht mehr von

179 Siehe GöKTÜRK (2000): S. 333. 
persönlichen Anliegen sprechen, sondern über Wohnheime und den Staat, und beide Male in den Raum hineinrufen, von dem wir nur die Hälfte sehen: »Was geht euch das an? «(Size ne?). Auf der Dursun entgegengesetzten Seite des Raumes, in der anderen dunklen Hälfte, sitzt sein eigentlicher Dialogpartner, den er als ein Kollektiv anspricht und der zugleich inner- und außerhalb des Raums ist. Trotz geschlossener Türen, trotz des Verbots für Turna, die Wohnung zu verlassen, ist das Verhältnis zwischen Drinnen und Draußen in 40 QM DEUTSCHLAND ephemer und durchlässig, vermag die Akteurinnen und Akteure aber nicht in Bewegung zu versetzen. ${ }^{180}$

So liegt die besondere Stärke (Filmkritik) oder Schwäche (Forschung) des Films nicht darin, eine Innensicht in das türkische Leben in Deutschland zu ermöglichen oder ihre Akteure einfach als Opfer darzustellen. Zentral ist vielmehr, dass er eine Struktur der mehrfachen Grenzarbeit und Kommunikation aufzeigt. Es geht dabei um eine epistemische Gewalt, die im Raum steht und Dursun zum Sprechen bringt; ein Sprechen, das in der Gesamtstruktur des Films vielmehr zeigt, was nicht gesagt werden kann als das, was gesagt wird. Abgeschnitten von all der Mobilität der Migration, ihres Prozesses, ihrer Wege der Ankunft und abgeschnitten vom Betreten des öffentlichen Raums ist ein Sprechen des Anderen nicht möglich. So bleibt gegen die Gefahr der Assimilierung des Anderen für Spivak nach Jacques Derrida nur noch die »Neuschreibung des utopischen Impulses als Impuls >die innere Stimme, die Stimme des anderen in uns, delirieren [zu] lassen « ${ }^{181}$, wie auch Turna anfängt, zwischen den Wänden ihren Namen zu vergessen. ${ }^{182}$ Başers Film ist vom Bemühen bestimmt, sich »in die Repräsentation einzubringen«, was sich als ein Bemühen des »nicht Sprechens« darin zeigt, wie schwer es ist, in den 1980er Jahren in der Bundesrepub-

180 Siehe hierzu: SPIVAK (2007): S. 127.

181 SPIVAK (2007): S. 106.

182 Auf ähnliche Weise muss auch die marokkanische Soziologin Fatema Mernissi in ihrer Publikation Der Harem ist nicht die Welt die eigene Person, ihre individuelle Identität vergessen haben. In diesem Sammelband aus dem Jahr 1984 geht es um elf Berichte aus dem Leben analphabeter marokkanischer Frauen. Als Selbstpositionierung und Motto des Buchs hält Mernissi zu Anfang fest: »Ich bin 1940 geboren, und nur sehr wenige Marokkanerinnen meiner Generation haben überhaupt lesen und schreiben gelernt - ganz zu schweigen von der Möglichkeit, eine weiterführende Schule zu besuchen. Es erscheint mir fast wie ein Wunder, daß ich nicht Analphabetin geblieben bin. Wenn ich also versuche, eine Frau ohne Schulbildung dazu zu bringen, daß sie ihre Meinung äußert, dann ist das für mich, als ob ich mir selbst das Wort erteile, jenem anderen möglichen Selbst, das im traditionellen Schweigen hätte verharren müssen.« MERNISSI, Fatema (Hg.) (1988): Der Harem ist nicht die Welt. Elf Berichte aus dem Leben marokkanischer Frauen, Frankfurt a. M.: Luchterhand, S. 2. 
lik von Innen nach Außen zu gelangen. ${ }^{183}$ So lautet etwa ein zentrales Ergebnis der Forschungen von Wolfdietrich Bukow und Roberto Llaryora zur Ausländerpolitik der 1980er, dass die Identitätspassage nicht einfach verweigert, sondern vielmehr im Vollzug einer Politik der Ethnisierung abgesprochen wird. ${ }^{184}$ Diese Politik ist in besonderer Weise von strukturellen auf alltägliche Bereiche übergegangen. ${ }^{185}$ Davon spricht auch Dursun, wenn er die Türken nur als Klienten des Staates erwähnt, die versorgt werden müssen, aber nicht als potentielle Bürger mit Möglichkeiten der Repräsentation. Dass auf der anderen Seite dieses fragilen Bewusstseins (Elwert) eines geteilten Subjekts in der Bundesrepublik tatsächlich nur die Assimilierung (Esser) steht, und es kein wirkliches Dazwischen gibt, zwischen eigener Kultur und Assimilation, wie in Dursuns Hamburger Hinterhofwohnung zeigt auch eindrücklich Başers zweiter Film ABSCHIED voM FALSCHEN PARADIES, der ein Jahr nach 40 QM DeUTSChland entstanden ist. Dieser Film wirkt wie die Fortsetzung des ersten, nur dass hier auf eine besondere Art und Weise eine Integrationsgeschichte als eine Assimilationsgeschichte erzählt wird. An die Stelle der Wohnung tritt nun das Gefängnis. Wie in 40 QM DEUTSCHLAND die Wohnung und das Handeln durch die Re-Präsentation verdoppelt werden, sind es hier das Gefängnis und die Entwicklung der Figur Elifs, die immer auch für etwas anderes stehen. Wenn in Başers erstem Film die innere, psychische Emanzipation und die physische Emanzipation vom türkischen Mann nötig ist, um nach draußen zu gelangen, sind es in seinem zweiten Film die Assimilation der Hauptfigur und ihr Rechtsstatus, die ihr ein wirkliches Heraustreten aus dem Gefängnis ermöglichen könnten. Die Assimilation gelingt in diesem Film zwar, doch gibt es für diese Entwicklung der Person keine rechtliche gesellschaftliche Entsprechung.

Denn im Spielfilm ABSchIED vom FALSCHEN PARAdIES, der auf die Erzählung Frauen, die sterben, ohne dass sie gelebt hätten von Saliha Scheinhardt zurückgeht, ${ }^{186}$ bewegt sich Başer in der Bahn einer Integrationstheorie, wie sie Esser in den 1980ern theoretisch beschreibt. Um diese erzählen zu können, löst er in seinem zweiten Film die inneren Bildmontagen auf. Allerdings geht die lineare Erzählstruktur von ABSCHIED vom FALSCHEN PARADIES im Unterschied zu 40 QM Deutschland nicht auf Kosten der Intensität des Bewusstseins. Denn das linear integrative Erzählen führt zu keiner Kohärenz. In ABSCHIED VOM FALSCHEN PARADIES steht erneut eine Frau im Zentrum des Geschehens. Sie wird zu 6 Jahren Haft verurteilt, weil sie ihren türkischen Mann getötet hat, der sie in der Türkei heira-

183 Vgl. SPIVAK (2007): S. 145.

184 BuKow/LlaRYoRA (1998): S. 94.

185 Siehe hierzu: Ebd., S. 84-110.

186 ScheINHARDT, Saliha (1983): Frauen, die sterben, ohne dass sie gelebt hätten, Freiburg: Herder. 
tete und mit nach Deutschland nahm. Im Unterschied zu Turna tritt die Protagonistin gleich zu Beginn als Handelnde und Täterin auf, wobei die Tat selbst nicht gezeigt wird und wir nur durch eine Rückblende im Film davon erfahren. Erneut ist die Kameraführung äußerst interessant, die von einer Straßenaufnahme durch die Aufnahme eines Treppenhauses in eine kleine Hinterhofwohnung führt, in der Kopftuch tragende Frauen den Tod einer Person beklagen. Das Motiv für den Mord bleibt verborgen. Der Film spielt ausschließlich im Gefängnis und zeichnet eine Integrationsgeschichte nach, die abseits der öffentlichen Gesellschaft geschieht. Elif lernt im Gefängnis Deutsch und freundet sich mit den deutschen Mithäftlingen an. Zu Anfang des Films sehen wir sie als eine schüchterne, ängstliche Frau, die kein Wort Deutsch spricht, ein Kopftuch trägt und anatolisch-dörflich gekleidet ist. Die Figur wandelt sich mit zunehmenden Deutschkenntnissen und den gewonnenen deutschen Freundinnen. Anfangs sind es noch die Wörter »Hunger. Kalt. Angst «, die ihre existenzielle Situation im Gefängnis ausdrücken. ${ }^{187}$

Damit korrespondiert, dass die erste halbe Stunde des Films in kleinen, dunklen, kaum lichtdurchlässigen Gefängnisräumen gedreht ist. Die Protagonistin ist in der Regel allein und sprachlos. Im zweiten Drittel des Films dominieren die Aufnahmen im Gefängnishof, im Freien und in der Kantine, wo Elif von einer Liebesgeschichte erzählt und ihrem Wunsch, in Deutschland Busfahrerin zu werden. Sie ist nicht mehr allein. Ein eindeutiges Zeichen für ihren Wandel ist ihr Äußeres. Stück für Stück legt sie ihre anatolische Kleidung ab. Zuerst verschwindet das Kopftuch, dann folgt ein Abendkleid, das sie für das erste Treffen mit einem noch unbekannten Geliebten trägt - er sitzt im Gefängnistrakt der Männer -, und schließlich sehen wir Elif nur noch in Jeans und Bluse. Dass dieser Kleiderwechsel im Unterschied zu demjenigen von Shirin aus Sanders-Brahms Film SHIRINS HocHzEIT hier für einen Identitätswechsel steht, dokumentiert auch die deutsche Sprachkompetenz, die sich Elif parallel dazu aneignet. Je westlicher sie gekleidet ist, desto besser spricht sie Deutsch. Im letzten Teil des Films macht sich jedoch wieder Hoffnungslosigkeit breit. Elif erfährt, dass ihr die Ausweisung und ein zweiter Gerichtsprozess in der Türkei bevorstehen, da sie türkische und nicht deutsche Staatsbürgerin ist. ${ }^{188}$ Einen Tag vor ihrer Entlassung unternimmt sie

187 KILB, Andreas (1989): „Elif war hier«. In: DIE ZEIT, 05.05.1989, www.filmportal.de/node/26537/ material/739160 (31.07.2016).

188 Die Bedeutung der Staatsbürgerschaft, von Arbeitserlaubnissen und besonders von (begrenzten wie unbegrenzten) Aufenthaltstiteln, und welche Schwierigkeiten und Möglichkeiten mit ihnen verbunden sind, steht im Zentrum der meisten hier genannten Produktionen. In der Regel sind die Thematisierungen der jeweiligen Rechtszustände mit psychischen Dispositionen verbunden. Beispielsweise bedeutet für den Protagonisten Ali Itir in Aras Örens längerer Kriminalerzählung Bitte nix Polizei von 1981 der Erwerb der Arbeitserlaubnis und der damit ver- 
einen Selbstmordversuch, der scheitert. Am Ende erscheint Elif modern gekleidet, jedoch wieder voller Angst vor der Welt jenseits der Gefängnismauern. Wir sehen sie ängstlich im Flur, wie sie das Gefängnis verlässt. Und erneut folgt in einem Flur kurz vor der Ausgangstür der Abspann des Films. ${ }^{189}$

In ABSCHIED VOM FALSCHEN PARADIES ist an die Stelle der kleinen abgeschlossenen Hamburger Hinterhofwohnung ein Staatsgefängnis getreten. Beide Filme stehen in einem wechselseitigen Verhältnis und verweisen aufeinander, allerdings auf eine gebrochene Art und Weise. Wenn auf der einen Seite ein delirierendes Bewusstsein gegen die Assimilation nicht zur Sprache findet, findet auf der anderen Seite wiederum die Assimilation nicht in den öffentlichen Raum. Dass aber subalterne Artikulationen zwischen Bewusstsein und Assimilation in den ästhetischen Reflexionen der 1980er Jahre zur Migration nach Deutschland und ihrer Folgen nicht nur in engen geschlossenen Wohnungen oder Gefängnissen ihren Ort haben, sondern auch in öffentlichen Räumen, das zeigt die zeitgleich entstandene Literatur Aysel Özakıns, der wir uns nun intensiver widmen. In ihren Romanen Die Leidenschaft der Anderen und Die blaue Maske werden wir ebenfalls feststellen, dass die Existenz einer epistemischen Gewalt im Raum an ein Weitersprechen gebunden ist. Denn dieser Konnex reicht weit über eine geschlossene Wohnung hinaus. Hinsichtlich ihrer Biografie und Mobilität stehen Özakıns Protagonistinnen im Gegensatz zu Başers Figuren. Sie sind gebildet, selbstbewusst und unterwegs. Dennoch sind auch sie von nicht überwindbaren Wänden und Mauern umgeben.

\subsection{Im Zwiespalt zwischen Innen und Außen}

Die Szene, in der sich eine alteingesessene deutsche Frau und eine türkische Einwanderin im Zugabteil begegnen, mit der wir das dritte Kapitel eingeleitet haben, ist durch zwei Sätze direkter Rede gerahmt: »Sind sie Französin? [...] Ich bin Türkin«. Der innere Monolog der erzählenden Einwanderin erstreckt sich

bundenen Aufenthaltsgenehmigung, dass er von einer »Unperson« zu einer Person wird. Sieben Monate ist Ali Itir »jetzt schon eine Unperson, ein Niemand, und, Recht muss Recht bleiben, ohne seinen Vetter Ibrahim Gündoğdu und dessen Frau, die breitarschige Sultan hätte er vielleicht nicht einmal ein Dach über dem Kopf gehabt. [...] Wenn ich erst einmal Arbeiter bin, dann werde ich euch zeigen, wie man in Deutschland eine Persönlichkeit wird, wie Ali Itir zu einem geachteten Mann wird, an dem ihr euch alle ein Beispiel nehmen könnt." ÖREN (1981): S. 26.

189 Siehe die weiterführende ausführliche Analyse von ABSCHIED vom FALSCHEN PARAdIES in: EzLI, Özkan (2009): »Von der interkulturellen zur kulturellen Kompetenz«. In: Wider den Kulturenzwang, S. 207-230, S. 210-214. 
zwischen diesen beiden Sätzen jedoch über zwei Seiten. Der Sprechakt als eine soziale Handlung und Einheit von Frage und Antwort ist hier zeitlich unterbrochen und geteilt. Denn zwischen beiden Sätzen liegt eine Assoziationskette, eine wuchernde Reflexion Özakıns, ${ }^{190}$ eine Spannung, die sie selbst als einen "geheimen Kampf «, als einen Komplex beschreibt. ${ }^{191}$ Die Frage nach der nationalen Identität löst eine Kette von Vorstellungen bei der Ich-Erzählerin aus, die vom Misstrauen der alten Frau, über Gedanken, was Grenzbeamte und andere denken werden, wenn sie anhand ihres türkischen Passes feststellen, dass sie Türkin ist, bis zu den Assoziationen über die »Türkenproblem «-Debatten in Fernsehen und Presse Anfang der 1980er Jahre. ${ }^{192}$ Sie gerät in einen inneren Zustand, den sie vor ihrer Migration nach Deutschland nicht kannte. ${ }^{193}$ Dies alles teilt sie ihrem Gegenüber nicht mit, sondern nur, dass sie Türkin ist.

Die Autorin Aysel Özakın ist Ende 30, als sie nach Deutschland kommt. Kurz nach dem Militärputsch in der Türkei am 12. September 1980 reist sie auf Einladung des Berliner Literarischen Colloquiums nach Berlin. Aufgrund der politisch prekären Lage in der Türkei entscheidet sie, in Deutschland zu bleiben. ${ }^{194}$ Zuvor

190 Ich setze in diesem Abschnitt Ich-Erzählerin und Autorin gleich, da mit Lejeune hier auch ein autobiografischer Pakt vorliegt, selbst wenn die Entwicklung zur eigenen Person als eine nicht mögliche gezeigt wird. Siehe hierzu: LejEune, Philip (1974): Der autobiographische Pakt, Frankfurt a. M.: Suhrkamp, S. 22.

191 ÖZAKIN (1983): S. 28.

192 Wie in der Einleitung dieses Kapitels schon festgehalten, sind besonders in Politik und Medien die Jahre zwischen 1979 bis Mitte der 1980er Jahre von den »Türkenproblem«-Debatten bestimmt, und die Stimmung gegenüber Ausländern ist sehr angeheizt. Von der Debatte, die Eibl-Eibesfeldt mit seiner kulturalisierenden Diktion »Türken sind auch Menschen, aber Menschen mit einer anderen Kultur « auslöste, über das Heidelberger Manifest vom 17. Juni 1981, in dem vor der Gefahr der »Unterwanderung « und »Überfremdung« des deutschen Volkes gewarnt wird, bis hin zum Rückkehrförderungsgesetz. Wie der damalige Arbeitsminister Norbert Blüm vor der Verabschiedung des Gesetzes am 10. November 1983 festhielt, seien die »Entscheidungsnotwendigkeit« für die Ausländer zur Rückkehr zu klären und »die finanziellen Belastungen für Staat und Rentenversicherung in überschaubaren Grenzen« zu halten. HunN (2005): S. 475. Siehe hierzu auch: HERBERT (2001): S. 251.

193 ÖZAKIN (1983): S. 28. Hamid Naficy zitiert in seinem Werk An Accented Cinema den Filmregisseur Joseph Losey zu seinen Exilerfahrungen in Europa, dass dieser, als er nach England und nach Italien ins Exil ging, nie darauf vorbereitet und eingestellt war, dass er in diesen Ländern »Pariah« sein würde. »I had no preparation for being a `Jew«, for being a minority person. « NAFICY (2003): S. $189 f$.

194 Im Herbst 1980 putscht das Militär in der Türkei, um zum einen »wachsende Spannungen zwischen sunnitischen und alevitischen Bevölkerungsteilen zu kitten«. Gelingen soll dies, indem der Islam für die Religions- und Sittenerziehung unter staatlicher Aufsicht zur zentralen Referenz wird. Zum anderen erfolgt der Putsch, um besonders gegen linke Extremisten und islamische Gruppen und Wortführer vorzugehen. Im Zentrum des Putschs steht eine Apolitisie- 
studierte sie an den Universitäten in Izmir und Ankara Französisch und Pädagogik und arbeitete anschließend elf Jahre lang als Französischlehrerin in Istanbul. In dieser Zeit schrieb und veröffentlichte sie die zuvor genannten Romane, die Michael Santak 1990 als »multikulturelle Emanzipationsromane « begreift. ${ }^{195}$ Ihre Istanbuler Zeit spielt in dem Roman Die blaue Maske eine wichtige Rolle. Özakın wird 1942 in der südostanatolischen Stadt Urfa geboren. Nach zehn Jahren in Deutschland, von 1980 bis 1990, wandert sie nach England aus, weil sie sich in Deutschland »durch gängige Kategorisierungen nach stereotypischen Vorstellungen hinsichtlich türkischer Kultur und Geschlechterbeziehungen in ihrer persönlichen und künstlerischen Freiheit eingeengt fühlte«. ${ }^{196}$ Wie hier bereits angedeutet, beschränken sich die Spannung und die Reflexionen in Gang setzende Irritation, die die alte Dame in Die Leidenschaft der Anderen mit der Frage nach

rung der türkischen Bevölkerung, die auf die politisch äußerst aktive Zeit der 1970er Jahre in der Türkei reagiert. Geplant ist eine Wende in Richtung einer »türkisch-islamischen Synthese«. Laizismus und Atatürkismus gelten zwar weiterhin, doch ist die Religion nicht mehr einfach eine private Angelegenheit der Bürger, sondern »soll zunehmend in den Staat integriert werden«. Dabei ist die große Aufgabe der öffentlichen Einrichtungen, den Jugendlichen beizubringen, »die türkische Nation wieder als eine Geschichts-, Kultur- und Schicksalsgemeinschaft zu betrachten und zu verteidigen«. KREISER/NEUMANN (2009): S. 455, S. 471; ADANIR (1995): S. 106. Der verstaatlichte Islam in den 1980er Jahren ist als »moralischer Kitt « jedoch nur die eine Seite der politischen Konstellation, die in der Türkei die DIYANET, in der Bundesrepublik die DITIB repräsentiert. Parallel dazu entsteht in den 1980ern verstärkt auch ein intellektueller Islam, der ab den 1990er Jahren besonders die Religion als das eigentlich politisch zu etablierende Gesellschaftsmodell ansieht. Siehe hierzu: TEzCAN, Levent (2003): Religiöse Strategien der machbaren Gesellschaft. Verwaltete Religion und islamistische Utopie in der Türkei, Bielefeld: transcript. Interessant im Zusammenhang der Analyse von 40 QM DeuTschland ist der Text des türkischen Militärs zu den Ursachen des Putsches, dessen eigentlicher Adressat die türkische Bevölkerung ist. So wie Dursun mit jemandem im Raum kommuniziert, der nicht da ist, gibt auch die »Bekanntmachung Nr. 1« des türkischen Militärs eine ähnliche Kommunikationssituation wieder. Es wird keine Bevölkerungsgruppe, sondern ein Abstraktum, eine unbekannte vermeintlich vertraute Entität im Raum angesprochen: »Erhabene türkische Nation! Der uns von Atatürk anvertraute türkische republikanische Staat, dessen Staatsgebiet und Staatsvolk ein unteilbares Ganzes bilden, war, wie Du in den letzten Jahren verfolgen konntest, durch die Aufwiegelung von äußeren und inneren Feinden geistigen und materiellen Angriffen in verräterischer Weise ausgesetzt.« Neumann (2009): S. 455. Zu dieser Politik der Apolitisierung der Bevölkerung und Gesellschaft gehört auch die Gründung der DITIB 1980 in Köln, deren Klientel die Auslandstürken in Deutschland sind.

195 SANTAK, Michael (1990): "Auf der Suche nach Leidenschaft. Aysel Özakıns multikulturelle Emanzipationsromane«. In: Frankfurter Rundschau, 13.10.1990.

196 Zitiert nach: WIERSCHKE, Annette (1997): »Auf den Schnittstellen kultureller Grenzen tanzend. Aysel Özakın und Emine Sevgi Özdamar«. In: Denn du tanzt auf einem Seil. Positionen deutschsprachiger MigrantInnenliteratur, hg. v. Sabine Fischer, Moray McGowan, Tübingen: Stauffenberg, S. 179-194, hier S. 183. 
ihrer Herkunft ausgelöst hat, nicht allein auf Begegnungen mit Fremden. Die Fremdheit reicht hier, wie in Başers Filmen, weiter: bis in vermeintlich vertraulich wirkende soziale Beziehungen, ja sogar bis in die Konstitutionsbedingungen des eigenen Selbst hinein. Dies zeigt beispielsweise für einen weiteren Eindruck und für viele andere Szenen in Özakıns Literatur exemplarisch folgende Begegnung aus Die Leidenschaft der Anderen.

Auf ihrer einmonatigen Lesereise, die den zeitlichen Erzählrahmen ihres autobiografischen Romans darstellt, lernt Aysel Özakın Max als einen politisch Gleichgesinnten kennen und übernachtet bei ihm in seiner Wohngemeinschaft. Wir lernen außer Max niemanden aus dieser Gemeinschaft kennen. Als es zu einer Annäherung zwischen der Ich-Erzählerin und Max kommt, verliert sich erstere wieder in Reflexionen und denkt dabei auch für letzteren. Wie bei der Begegnung im Zugabteil mit der fremden Person wird auch hier eine mögliche vertraute Beziehung blockiert. Diesmal möchte sie vor Max nicht als eine Frau erscheinen, die nun sexuelle Freiheiten genießt, weil sie lange unter einem patriarchalischen Moralkodex gelitten hat. Denn, wenn der »Mut zu Abenteuern, der europäischen Frau so gut steht, könnte man dies einer Orientalin als billige Nachahmung oder Degeneration auslegen «. ${ }^{197}$ Die Ich-Erzählerin fragt sich, ob sie auf dem Weg zu einem selbstständigen Individuum eher die eigenen Komplexe oder die kulturellen Kategorien behindern. Diese erneute reflexive Spannung entlädt sich auch körperlich in der Begegnung mit Max.

\begin{abstract}
»Ich bin müde«, sage ich zu Max und lächle. Ich gebe ihm zu verstehen, daß ich jetzt allein sein und schlafen möchte. Als er aus der Tür geht, bleibt er einen Augenblick stehen. Er dreht sich um und schaut mich an. Einen Moment schauen wir uns gegenseitig an. Als wären die Arme, mit denen wir uns umarmen wollen, nach einem Augenblick der Unentschlossenheit plötzlich wieder schwer geworden. Was macht unsere Arme so schwer? Etwa die Vorstellung, daß wir uns als zwei Menschen aus zwei unterschiedlichen Welten sehen: er aus Deutschland, ich aus der Türkei? ${ }^{198}$
\end{abstract}

Wenn in Başers Filmen, das Auf-die-Straße-Gehen oder das In-der-deutschen-Gesellschaft-Ankommen-Können die zentralen Themen und Rahmungen sind, die nicht gelingen und bildlich mit sinneren Montagen eingefangen werden, so sind es in Özakıns Literatur der 1980er, auf buchstäblicher wie auf metaphorischer Ebene, gelingende oder nicht gelingende Begegnungen. Die Akteure in Özakıns Literatur verfehlen sich, weil eine bestimmte

197 ÖZAKIN (1983): S. 50.

198 Ebd., S. 50. Der geschwächte und verbrauchte Körper ist ein Motiv, das in den genannten Filmen, Texten und Dokumentationen der 1980er Jahre immer wieder auftaucht. Siehe: AKÇAM (1983); BEKTAŞ (1981); MEERAPFEL (1985); GÜR (1987); DAL (1988). 
narrative Struktur sich immer wiederholt: Auf deskriptive Szenen, meistens Begegnungen, folgen Assoziationen, die die eventuell möglichen sozialen Bindungen nicht miteinander verknüpfen, sondern sie an Abstrakta wie `Nation`, `Stadt` oder >Land koppeln. ${ }^{199}$ Das Weitersprechen wird in die Erzähler selbst hineinverlegt. Wie in Başers Film gibt es aber auch bei Özakın eine permanente Außenkommunikation, die den Erzählverlauf irritiert. Sie bestimmt, wie wir am Ende dieses Analyseteils sehen werden, auch den narrativen Umgang mit der eigenen Biografie.

Ihr bekanntester und am häufigsten in der Forschung thematisierter Roman Die blaue Maske, ${ }^{200}$ der fünf Jahre nach Die Leidenschaft der Anderen erscheint, erzählt am Anfang und am Ende des Romans jeweils von einer verfehlten Begegnung mit einem nicht-türkischen Mann. In Die Leidenschaft der Anderen stehen nicht nur in der Mitte mit Max, sondern auch zu Beginn Männer im Vordergrund. Im achtseitigen Prolog dieses Romans, der mit »Kleine Autobiographie» betitelt ist, erzählt Özakın mit einer Mischung aus Kritik und Ironie von ihrer Kindheit, dass in dieser Zeit ihre erste große Liebe der Prophet »Mohammed" und die zweite große Liebe »Atatürk« gewesen seien. Den zweiten habe sie insgeheim in ihrer Kindheit und Jugend mehr geliebt als den ersten, auch wenn ihre Mutter ihr gesagt habe, dass der Prophet an erster Stelle stehen müsse. ${ }^{201}$ Davon abgesehen ist ihre Kindheit von familiären und staatlichen Erwartungen und Unterdrückungen geprägt, die sich besonders auf die Sexualität der Frau richten. In Die blaue Maske wird dieser Umstand humoristisch, lapidar festgehalten und luzide mit der Unterscheidung Fortschritt und Rückstand gerahmt: »[A]nderswo [werden] Leute auf den Mond [ge]schickt, und bei uns haben sie immer noch nichts Besseres zu tun, als die Frauen zwischen den Beinen zu kontrollieren . $^{202}$ Der kurze Lebensabriss der Autorin endet in Die Leidenschaft der Anderen mit dem 17. Lebensjahr: Sie beschreibt, wie eine ihrer Freundinnen Selbstmord begeht, weil deren Bruder sie mit ihrem Freund vor dem Kino erwischt hat. Wir

199 Eine ähnliche Verhandlung von Identitätspolitik hält Erol Boran in seiner Geschichte des türkisch-deutschen Theaters und Kabaretts für das Schreiben und die kabarettistischen Aktivitäten von Şinasi Dikmen und Muhsin Omurca in den 1980ern fest: »Bezüglich der Türkendarstellung fällt auf, dass einer breiten unintegrierten (das heißt saufklärungsbedürftigen`) türkischen Masse stets einige restlos überintegrierte Individuen gegenüberstehen «. BORAN (2004): S. 214. 200 Für viele: RösCH (1992); WIERSCHKE (1997); BAUMGäRTEL, Bettina (1997): »Identitätsbalance in der Fremde. Der Beitrag des symbolischen Interaktionismus zu einem theoretischen Rahmen für das Problem der Identität in der Migrantenliteratur «. In: Denn du tanzt auf einem Seil, S. 53-70. 201 Das politische Denken in der Türkei erfährt besonders Ende der 1970er und in den 1980ern eine starke nationale Rahmung in Form einer »Türkisch-Islamischen Synthese«, wie diese auch die Beziehung Özakıns zu den beiden Figuren belastet.

202 ÖZAKIN (1989): S. 90. 
befinden uns an dieser Stelle der Biografie im Jahre 1959, und der direkt daran anschließende und letzte Absatz des Prologs springt 20 Jahre weiter. Zuvor ist die Abfolge der Absätze nach den Lebensjahren der Erzählerin vom vierten bis zum 17. Lebensjahr strukturiert. Ihr Leben von 18 bis 38 bleibt unerwähnt. Die »Kleine Autobiographie« schließt mit dem 12. September 1980, dem dritten Militärputsch in der türkischen Geschichte - ein Tag, den sie ironisch als den Tag beschreibt, an dem »die Generäle in Atatürks Republik die Macht [ergreifen], um sie vor der Zerstörung zu bewahren « und nach deren politischer Diktion Frauen und Männer nun mit ihrem Herzen, ihrem Körper und ihrem Verstand zu Soldaten werden müssen, »um unser Vaterland zu schützen «. ${ }^{203}$

Dass dieses Ereignis für einen biografischen Bruch steht, verdeutlicht eindringlich der Übergang vom Prolog zum ersten von 21 Kapiteln in diesem autobiografischen Roman. Nicht etwa ein familiärer Zwist löst ihn aus, sondern eine militärische Intervention zum Wohle des Volkes. Özakıns Autobiografie wird nach diesem Prolog, ohne jegliche Schilderung, wie sie in die Bundesrepublik Deutschland gekommen ist, in Berlin Jahre später weitererzählt. Diese Bewegung ähnelt Başers Anliegen, in seinem ersten Film eine Frau in der Türkei einschlafen und in Deutschland wieder aufwachen lassen zu wollen. Aber auch Yüksel Pazarkaya setzt ohne Umschweife, ohne den Weg der Familie Balta nach Deutschland darzustellen, in der Familienserie UnSERE NACHBARN, Die BALTAS mit dem Leben der türkischen Familie in der kleinen Wohnung in einer deutschen Stadt zu Beginn der 1980er Jahre an. ${ }^{204}$ Der Teil von Özakıns autobiografischem Roman, der in Deutschland spielt, beginnt mit dem Namen und der Figur Johannes, der für die Ich-Erzählerin in Berlin als Lektor des Buntbuch-Verlags eine einmonatige Lesereise organisiert. Zwischen ihr und ihm wird im Laufe des Romans eine Liebesatmosphäre entstehen, wie auch später zwischen ihr und Max. Man kann hier nur von einer »Atmosphäre« sprechen, weil sie mit keinem der beiden eine verbindliche Beziehung eingeht oder ein sexuelles Verhältnis unterhält. Zwar leitet die Autobiografie damit ein, dass sie sich kurz vor Beginn der von Johannes organisierten Lesereise nach 15 Monaten Beziehung von ihrem Partner Hans trennt, weil dieser heiraten wollte. Mit keinem weiteren Satz wird erwähnt, was in dieser Beziehung geschehen ist. Von dieser Lesereise an bis zum Ende des Romans Die blaue Maske bleiben die Beziehungen zu deutschen Männern und zu deutschen Frauen immer kurz vor der körperlichen Berührung stehen und verlieren sich dann in gedanklichen sich abgrenzenden Assoziationsketten. ${ }^{205}$ Ähnlich

203 ÖZAKIN (1980): S. 13.

204 PAZAKaYA (1983): S. 3.

205 In Hark Bohms Film YASEmin zeigt eine Sequenz eindrücklich das Signum des Verhältnisses der türkischen Frau zum deutschen Mann in der ästhetisch-politischen Bearbeitung in den 
wie in Dikmens Satiren kommt es zu Brüchen in der Kommunikation. Am Ende von Die Leidenschaft der Anderen ist es dann eine Frau, die Schriftstellerkollegin Diana im Literarischen Colloquium Berlin, mit der sie in einer möglichen Liebesbeziehung steht. In die Die Blaue Maske findet sich eine ähnliche Konstellation zwischen Frau und Mann. Dem Mann, dem die Ich-Erzählerin dort zu Anfang bei einer Lesung von ihr begegnet, und den sie über den ganzen Roman versucht, wieder zu treffen, war mit ihrem türkischen Pendant, Dina, verheiratet, die sie aus Istanbuler Zeiten kennt und damals versuchte, ihre äußerst unkonventionelle über kulturelle Codes hinausgehende Lebensweise nachzuahmen. Am Anfang von Die Blaue Maske erfährt die Erzählerin von ihrem Mann, dass Dina in einer psychiatrischen Anstalt verstorben sei. Dies erinnert an Güney Dals Roman Der enthaarte Affe, in dem die an seiner eigenen täglich erscheinenden Wandzeitung, an seiner täglich in der eigenen Wohnung stattfindenden Auseinandersetzung zwischen öffentlich und privat, den Protagonisten im wahrsten Sinne des Wortes zu einer Teilung seiner Person treibt. ${ }^{206}$

Die Leidenschaft der Anderen erzählt, abgesehen vom Prolog, von den Erfahrungen der Autorin auf einer einmonatigen Lesereise durch Deutschland. Städte, in denen sie in den Buchläden liest und die im Roman genannt werden, sind Wuppertal, Hamburg und Bielefeld. Sie liest aus ihrem ins Deutsche übersetzten Roman Preisvergabe (Genc Kız ve Ölüm) und aus dem in Deutschland entstandenen Erzählband Soll ich hier alt werden? Dass sie aus genau diesen Büchern liest, geht aus dem Roman selbst explizit nicht hervor. Die Erzählerin erwähnt nur, dass es sich um zwei ihrer Bücher handelt, die bereits auf Deutsch erschienen sind. ${ }^{207}$ Worum es in ihnen geht, wird nicht thematisiert. Die Autorin beschreibt sie als Begleiter und fremde Partner ihrer Reise. Ein Grund dafür, dass die Literatur nicht in der Literatur auftaucht, ist mitunter, dass es in den Lesungen nie um die Literatur ihrer Literatur geht, nicht um die Frage der Gestaltung, sondern immer um ihre Person als Türkin, auf politischer wie auf moralischer Ebene. ${ }^{208}$ Linke türkische Männer kritisieren, warum sie sich von der europäischen Frauenbewegung habe einnehmen lassen und nicht mehr wie früher über Arbeiter

1980er Jahren. Die intimste Szene zwischen dem deutschen Protagonisten Jan, der sich im Laufe des Films in die türkische Yasemin verliebt, und ihr, ist, als sich beide an Yasemins geschlossenem Fenster küssen, also die Lippen nur jeweils eine Fensterseite küssen, sich aber nicht berühren. Denn Jan darf zu Yasemin keinen Kontakt haben. Aber selbst diese Kusssequenz ist so arrangiert, dass Yasemin nicht dazu kommt, das Fenster zu öffnen, was eine klassische Liebesszene wäre. Dass es in Bohms Film auch nicht wirklich um die Liebe geht, wird sich später zeigen.

206 DAL (1988): S. 340.

207 Der Erzählband und der Roman sind beide 1982 auf Deutsch erschienen.

208 Vgl. hierzu: WieRSCHKE (1997): S. 184. 
und Streiks schreibe - und das, wo doch aktuell in der Türkei eine Diktatur herrsche und in Deutschland der Fremdenhass regiere. ${ }^{209}$ Der erste Schritt wäre doch, zuerst die sozialen und ökonomischen Probleme zu lösen; danach könne man sich immer noch der Frauenthematik widmen. ${ }^{210}$

Dass diese Kritik nicht ganz unbegründet ist, zeigt sich, als die Ich-Erzählerin an anderer Stelle festhält, dass sie, wenn sie einen linken Türken treffe, immer mit ihrer Vergangenheit mit der türkischen Linken abrechne, die sie seit zwanzig Jahren kenne. ${ }^{211}$ Sie stellt zwar damit auch ihre eigene Identität und ihre Vergangenheit immer wieder in Frage, aber es geht ihr darum, sich selbst neu kennenlernen zu wollen. Diese Suche definiert sie als ihre neue Sozialisation. ${ }^{212}$ An einem anderen Abend fragt sie ein konservativer Türke, wie sie als »türkische Frau « allein in Berlin leben könne. ${ }^{213}$ Und als sie Johannes bei ihrer ersten Lesung umarmt, weil er ihr türkische Süßspeisen mitgebracht hat, bemerkt sie aus ihren Augenwinkeln, »wie zwei schnurbärtige, dunkelhäutige Männer den Buchladen betreten. Es sind Landsleute ... ıwas werden sie jetzt wohl denken?`, fährt es mir durch den Kopf «. ${ }^{214}$ Aber auch auf deutscher Seite fällt sie auf und sorgt beispielsweise selbst bei Max für Erstaunen: ${ }^{215}$ »Ich wecke lediglich Neugierde, oder gebe Informationen über dieses seltsame Thema stürkische Frau in Deutschland`«, hält die Erzählerin summierend ihre Erfahrungen bei den Lesungen fest. ${ }^{216}$ Ihr eigenes Anliegen sei es hingegen, ein Individuum zu sein, jede Art von »ObjektSein $\aleph^{217}$ abzulehnen und »dennoch als Teil in einer Gemeinschaft leben [zu] können «. ${ }^{218}$ Ein vergleichbares Verhältnis skizziert aus integrationstheoretischer Perspektive auch Georg Elwert zwischen individuellem Bewusstsein und Gemeinschaft. Allerdings ist die Kultur der Herkunft bei Elwert Teil der Lösung, während sie bei Özakın Teil des Problems ist. Allein die hier aufgezeigten Beispiele aus

209 ÖZAKIN (1983): S. 40.

210 Dass dieser Wandel nicht nur die Literatur von Frauen türkischer Provenienz betrifft, sondern auch beispielsweise den Roman Bitte nix Polizei von Aras Ören und dessen Protagonist Ali Itir, wird an anderer Stelle in diesem Buch noch thematisiert. In jedem Fall stehen dort auch nicht mehr explizit die sozialen und ökonomischen Probleme im Vordergrund, sondern vielmehr die Anerkennung durch Pass und Person. Vgl. ÖREN (1981).

211 Es sind die zwanzig Jahre, die im Prolog keine Erwähnung finden.

212 ÖZAKIN (1983): S. 76.

213 Ebd., S. 53.

214 Ebd., S. 19.

215 Ebd., S. 53.

216 Ebd., S. 49.

217 Ebd., S. 68.

218 Ebd., S. 70. 
Özakıns Roman zeigen, dass das Darstellen eine Frage des Vertretens geworden ist und nicht mehr eine des Zeigens.

Es sind nicht allein die Zuschreibungen und Gegenzuschreibungen, die in Özakıns Roman permanent auftauchen, eine Redundanz konstituieren und für einen unendlichen Dialog - oder in Mickschs Worten für eine »ständige Kommunikation ${ }^{219}$ - stehen, die das Repräsentationsproblem durchweg dokumentieren. Während bei Elwert und Micksch Dialog und Kommunikation jedoch die Grundlagen für ein gelingendes Zusammenleben darstellen, sind sie für Özakın das eigentliche Problem bei der Neuausrichtung von Individuum und Gemeinschaft. Dazu zählt auch die Tatsache, dass Özakın zu Anfang des Romans von der deutschen Ausländerbehörde keine Verlängerung ihrer Aufenthaltsgenehmigung bekommt. ${ }^{220}$ Auf diese De-Legitimierung ihres weiteren Aufenthalts in Deutschland folgt die Lesereise, die von unzähligen Ortswechseln geprägt ist. Die Ausländerbehörde ist auch in Die blaue Maske ein begleitendes und letztlich konstitutives Thema. ${ }^{221}$ So stehen neben den Beschreibungen um den Kampf um Repräsentation, die die Lesungen gar nicht erst zur Lesung werden lassen, der Mangel an staatlicher Legitimität und der mit jedem Kapitel einsetzende Ortswechsel der Akteurin, die ihren Aussagen materielles und faktisches Gewicht verleihen. ${ }^{222}$ Der Mangel an Zugehörigkeit und dass man weder als individuelle noch als soziale Person aufgenommen wird, geben dem Roman eine intensive und redundante Struktur, die auch das Projekt einer modernen und postmodernen Autobiografie konterkariert. Denn weder steht klassisch die Entwicklung einer Person im Vordergrund, noch eine spielerische Art zu zeigen, dass jeder Akteur

219 MicкSCH (1984): S. 9.

220 In Jeanine Meerapfels Dokumentarfilm kommt die Ausländerbehörde auch vor: In einer Aufnahme sehen wir im Büro der Anmeldestelle der Behörde ein großes Plakat an einer Wand mit dem großen Statement, dass sich Deutsche und Ausländer viel zu sagen hätten (»Wir haben uns viel zu sagen«). Doch spiegeln die Sequenzen im Film eher das Gegenteil als die Erfüllung dieses Slogans. Die Begegnung von Deutschen und Türken ist blockiert. Siehe hierzu: MEERAPFEL (1985).

221 ÖZAKIN (1989): S. 73.

222 Im Gegensatz zu diesen prekären Aufenthaltszuständen wird die Türkei in den Dokumentationen von Akçam, Gür und Geiersbach als Territorium und Land vorgestellt. Ziel und Vorgehen vieler türkischer Gastarbeiter ist in diesem Zusammenhang auch der Erwerb von Grund und Boden oder eines Hauses in der Türkei. Siehe hierzu für viele: GöREN (1979); GeIERSBACH, Paul (1982): Bruder, muß zusammen Zwiebel und Wasser essen! Eine türkische Familie in Deutschland, Berlin: Dietz, S. 87. Auch in den ästhetischen Reflexionen wie 40 QM Deutschland, ABSCHIED vom faLSCHEN PaRAdies oder Yasemin taucht die Türkei in den Rückblenden oder Bildern immer als ein Territorium auf. 
ein »diskursiver Effekt « ${ }^{223}$ ist, dem nur die Bastelei der eigenen Biografie bleibt oder das Spiel damit, das keine Herkunft kennt. Ebenso wenig geht es um ein authentisches Tagebuch, das aus dem Alltag heraus migrantisches Leben in der Bundesrepublik dokumentiert. Entgegen dieser Ausrichtungen stehen in Özakıns Literatur vielmehr der Anspruch auf das Recht auf Repräsentation und der Kampf im Vordergrund, obwohl die Autorin selbst diese Sprecherposition, den Zwang, sich als Türkin zu artikulieren, als lächerlich empfindet. Die »diskursive Zwickmühle«, die Özakın beschreibt und ihre Romane so als ein Bemühen um Repräsentation darstellen, ist kein postmodernes Wahrheitsspiel. Einen identischen Ausgangspunkt hat Gayatri Spivaks bekannter und wirkmächtiger Text Can the Subaltern Speak?. Darin distanziert sich die Autorin von Theoretikern wie Michel Foucault und Gilles Deleuze, die für sie durch die Hintertür ein stabiles sprechendes Subjekt wieder einführen, nämlich sich selbst als die Darsteller des Endes der Repräsentation. ${ }^{224}$

Dass Repräsentation zumindest für Özakın nicht enden kann, zeigt das ungewöhnliche und paradoxe Verhältnis von Zwang, Dagegensprechen und nicht wirklich Ernst-genommen-werden in Özakıns Autobiografie. Sie zeigt Disparata auf, denen die kommunikative Bindung fehlt. Dasselbe gilt für Spivaks Text, in dem sie zwar konstatiert, das aufgrund der »diskursiven Zwickmühle« der Repräsentation, in der sich der Subalterne befindet, er nicht wirklich sprechen kann, er aber dennoch darüber weiterspricht. Dass dieses Weitersprechen im Kern keine soziale Praxis ist, sondern zwischen Darstellen und Vertreten hin und her pendeln muss, stellen die Reflexionen der 1980er Jahre als zentrales Problem dar. Und weil diese Repräsentation nicht vorhanden ist, haben wir es hier erneut mit einer epistemischen Gewalt zu tun, die in Özakıns Literatur von der türkischen Seite mitbestimmt wird. Eine ähnliche Perspektive nimmt auch Şerif Görens Film PoLIzEI ein. Auch hier ist die Bindung blockiert, weil eine organisierende Kategorie fehlt. Die Zukunft ist daher für Özakın eine »verschlossene Tür«; ${ }^{225}$ gegen Ende

223 Sмітн, Robert (1995): Derrida and Autobiography, Cambridge: Cambridge University Press, S. 64 .

224 Siehe: SPIVAK (2007): S. 20.

225 Auch Jeanine Meerapfels Dokumentation beginnt mit Aussagen von Gastarbeitern in der Türkei, die ebenfalls in den 1980er Jahren zurückgekehrt sind. In der Regel haben sie zwischen dem 20. und 40. Lebensjahr in der Bundesrepublik gearbeitet und sagen nun, dass es für sie keine Zukunft mehr gebe. Äußerst interessant ist, dass sie mit »Zukunft « nicht direkt die berufliche meinen. Sie sprechen in leicht gebrochenem Deutsch sehr schnell von Identitätsfragen: dass sie in den 10, 15 Jahren in der Bundesrepublik Deutsche geworden seien, und jetzt wären sie wieder Türken. Aber so richtig klar sei ihnen jetzt nicht mehr, was sie seien. Auch Melek spricht weniger von beruflichen Aussichten in der Türkei, sondern vielmehr davon, dass sie jetzt endlich verstehen müsse, wer sie eigentlich sei. Sie habe in den 14 Jahren in Deutschland nicht gelebt, »davor wahrschein- 
ihrer Lesereise kommt es ihr so vor, als ob alle Orte »voll mit Wänden« wären. Damit resultiert die Fremdheit nicht aus Özakıns Viele-Orte-Schema, wie Maria Brunner angenommen hat. ${ }^{226}$ Problematisch ist vielmehr, dass die Orte keinen Bezug zueinander haben. ${ }^{227}$ Wenn es Başers Protagonistin darum ging, aus der Wohnung zu kommen, die verschlossene Tür hinter sich zu lassen, ist das eigentliche Thema in Özakıns autobiografischem Roman, den Zuschreibungsmaschinerien und -kontexten von deutscher und türkischer Seite zu entkommen. Das oben genannte Weitersprechen befriedet die Gewalt jedoch nicht, sondern sie erfährt im Gegenteil eine Kultivierung. Denn auch die Vertrautheit, die sie mit ihrer Kollegin Diana am Ende im Literarischen Colloquium Berlin verbindet, kann nicht nach außen dringen:

Ich weine angesichts des Sees, von dem ich genau weiß, daß es nicht das Meer ist. Diana fragt nichts, doch fühle ich mich gezwungen, ihre nicht gestellte Frage zu beantworten. [...] Im gleichen Augenblick fällt mir ein, daß ich am Ufer des Wannsees neben Diana, einer deutschen Dichterin, souverän bleiben muß und schiebe die schwere Tür in meinem Herzen wieder an ihre alte Stelle. ${ }^{228}$

Özakın setzt diesem Dilemma eine luzide Form der Projektion von Integration entgegen. Entgegen den inneren Schließungsprozessen gibt die Autorin zwei Hinweise, wie ein neues Verhältnis von Selbst und Sozialisation möglich wäre, auch wenn es in Die Leidenschaft der Anderen selbst nicht dazu kommt. Dadurch hofft sie, die innere Spannung, ihren »Zwiespalt von Innen und Außen«, den sie vor ihrer Migration nach Deutschland noch nicht kannte, schließen zu können. Dies könne zum einen über die deutsche Sprache gelingen, denn diese befinde sich noch außerhalb von ihr. Sie bekomme diese Sprache noch »nicht unter die Haut«: »Dabei möchte ich auch das Deutsche gern in mir haben. [...] Aber das kann noch Jahre dauern. Bis dahin werde ich mit dem Zwiespalt von Innen und Außen aus-

lich auch nicht«. Sie komme erst jetzt, kurz vor der Rückkehr, dazu, sich selbst kennenzulernen. Denn »ich kenne mich selber nicht«. Sie weiß zumindest, dass sie die Türkei als Land kennenlernen möchte. Das werde sie in jedem Fall tun, wenn sie zurück sei. Siehe hierzu: MEERAPFEL (1985). 226 Siehe hierzu: BRunNER, Maria E. (1999): „Daß keinem seine Gestalt bleibt, ist die treibende Kraft der Kunst. Migrationsliteratur von Aysel Özakın«. In: Sprache Literatur 30, 80, S. 47-61, S. 54 .

227 Vgl. KAPUTANoĞLu, Anil (2010): Hinfahren und Zurückdenken. Zur Konstruktion kultureller Zwischenräume in der türkisch-deutschen Gegenwartsliteratur, Würzburg: Königshausen \& Neumann, S. 158.

228 ÖZAKIN (1983): S. 119. 
kommen müssen«. ${ }^{229}$ Das Verhältnis von Fremdsprache und Körperlichkeit, das Özakın hier schon ankündigt, wird eines der zentralen Episteme der Literatur, des Films, der öffentlichen Debatten und Theorien der 1990er Jahren in unterschiedlichen Akzentsetzungen und Darstellungen sein. Als weitere Projektionen der Integration erwähnt Özakın die Zeit und das Alter. Als eine alte deutsche Frau auf einem schneeweißen Rad an ihr vorbeifährt, denkt Özakın: »[W]enn ich so alt bin wie sie, werde ich dann meinen Ausländerkomplex überwunden haben? « ${ }^{230}$ Diese mehrfach gebrochenen autokommunikativen Spiegelungen prägen auch den Roman Die blaue Maske, der trotz seiner fiktionalen Rahmung Ende der 1980er Jahre eine Bilanz ihrer Migrationsgeschichte in der Bundesrepublik zieht. ${ }^{231}$

Auf einer Lesung in Zürich lernt die Ich-Erzählerin einen Unbekannten kennen, der mit ihrer alten Freundin Dina verheiratet war. Sie erfährt von ihm, dass ihre Freundin vor Kurzem in einer psychiatrischen Anstalt in der Schweiz verstorben ist. Hauptanliegen der Erzählerin und Rahmenhandlung des Romans sind, den Unbekannten so schnell wie möglich wiederzusehen. ${ }^{232}$ Doch erst am Ende des Romans wird sie ihm auf dem Züricher Karneval begegnen. Ihr Handeln ist bis dahin von einer bemerkenswerten Unfähigkeit geprägt, ein Treffen zu arrangieren; sie ist unfähig, »einem Bewegungsimpuls zu folgen «. ${ }^{233}$

Da der Gedanke an den Unbekannten die Erzählerin erregt, wirkt es anfangs so, als würde dieser Roman eine interkulturelle Liebesgeschichte erzählen. Als Leser erfahren wir aber nichts über den Unbekannten, dafür viel über Dina und noch viel mehr über die Ich-Erzählerin, über die Autorin selbst. Nach der Begegnung mit dem Fremden wird der Leser per Rückblende in die Anfänge der 1970er Jahre zurückversetzt, also in die Zeit, die Özakıns Autobiografie zwischen Prolog und Romanbeginn ausgeblendet hatte. Die Erzählerin arbeitet zu dieser Zeit als Lehrerin in der Nähe von Istanbul. Ihr Beruf und ihre Ehe erfüllen sie nicht. Sie ist unruhig, beginnt zu schreiben. Ihren Beruf begreift sie als eine Lüge, weil sie mit der Vorbildfunktion als Lehrerin und Beamtin nichts anfangen kann. Ihr Leben sei schon zu Ende erzählt gewesen, bevor es überhaupt angefangen habe. Sie lernt Dina kennen, und ihr existenzielles Unbehagen wird größer: »Bei Tisch

229 Ebd., S. 44. Emine Sevgi Özdamar hält in ihrem vielbeachteten literarischen Debüt Mutterzunge fest, dass sie ihre Zunge in die deutsche Sprache gedreht habe und dabei glücklich geworden sei. Diese Aussage ist zugleich von einem poetologischen Konzept gerahmt, das die Autorin auf die Aussage folgen lässt und das die Diktion ihrer Literatur der 1990er auch bestimmen wird. Im folgenden Kapitel werde ich darauf näher eingehen. Siehe hierzu: ÖzDAMAR, Emine Sevgi (1990): Mutterzunge, Köln: Kiepenheuer \& Witsch.

230 ÖZAKIN (1983): S. 103.

231 Vgl. Rösch (1992): S. 111.

232 Vgl. KAPUTANOĞLU (2010): S. 163.

233 Ebd., S. 162. 
spürte ich wieder den Unterschied zwischen Dina und mir. Ich hatte meine Kindheit in einem der Tradition und der Religion verhafteten Randviertel verbracht und war als junge Frau nun Lehrerin in der Provinz. Dina dagegen ... « ${ }^{234}$

Auf die Auslassungszeichen folgt keine weitere Beschreibung von Dina oder dessen, was das traditionelle Leben vom modernen trennt. Seiten später schildert sie, wie Dina sie nach einer Heldin Tschechows Natascha nennt. Dina hilft ihr bei der Abtreibung ihres Kindes und will, dass sie bei ihr bleibt. Die Erzählerin ist einverstanden und von ihrer Antwort selbst überrascht. Gleichzeitig erhascht sie im Rückspiegel den Blick des türkischen Taxifahrers. »Es ist ein wütender und verächtlicher Blick. Dina redet weiter: ১Und dann gehen wir zusammen weg. Entweder nach Berlin oder nach Zürich`. « ${ }^{235}$ Danach springt die Erzählung wieder 15 Jahre in die Zukunft; die Erzählerin wartet in einem Bahnhofsbistro auf Dinas Mann. Es ist nicht klar, ob sie verabredet sind. Er taucht nicht auf, und sie will weiter versuchen, ihn zu finden.

In Die blaue Maske haben wir es mit den Suchbewegungen einer Ich-Erzählerin zu tun, die auf mehreren Ebenen gleichzeitig stattfinden: von traditionellrückständigen und modern-fortschrittlichen Lebensformen über das Recht auf Repräsentation bis hin zur Suche nach der eigenen Sozialisationsgeschichte. Zwischen dem dritten und letzten, 15. Kapitel, die auf die beschriebenen Szenen aus Zürich und Istanbul folgen, werden die Türken in Deutschland, respektive in Berlin, beschrieben. Die Ich-Erzählerin schildert ihr Verhältnis zu türkischen Männern, $\mathrm{zu}$ türkischen Intellektuellen und nicht zuletzt zu Dina. In diesem Prozess ist Dina von Anfang an eine stabilisierende, aber zugleich prekäre Instanz ihrer Beschreibungen. Wir wissen von Beginn an, dass sie in einer psychiatrischen Anstalt in Zürich sterben wird. Da es Dina von Berlin nach Zürich verschlagen hat, vermutet die Erzählerin, dass sie - wie sie selbst - vor dem Bild der Türken in Deutschland davongelaufen sein muss; vor diesem "groben und lächerlichen Bild, das nur eine Masse sah und nicht den einzelnen. Vielleicht war sie auch vor dem Anatolien in Berlin davongelaufen, einem Anatolien, das sich mit Arabeskenschnulzen, mit kleinen Mädchen in Kopftüchern, mit schnauzbärtigen Männern immer tiefer in Religion und Dörflichkeit begrub [...] «. ${ }^{236}$ Die Spannung zwischen Bild, Zuschreibung und Realität - in allen ist von Kollektiven die Rede -, die die Erzählerin hier schon andeutet, ist ein konstitutives Element für alle Themen in ihrem Roman. Ob die Türken in Deutschland oder in der Türkei dem Bild nun entsprechen oder vielleicht doch ganz anders sind, wird weder an dieser noch

234 ÖZAKIN (1983): S. 17.

235 Ebd., S. 21.

236 ÖZAKIN (1989): S. 10. 
an einer anderen Stelle im Roman geklärt. Wie in Die Leidenschaft der Anderen herrscht ein dilemmatisches Verhältnis von Repräsentation und Selbstverortung vor, das besonders für die Erzählerin, aber auch für ihr alter ego Dina gilt.

Im Tiergarten lagen junge Deutsche nackt auf dem Rasen in der Sonne. Eine Gebetskette an der Hand, trotz der Hitze im Anzug aus dickem Wollstoff und mit einer Schirmmütze, ging ein kleiner, dicklicher Mann, dessen Sprache ich sprach, mir fremder war als die jungen Deutschen, die ich damals noch nicht verstehen konnte. Dennoch schämte ich mich, weil er so roh und rückständig war, als wäre ich mitschuldig daran. Ich hatte ihm gegenüber meine Pflicht nicht getan, hatte ihm nicht beigebracht, wie man sich in der Fremde unter zivilisierten Menschen benahm. ${ }^{237}$

Ein anderes Beispiel:

In der Uhlandstraße gingen drei Frauen mit Kopftüchern vor mir. Sie trugen Plastiktüten; wie die Putzfrauen, die in Istanbul in die Häuser der Reichen gehen, um dort sauberzumachen. Sie unterhielten sich brüllend, als liefen sie nicht in Berlin, sondern in einer anatolischen Kleinstadt herum. Die einzigen, die sich wirklich in Berlin aufhielten, das waren Dina und ich. Wir mussten uns in Berlin rechtfertigen. ${ }^{238}$

Doch nicht nur die türkischen Dörfler in Berlin sind für Özakın ein Problem, auch die türkischen Intellektuellen, die sich vom Westen abgewendet haben. Sie bieten ihr bei Treffen und Begegnungen nicht mehr wie früher »Cognac oder

237 Ebd., S. 31. Szenen im Berliner Tiergarten oder im Kölner Park sind auch in den Filmen PolizeI und GuRbetçı ŞABAN wichtig. Der Vater des Straßenkehrers Ali Ekber hat Besuch von seinem Bruder aus der Türkei. In einer Sequenz picknicken sie im Tiergarten als Familie, und der Bruder kann es in der ganzen Sequenz nicht lassen, sich die leicht bekleideten deutschen Frauen anzusehen. Ekbers Vater versucht ihn zurechtzuweisen, dass man so nicht schauen solle. Doch dieser erwidert ihm nur, dass es eine fromme Tat sei, sich Ungläubige anzusehen. Weiter unbeirrt von der Zurechtweisung seines Bruders fragt er, wann er ihm denn endlich einmal die Sexshops in Berlin zeigen wolle. Ali Ekber, der dieses Gespräch wie zuvor die Zeitung lesenden Türken verfolgt, reagiert mit einem ähnlichen Gesichtsausdruck wie zu Beginn des Films. Er unterbricht, wie an anderen Stellen des Films, den Rhythmus der Komödie. Und im Unterschied zu Görens Film von 1979, ALMANYA ACI VATAN, werden wir hier keinen Sexshop von innen zu sehen bekommen. Siehe hierzu: GöREN (1988). Erwähnenswert ist auch, dass die Aussage des Bruders, dass es eine fromme Tat sei, sich Ungläubige anzusehen, eine Abwandlung der bekannten türkischen Redewendung ist, dass es eine fromme Tat sei, sich schöne Menschen anzusehen. Dass die schönen Menschen nun Ungläubige geworden sind, korreliert zum einen mit der »Christenkälte» in Örens Erzählung Bitte nix Polizei (1981) und zeigt zum anderen deutlich den Übergang von unserem ersten Leitsatz »Wir wollten alle Amerikaner werden« zum zweiten Narrativ »Wie lebt es sich als Türke in Deutschland?«.

238 ÖZAKIN (1989): S. 82. 
Whiskey« an, sondern nur türkischen Tee. Und in ihren Buchregalen stehen nicht mehr »dicht an dicht deutsche und englische Bücher, sondern Märchen und Mythen«. Sie reden ebenso wie die deutschen Professoren des Heidelberger Manifests nur noch vom >Volkı, und dass sie sich aus der Nachahmung des Westens lösen müssten. Sie müssten »mit ihrem Volk verschmelzen und ihren Platz im vorrevolutionären Kampf einnehmen «, sagt beispielsweise Musa. ${ }^{239}$ Er ist verheiratet, die ebenfalls verheiratete Ich-Erzählerin und er haben ein Verhältnis. Ihr türkischer Ehemann wird nach der Abtreibung nicht mehr erwähnt. Vor Musa möchte sie souverän und als »selbstständige« Frau auftreten und nicht als eine, »die auf ihre Ehre bedacht ist « ${ }^{240}$. Sie schläft mit ihm, ohne zu verlangen, dass er sich von seiner Frau trennt. »Er sollte sehen, wie ungezwungen ich mich verhalten konnte. « ${ }^{241}$ Maria Brunner bezeichnet dieses Problem bei Özakın lapidar als »eine Flucht vor weiblichen Ritualen «. ${ }^{242}$

Doch ist die Position der Frau bei Özakın komplexer. Denn mit dem türkischen `Volkı kann die Ich-Erzählerin nichts mehr anfangen. Stattdessen gibt Dinas Vater eine Richtung vor, indem er die Ideale der modernen Republik vertritt. Im Gegensatz zu den fanatischen Muslimen ist Dinas Vater fortschrittlich. »Die türkische Gesellschaft ist nicht gefestigt, sie hat noch nicht zu sich selbst gefunden, sie hat es noch nicht geschafft, eine zivile Gesellschaft $\mathrm{zu}$ werden«, lautet eine seiner Aussagen. Für ihn hat die Türkei keine Alternative zum Westen. ${ }^{243}$ Eine Szene aus der Mitte des Romans gibt auch eine idyllische Alltagsszene wieder, die jedoch nachts mit einem Selbstmordversuch Dinas endet.

\footnotetext{
Dina, zu Hause, sie saß in einem Zimmer, das sie sich mit ihrer älteren Schwester teilte, und lernte ein Gedicht von Goethe auswendig. Ihr Vater fragte die Mutter, warum sie Nudeln gekocht hätte. Junge Menschen brauchen mehr Proteine! Im Radio klassische türkische Musik: »Heute wandelte ich wieder im Garten meines Herzens, ich schaute dich an, du warst schön wie Mond und Frühling. «Ihr älterer Bruder stand auf, schaltete das Radio aus und legte Edith Piaf auf den neuen Plattenspieler. Es war ein Abend wie jeder andere. ${ }^{244}$
}

Der Bruder geht aus und trifft sich in Beyoğlu mit seinen Freunden, der Vater zieht sich den Pyjama an und liest Zeitung, die Mutter legt sich die Haare ein und kontrolliert danach die Hausaufgaben der Kinder, Dina putzt sich die Zähne. Im Flur sind an der Wand die Notizen des Vaters vermerkt: 1) geh früh ins Bett, steh früh

\footnotetext{
239 Ebd., S. 54.

240 Ebd., S. 38.

241 Ebd., S. 39.

242 BAUMGÄRTEL (1997): S. 60.

243 Ebd., S. 188f.

244 ÖZAKIN (1989): S. 75.
} 
auf und 2) verschiebe nichts von heute auf morgen. ${ }^{245}$ Nachts steht Dina auf, geht durch das Wohnzimmer, an einem Büffettisch und an einer bronzenen Atatürkbüste vorbei, findet im Bad Tabletten und schluckt eine nach der anderen. Später im Krankenhaus sagt sie, sie habe es getan, weil sie Lust darauf gehabt hätte und weil ihr Wohnung, Gasse und Schule zu eng geworden seien. ${ }^{246}$ Damals sehnt sich die Ich-Erzählerin wie Dina nach einem anderen Leben, sie allerdings gerade nach dem, das Dina bereits führt: »Ich wollte unten in der Stadt leben, in einer Etagenwohnung unter vornehmen, eleganten Menschen. « ${ }^{247}$ Sie wollte nicht mit Frauen zusammenleben, die auf ihren Kelims »saßen und sich lachend erzählten, wie ihnen der Mann gesagt hatte, Mädchen, komm, zieh dir die Unterhose aus «. ${ }^{248}$

Für sie geht es um ein anderes Verhältnis zwischen Mann und Frau, eines ohne Erregung. Sie entdeckt dieses andere Verhältnis in einem Meditationskurs in Zürich. ${ }^{249}$ In einer Übung legen sich die Teilnehmer auf Wolldecken und umarmen sich. Özakın beschreibt diese Umarmung als eine noch nicht erprobte neue Art sozialer Beziehung. Sie sieht nicht nach der Umarmung zweier Liebender aus, »ist aber auch anders als die zweier Geschwister«. Es ist ein »Nahsein [...] ohne Erregung «. ${ }^{250} \mathrm{Im}$ Gegensatz dazu steht die Erinnerung an eine türkische Hochzeit, als Verwandte und Bekannte sie auffordern, mit ihnen zu tanzen.

Diese erzwungene Körperlichkeit auf der türkischen Hochzeit wird kontrastiert mit spontanen Kontaktgeschichten Dinas, die etwa mit einem fremden Mann im Kino Händchen hält. Außerdem versucht die Ich-Erzählerin, ihren türkischen Geliebten von etwas zu überzeugen, das sich jenseits von Politik und Sex bewegt. „Sie weiß aber selbst nicht, was das sein könnte. ${ }^{251}$ Im letzten Kapitel, das im Züricher Karneval spielt und in dem sie Dinas Mann endlich trifft, kommt Özakın die Erkenntnis, dass sie ohne eine Maske nicht zu sich finden könne. Sie sei vor ihrer Familie davongelaufen, vor ihrem Beruf, vor Anatolien, vor ihrer Religion, vor den Soldaten, vor den Männern, vor Berlin, sinniert die Protagonistin in einem inneren Monolog. Sie habe sich von allem zurückgezogen, sich

245 Ebd., S. 76.

246 Ebd., S. 77.

247 Ebd., S. 79.

248 Ebd.

249 Dieses Kapitel ist wie ein weiteres, in der das Verhältnis der Ich-Erzählerin zu Musa beschrieben wird, in der türkischen Version des Romans nicht enthalten.

250 In Hark Bohms Film YASEMIN, dem wir uns analytisch noch genauer zuwenden werden, lernen sich Yasemin und Jan beim Karateunterricht kennen. Körperliche Erregung spielt in dieser interkulturellen Liebesgeschichte keine Rolle. Dennoch ist auch diese Erzählung von einer kommunikativen Störung bestimmt.

251 ÖZAKIN (1989): S. 45. 
»in ein Gefängnis gesperrt, in ein düsteres, enges Zimmer «. ${ }^{252}$ Und das alles, weil sie anders sein wollte als Dina, um sich »ihr Ende zu ersparen«. Indem sie aber durch das Schreiben Dina besser kennenlernt, entdeckt sie sie in sich selbst. Und auf dem Karneval zwischen »Fackeln, Trompeten, Tanzenden erscheint mir Dina als die einzige Maske, die ich [...] aufsetzen kann «. ${ }^{253}$ Später, als sie die titelgebende blaue Maske wieder absetzt und Emils, das Gesicht des Unbekannten, streichelt, an diesem Gefallen findet und ihm zulächelt, lächelt er nicht zurück. Er ist »regungslos und starrt aus leeren Augen wie ein Denkmal in die Ferne«. Sie geht in ihr Zimmer, packt ihre Sachen und läuft auf die Straße. Dabei sieht sie einen »dunkelhäutigen, kleinen dicken Mann im orangefarbenen Overall, einen Ausländer«, die Straße kehren. Sie grüßt ihn. Er hört sie nicht. ${ }^{254}$

Auch wenn sich viele Möglichkeiten zu Liebe und Kontakt bei Özakın ergeben, gelingt die Organisation einer sozialen Einheit durch Vertrauen oder Liebe in beiden Romanen nicht. Es dominiert hingegen eine Struktur verfehlter Begegnungen, obwohl Özakın selbst und ihre Protagonistinnen in beiden Romanen mit dem Grad ihrer Bildung, ihrer Profession und Kontaktsuche westlicher und »integrationswilliger « nicht sein könnten. ${ }^{255}$ Aus integrationstheoretischer Perspektive ist sie und sind ihre Akteurinnen Gegenfiguren zu Başers Protagonistinnen. Aber auch im Einsatz von Orten unterscheidet sich die Literatur Özakıns evident von Tevfik Başers Filmen. Während in den Filmen alles auf 40 qm oder in einem Gefängnistrakt sowie den jeweils dazugehörigen Innenhöfen stattfindet, wechseln die Lokalitäten in Özakıns Romanen in kurzen Kapitelfolgen. Von Bahnhöfen zu Buchläden und von dort zu fremden Wohnungen und Hotelzimmern in Die Leidenschaft der Anderen, oder von Städten wie Zürich, Istanbul und Berlin im Roman Die blaue Maske.

Dennoch ist die Integration nach und in Deutschland trotz der transnationalen Mobilität ebenfalls blockiert. Grundlage dafür ist eine innere Dynamik der Repräsentation, die an die Stelle der Darstellung, wie sie noch in den 1960er und 1970er Jahren zu finden war, die Vertretung rückt. Orte und Bewegung treten nun in den Hintergrund zugunsten eines Narrativs, in dem nicht mehr sozialpolitische Fragen, Beobachtungen und Praktiken im Vordergrund stehen, sondern

252 Ebd., S. 162.

253 Ebd.

254 Ebd., S. 196.

255 Die Aussage, dass die Türken integrationsunwillig seien, ist in den öffentlichen Debatten der 1980er Jahre sehr prominent. Siehe hierzu: RaueR (2013): S. 70. Thilo Sarrazin hat diese Behauptung vor einigen Jahren für Muslime in Deutschland wieder sehr prominent aktualisiert. Siehe hierzu: SARRAzIN, Thilo (2010): Deutschland schafft sich ab. Wie wir unser Land aufs Spiel setzen, Berlin: Deutsche Verlagsanstalt, S. 266. 
Fragen nach nationalen Prägungen und ein unendlicher nach innen gewendeter Dialog. Die Beschreibung der Lebensformen und Suchbewegungen, die sich darunter subsumieren, führen in Film und Literatur zu den identischen ästhetischen Schließungsprozessen: zu verfehlten Begegnungen, die auf innere Montagen oder auf assoziativ strukturierte innere Monologe zurückgehen. Sie dokumentieren einen Überschuss an Energie, der durch gesellschaftliche Regelbildungen nicht kanalisiert werden kann. Eine überaus eindringliche Metapher ist hierfür auch, dass selbst die Fragen ästhetischer Gestaltung nicht an die Oberfläche dringen können. Denn in keiner der vielen Vorlesesituationen, die Özakın beschreibt, kommt es dazu, dass wir auch hören (bzw. lesen), was sie liest. Die Bindung von Sprechen und Hören ist also auch im Gesamtkonzept des Romans unterbrochen.

Was Başers Filme und Özakıns Romane verbindet, ist die Crux der Repräsentation, wie sie beispielsweise Stuart Hall als Grundlage für eine Politik der Repräsentation festgehalten hat. Die dafür zentrale Fragestellung lautet nach Hall: Wie können bestehende hegemonial kulturalisierende Repräsentationsverhältnisse verschoben werden, wie eine Politik der Repräsentation verwirklicht werden, ohne dabei die »reale Heterogenität der Interessen und Identitäten zu unterdrücken «? ${ }^{256}$ In meine Kulturgeschichte und an diese Stelle übersetzt, könnte man fragen: Wie lässt sich eine Form der Gleichheit zwischen Deutschen und Türken artikulieren, ohne differente kulturelle Prägungen, die in den Filmen und Erzählungen mitverhandelt werden, gänzlich zu nivellieren oder auszuschließen? Oder ästhetisch und politisch zugleich gefragt: Wie kann die Kritik an Zuschreibungen als Ausdruck in Prozesse der Gestaltung überführt werden, die den Kontakt und das Zusammenleben neu rahmen könnten? In den Werken Başers und Özakıns findet ein Kampf um Repräsentationsverhältnisse statt, der in Şinasi Dikmens Satiren und in den türkei-türkischen Filmen zur türkischen Migration nach Deutschland ebenfalls ausgefochten wird. Tevfik Başer zielt mit seinen Filmen auf die Verschiebung von Repräsentationsverhältnissen:

Wenn deutsche Regisseure Filme - auch sehr gute Filme - über Türken machen, dann erzählen sie immer Geschichten drumherum, mit ihren Gefühlen, aber nicht aus der Mitte des Erlebens der Betroffenen heraus. Ich will versuchen, etwas von den Gedanken der Menschen aus einer den Deutschen fremden Kultur deutlich zu machen, an der ich zwar manches zu kritisieren habe, die ich aus ihrer Tradition heraus jedoch verstehe. Ich möchte, dass die Deutschen uns kennenlernen, denn Unbekanntes macht Angst und erzeugt Haß, wie an den Ausschreitungen gegenüber den Türken zu sehen ist. Deshalb schildere ich an

256 HALL, Stuart (2008): »Neue Ethnizitäten«. In: Kulturwissenschaft. Eine Auswahl grundlegender Texte, Frankfurt a. M.: Suhrkamp, S. 505-516, hier S. 510. 
einem besonderen Fall die Gastarbeiterverhältnisse in der Bundesrepublik, ohne in meinem Film Wohnung und Haus auch nur ein einziges Mal zu verlassen. ${ }^{257}$

Aysel Özakın hält in ihrem Gedichtband Zart erhob sie sich, bis sie flog, der zwischen den beiden von mir behandelten Romanen erschienen ist, fest: »Man will hier gerne / Von mir hören / Wie ich gebrochen habe / Die Kette / Des Islam. / Man will hier gerne / Von mir hören / Aufregende, atemberaubende / grausame Geschichten / Und man wendet den Kopf ab / Wenn ich alles in Frage stelle. « $^{258}$ Sowohl bei Başer als auch bei Özakın geht es um einen spezifischen Zugang zum Recht auf Repräsentation.

Stuart Hall hält für eine neue Politik der Repräsentation, die alte Repräsentationsverhältnisse verschiebt, drei Grundlagen für erforderlich. Erstens muss es einen Übergang von der Ausdrucksebene auf die Gestaltungsebene geben. Zweitens muss diese Gestaltung gänzlich unabhängig vom Staat möglich sein. Drittens brauchen diese beiden Prozesse einen kategorisierenden Überbegriff, der das zentrale Problem der Repräsentation minimieren oder vielleicht sogar lösen könnte: Wie lässt sich eine Politik entwickeln, »die mit den Unterschieden und durch sie arbeitet. Eine Politik, die imstande ist, solche Formen von Solidarität und Identifikation aufzubauen, die einen gemeinsamen Kampf und Widerstand ermöglichen, ohne jedoch die reale Heterogenität der Interessen und Identitäten zu unterdrücken ${ }^{259}$ Der explizite Verweis auf die Formen deutet an, dass das postkoloniale Anliegen nach Hall in seinem Kern ein ästhetisches ist. Sein Gelingen, die Verschiebung der Repräsentation und die Entstehung neuer Ethnizitäten, leitet Hall zum Großteil aus fiktionalen Werken ab. ${ }^{260}$ Den identischen Mechanismus der Theoriegenerierung finden wir in Homi Bhabhas bekannter Publikation Location of Culture. ${ }^{261}$

Wenn wir uns die Dramaturgien, Assoziationsketten und mehrfachen Kommunikationsebenen in Özakıns Literatur und Başers Filmen anschauen, finden wir keinen geraden Weg vom Ausdruck zur Gestaltung, keine Emanzipation vom Staat und auch keinen kategorisierenden Überbegriff, der den Protagonis-

257 MundZEcK, Heike (1986): »40 qm Deutschland - Ein türkischer Regisseur drehte in Hamburg einen Kino-Film über eine Gastarbeiter-Ehe«. In: Frankfurter Rundschau (18.01.1986).

258 ÖZAKIn, Aysel (1986): Zart erhob sie sich, bis sie flog, Hamburg: Galgenberg, S. 75.

259 HALL, Stuart (1994): »Neue Ethnizitäten«. In: ders.: Rassismus und kulturelle Identität. Ausgewählte Schriften 2, Hamburg: Argument, S. 15-24, hier S. 19.

260 Ebd.

261 Dort sind es vor allem Werke von Autoren wie Toni Morrison, Salman Rushdie und Nadine Gordimer. Siehe hierzu: BнAвHA, Homi (1994): „Dissemination. Time, narrative and the margins of the modern nation «. In: ders.: The Location of Culture, New York: Routledge, S. 139-170. 
ten $\mathrm{zu}$ einer Identifikation verhelfen könnte, die nicht national verfasst ist. Als organisierende Kategorien stehen in den 1980er Jahren im Kontext der Sprechweisen der und über die Migration nur national-kulturelle Begriffe im Raum. So ist etwa die Bestimmung der Herkunft als Ausgangspunkt zentral. ${ }^{262}$ Selbst die Bezeichnung »Deutsch-Türke« als Bindestrich-Identität ist in den 1980er Jahren weder geläufig noch verbreitungsfähig - ihre Zeit wird erst in den 1990er Jahren anbrechen, zusammen mit der Literatur, den Filmen und den Theorien zum Transnationalismus, zum Multikulturalismus, zur Inklusion und schließlich zur Hybridität. ${ }^{263}$ Spätestens dann werden sich die hybriden Konstellationen von assimilatorischen Vorstellungen getrennt haben, die bei Park und Gordon noch zusammengehörten. Und als ob es dieses Spannungsfeld in Özakıns Literatur nicht geben würde, konstatiert die Forschung bisher, dass sie in ihrer Literatur Persönlichkeit zeige, dynamische Identitäten entwerfe, mit denen sie spielerisch

262 In dem niederschweligen Format Tag des ausländischen Mitbürgers (TAM) - ab 1983 Woche des ausländischen Mitbürgers (WAM) - des Austauschs und Kontakts zwischen Alteingesessenen und Ausländern setzt auch in den 1980er Jahren ein Wandel ein. Zum zentralen Ziel wird, »die verschiedenen Kulturen in eine Beziehung des gegenseitigen Gebens und Nehmens « im Einwanderungsland Deutschland zu bringen. Die einstigen Themen wie soziale Bedingungen, z. B. Wohnraum, Kontakte und Freizeit der 1970er Jahre, werden nun ersetzt durch Fragen nach der kulturellen Herkunft. Zentrale Begriffe dabei werden »kulturelles Erbe«, »Herkunft«, »Verstehen « und die »Nachbarschaft unterschiedlicher Kulturen«. In dieser Phase etablierten sich verstärkt Organisationsformen wie Ausländerbeiräte und Kulturvereine, durch die sich die ausländischen Mitbürger selbst vertreten konnten; diese förderten nun auch verstärkt die WAM. In ihren Programmen der 1980er Jahre fällt in diesem Zusammenhang die Häufung national-kultureller Abende oder Diskussionen über die Schwierigkeit der jungen zweiten Generation mit zwei Kulturen zu leben. Dennoch nimmt die Woche des ausländischen Mitbürgers mit ihrem Fokus auf Geselligkeit und gesprächsorientierte Formate der Kulturalisierung ihre Ernsthaftigkeit. Die Frage, »woher man komme«, war in diesem Zusammenhang stets ein Dialogöffner. Der Begriff des ausländischen Mitbürgers erfährt in dieser Dekade seine stärkste politische Entfaltung. Erstens, weil das kommunale Wahlrecht für Ausländer zum zentralen Thema wird und zweitens, die Begriffsbindung von fremd und zugehörig es den Ausländern ermöglicht, sich hinter diesem Begriff zu gruppieren. Doch trotz der kommunalpolitischen Frage blieb die WAM in den 1980er Jahren, eine Veranstaltung, bei der sich unterschiedliche Kulturen begegnen. Siehe hierzu: EzLI, Özkan (2020) S. 43-48. Auch Dolf Sternberger bestimmt mit Ralf Dahrendorf zusammen Herkunft und Zugehörigkeit als Grundlagen der demokratischen Reaktualisierung patriotischer Gefühle für die Verfassung. »Jedenfalls gilt, daß Menschen irgendwo hingehören müssen, bevor sie sich für weitere Horizonte öffnen können.« STERNBERGER (1982): S. 7.

263 Siehe hierzu: GLICK-SCHILLER, Nina (2004): „Pathways of Migrant Incorporation in Germany«. In: Transit 1:1, UC Berkeley Department of German, Article 50911 (16 Seiten); TAYLOR, Charles (1993): Multikulturalismus und die Politik der Anerkennung, Frankfurt a. M.: Suhrkamp; Cohn-Bendit, Daniel/Schmid, Thomas (1992): Heimat Babylon. Das Wagnis der multikulturellen Demokratie, Hamburg: Hoffmann und Campe. 
umgehe. ${ }^{264}$ Ihr gelinge, so Bettina Baumgärtel, eine Identitätsbalance, die sich in »Rollendistanz« und »Ambiguitätstoleranz« zeige. »Rollendistanz« meint dabei eine Kompetenz, »sich über die Anforderungen von Rollen zu erheben, um auswählen, negieren, modifizieren und interpretieren zu können «. ${ }^{265}$ Oder es wird festgehalten, dass durch ihre Literatur »neuartige Lebensentwürfe« aufgezeigt werden, die »neue interkulturelle Perspektiven« ermöglichen. Diese Öffnung und diese Wahlmöglichkeiten, die Baumgärtel hier konstatiert, habe ich in Aysel Özakıns Literatur nicht finden können. Ihre Akteurinnen und Akteure sind wie die Protagonisten in Başers Film vielmehr ganz im Gegenteil von einer besonderen Handlungsunfähigkeit bestimmt. Positiv gewendet entfalten diese Werke einen blockierten Zustand von Integration, ein Bemühen um Repräsentation, deren Nicht-Gelingen eng mit dem Ausschluss der sozialen Frage und der Unmöglichkeit von Alltag im Zusammenhang steht. Ihre besondere Leistung besteht also darin, die verfahrene und widersprüchliche Situation zwischen Sprechen, Praxis und Ort auch als eine solche zu zeigen und sich nicht einfach über sie hinwegzusetzen. Diese Darstellung einfach nur als Opfersituation oder Distanzlosigkeit zur Rolle zu beschreiben, ist analytisch fahrlässig und kann uns auch nicht erklären, warum der Drang zum Ästhetischen und Fiktionalen in den 1990er Jahren so groß wird. Es gibt in den 1980er Jahren erzählerisch keine interkulturelle Position, die den Widerspruch - zwischen In-Deutschland-Sein und Doch-nicht-in-Deutschland-Sein - auflösen könnte.

Die Definition der Rollendistanz steht in engem Zusammenhang mit klassischen Vorstellungen zur modernen Autobiografie, die die Autobiografieforschung selbst seit den 1970er Jahren zentral in Frage stellt. ${ }^{266}$ Hier wird sie als ein stabiles Narrativ in die Analyse einer Literatur eingeführt, die mehr Fragen stellt als Antworten gibt. Allein die Tatsache, dass der Roman Die blaue Maske weitaus autobiografischer ist als der eigentliche autobiografische Text Die Leidenschaft der Anderen von 1983, ist bemerkenswert. Interessanterweise ähneln sich auch die Zeitstrukturen der beiden Texte sehr. In beiden beträgt die erzählte Zeit 3 bis 4 Wochen. Im ersten ist es die Zeit der Lesereise, im zweiten die Suche nach dem Unbekannten. Beide Romane sind im Präsens erzählt. Die Gegenwarts- und Vergangenheitsebenen werden durch Orte zusammengeführt. Allerdings gehen diese Orte zueinander keine wirkliche Bindung ein, weil die eigentliche Bindung einer inneren Logik

264 BRUNNER, Maria E. (1999); BAUMgÄRTEL (1997); WiERSCHKe (1997); KAPUTANoǦLU (2010).

265 BAUMGÄRTEL (1997): S. 65.

266 DE MAN, Paul (1993): »Autobiografie als Maskenspiel«. In: ders.: Ideologie des Ästhetischen, Frankfurt a. M.: Suhrkamp, S. 131-146. Siehe auch: SCHAPBACHER, Gabriele (2007): Topik der Referenz. Theorie der Autobiographie, die Funktion `Gattung` und Roland Barthes `Über mich Selbst`, Würzburg: Königshausen \& Neumann, S. 124. 
folgt. Grund hierfür ist, dass die äußeren Suchbewegungen mit den inneren nicht zusammenkommen, die eine besondere »innere Dynamik« der Repräsentation auslösen. Sie kommen nicht zusammen, weil beispielsweise in Die blaue Maske Dina, als Trägerin von Unruhe und von Wissen über die Ich-Erzählerin, am Anfang des Romans schon verstorben ist. Özakıns Suche führt nicht zu einer neuen Identifikation und auch zu keiner neuen Sozialisation. Sie bleibt in einem Diskurs der Rechtfertigung stecken. Doch trotz dieser Suchbewegungen und des Bewusstseins, das Özakın immer wieder aufbaut, ist ihr Roman mit der Definition des Theoretikers Philippe Lejeune, was eine Autobiografie auszeichnet, nicht zu greifen. In seiner gattungsbestimmenden Arbeit Der autobiographische Pakt beschreibt er die Autobiografie als »eine rückblickende Prosaerzählung einer tatsächlichen Person über ihre eigene Existenz, wenn sie den Nachdruck auf ihr persönliches Leben und insbesondere auf die Geschichte ihrer Persönlichkeit legt «. ${ }^{267}$ Dieser Fokus auf die eigene Person und ihre Geschichte ist in Özakıns Texten vorhanden. Doch spielt in beiden Romanen der Status ihres Aufenthalts in Deutschland oder in der Schweiz, in gleichem Maße wie die Begegnung mit Fremden und vermeintlich Vertrauten, eine gleichwertige Rolle wie das eigene Selbst. In Die Blaue Maske geht es darum, ob die Genehmigung verlängert wird; in Die Leidenschaft der Anderen wird sie nicht verlängert. So liegt der gewisse Projektionsmangel in Özakıns Literatur - alle Orte sind voller Wände, die Zukunft ist eine verschlossene Tür -, auch daran, dass in der bundesrepublikanischen Ausländerpolitik der 1980er Jahre ebenfalls keine Projektion von Integration existiert. Es gilt weiterhin das Ausländergesetz von 1965, dessen Interpretation immer noch lautet, dass »die Bestimmung der politischen Entwicklung in der Bundesrepublik allein Sache der Deutschen « sei. ${ }^{268}$ Der Begriff der Integration findet in dieser Zeit nur in Form einer Abgrenzungsrhetorik Anwendung, die in den Ausländern die andere Kultur, aber nicht den Ankömmling sieht. Alle Möglichkeiten für ein Integrationsprojekt sind gekappt worden, als man damit begann, den Einwanderer als Ausländer zu bezeichnen. So kann kein prozessorientiertes Narrativ der Integration sich entfalten, das neue soziale Verknüpfungen ermöglichen und Biografien und Kontakte entstehen ließe. Ein nachweislich sehr wirksamer Indikator für diese Blockade steckt bereits in politischen Begriffen wie `Ausländerpolitikı oder `Ausländerbeauftragte`, die die politische Sprechweise der Migration und Integration der 1980er Jahre bestimmen. Denn bei der Verwendung des Begriffs `Ausländer` geht es darum, Ausländer von Inländern zu trennen und beide Kategorien erst zu schaffen. Der mehrdimensionale Gebrauch von >Auslän-

267 Lejeune, Philippe (1994): Der autobiographische Pakt, Frankfurt a. M.: Suhrkamp, S. 14. 268 HeIne, Regina/MARX, Reinhard (1978): Ausländergesetz mit neuem Asylverfahrensrecht, Baden-Baden: Nomos, S. 16. 
der` reguliert Grenzen. Letztlich geht es in einer Ausländerpolitik nicht darum, die Situation von Ausländern oder Inländern zu verändern, sie in einen transformativen Prozess einer Entwicklung zu überführen. ${ }^{269}$

So sind die von Hall genannten Aspekte für eine gelingende Politik der Repräsentation in Özakıns Literatur und in Başers Filmen durch eine nicht endende Auseinandersetzung ineinander verkeilt. Sie können nicht in einer Erzählung mit Anfang, Mitte und Ende entzerrt werden. Dort, wo eine solche Erzählung entsteht, mündet sie wie in Başers Abschied vom falschen PARAdIEs in eine Assimilationsgeschichte. Dieser Zustand ist die Grundlage für Başers Bilder und Özakıns Beschreibungen. Der Hauptgrund für diese Verkeilung liegt zum einen darin, dass in den 1980ern in Deutschland das bestimmende gesellschaftspolitische Narrativ lautet, wie es sich als Türke in Deutschland lebt. Zum anderen entsteht die Verkeilung, weil an die Stelle der Beschreibungen von Sozialisationsprozessen politische und kulturelle Ordnungen getreten sind. Die politische Epistemologie, die diese Form der Beschreibung der Migration und ihrer Folgen zusammenhält und stabilisiert, ist die klare und kulturalistische Trennung von Herkunfts- und Ankunftsort. Dass diese Perspektive jedoch nicht einfach eine deutsch-türkische ist, sondern auch eine deutsche auf die Folgen der Migration nach Deutschland, zeigt neben Başers Film der bekannteste Film der 1980er Jahre: YASEMIN von Hark Bohm. Die Analyse dieses Films und seiner damaligen Rezeption wird noch zeigen, dass sich bei aller Interkulturalität, die in den 1980er Jahren auch heraufbeschworen wurde, die deutsche Seite im Zusammenhang der Migration jeglicher Selbstbestimmung und Selbstlegitimierung total entzogen hat. Auch wenn viele unterschiedliche Formen und Rahmungen intersubjektiver Situationen in Literatur, Film, in Theorie und öffentlicher Debatte gesetzt wurden, definiert sich das Deutsche in den 1980er Jahren in keiner einzigen dieser Situationen und Begegnungen zwischen Alteingesessenen und Einwanderern. Die deutsche Seite wird nicht zum Sprechen gebracht. Und was das für ein Sprechen der Interkulturalität heißt, wenn die andere Seite zwar da ist, sich aber als ein sichtbarer und sich gestaltender Akteur wie in Başers Filmen und Özakıns Prosa - nicht ins Spiel bringt, sehen wir in der Analyse von Hark Bohms Film YAsEmin. Sie führt hier ebenfalls zum Bruch von Handlungsfähigkeiten und markiert anschaulich den narrativen Wandel von den 1960ern, 1970ern zu den 1980ern von einer deutschen Seite.

269 Siehe hierzu auch: EzLI, Özkan/LAngenohl, Andreas/Rauer, Valentin/Voigtmann, Claudia (2013): »Einleitung«. In: Die Integrationsdebatte zwischen Assimilation und Diversität, S. 9-21, hier S. 10. 


\subsection{Blockierte Integrationen in Literatur und Film}

Hark Bohms YASEMIN war auf vielen Ebenen erfolgreich. 1989 bekam er den renommierten Bundesfilmpreis in Gold, im gleichen Jahr erhielten beide Hauptdarsteller den Bayerischen Filmpreis als beste Nachwuchsdarsteller, beim Deutschen Jugend-Video-Preis machte der Film den 2. Platz, und 1991 folgte schließlich der deutsche Fernsehpreis. ${ }^{270}$ Zugleich war YASEMIN ein Film, der von Anfang der 1990er Jahre bis Anfang des neuen Jahrtausends auf den Curricula der Mittel- und Oberstufe in deutschen Gymnasien stand und als beliebtes Lehrmaterial eingesetzt wurde.

Als pädagogisch »besonders wertvoll« wird an dem Film geschätzt, dass er alltagsnah das Leben der türkischen Einwanderer zeige und zugleich durch seine differenzierte Darstellung dieser Lebenswelt eine multiperspektivische Sicht auf ein bis dahin klischeebehaftetes Thema ermögliche. ${ }^{271}$ Er war ein Lieblingsfilm der Pädagogen, die in YASEMIN nicht den »Konflikt zwischen Liebe und Zwängen der Tradition (Familien-Ehre)« als den eigentlichen sahen, sondern »zwischen diesen und der Freiheit zur persönlichen Entwicklung «"272. So weckt dieser Film Empathien auf kultureller und auf individueller Ebene zugleich. ${ }^{273}$ Bei einer Befragung, wie dieser Film auf sie gewirkt habe, antworten Schüler Anfang der 1990er Jahre, dass er »sowohl emotional berührende Szenen wie auch abstrakte Themen« behandle. ${ }^{274}$ Interessanterweise ging der Regisseur Hark Bohm während der Postproduktionsphase seines Films ähnlich vor: Er zeigte ihn Schülern und Studenten und berücksichtigte ihre Kritik und ihren Zuspruch beim finalen Schnitt des Films. ${ }^{275}$

So pädagogisch das auch alles klingen mag, so betont Bohm auch, dass er mit YASEMIN keinen belehrenden Film gedreht, sondern vielmehr eine archaische Geschichte erzählt habe, ${ }^{276}$ in der ein Vater aus Angst um seine Tochter anfängt, sie vor Fremden zu schützen. Da sein Anliegen nicht kulturell, sondern existenziell orientiert ist, beinhaltet Bohms ästhetisch-politisches Credo auch

270 GeIs, Matthias (2002): »Perspektiven durch Kontraste in einem Klassiker des Fremderlebens. Yasemin von Hark Bohm«. In: Praxis Deutsch, 29/175, S. 35-43, hier S. 35.

271 Vgl. EHLERS, Ulrich (1993): »Yasemin. Ein Film für Zwölfjährige«. In: Teenie-Kino. Filmarbeit zwischen Kindheit und Jugend, hg. v. Bundesverband Jugend und Film, Frankfurt a. M.: Lang, S. 143-154. Siehe auch: GEIS (2002).

272 GEIS (2002): S. 36.

273 Ebd., S. 37.

274 EHLERS (1993): S. 145.

275 Bонм, Hark/WEINERT, Rita/Roth, Wilhelm (1988): »Plädoyer für das Erzählkino. Gespräch mit Hark Bohm«. In: epd Film, April 1988, S. 2-5.

276 Ebd., S. 4. 
keine explizit inter- oder multikulturelle Bestimmung. Denn der Künstler hat für ihn »in seiner archaischen Funktion [...] die Aufgabe, eine Gemeinde zu stiften, und in der Versammlung der Gemeinde wirst du aus deiner Angst, isoliert zu sein, nicht dazuzugehören, erlöst «. ${ }^{277}$ Nicht eine zu erreichende Zivilisation oder Gesellschaft, wie sie der klassische Begriff der Integration verlangt, steht hier im Vordergrund, sondern eine zu bildende Gemeinschaft; nicht das geregelte Auskommen miteinander, sondern ein intimes Verstehen des Anderen. Dieses Anliegen verfolgen auch Özakıns Protagonistinnen sowie die Dokumentationen von Dursun Akçam und Metin Gür.

Warum YASEMIN und die anderen genannten Produktionen dennoch als Beiträge des interkulturellen Verstehens für die deutsche Gesellschaft gelesen werden, hat zum einen mit den Inkohärenzen des Films, seiner Dramaturgie, und zum anderen mit Interpretationen zu tun, die auf der Verwechslung der sozialen Entitäten von Gemeinschaft und Gesellschaft beruhen. Diese Verwechslung finden wir auch bei Tevfik Başer, wenn es darum geht, eine Türkin auf die deutsche Straße zu schicken oder den Deutschen aus der Innenwelt der Türken berichten $\mathrm{zu}$ lassen. In jedem Fall ist jede Praxis, die gezeigt wird, doppelt codiert: ${ }^{278}$ Sie bewegt sich zwischen Moderne und Tradition und verhindert dadurch häufig jede Handlung. Diese Inkohärenzen siedeln sich im Film an zwischen Emotion und Abstraktion, zwischen Akteuren und Kulturen und generieren in diesen Zwischenwelten ein Narrativ der Integration, das sich strukturell in wissenschaftlichen und gesellschaftspolitischen Debatten der 1980er wiederfindet.

Wir schreiben das Jahr 1987. Jan (Uwe Bohm) hat sich in die 17-jährige DeutschTürkin Yasemin (Ayşe Romey) verliebt. Er wird irgendwann gegen Ende des Films Türkisch lernen, um ihr näherzukommen, um sie besser zu verstehen. Dabei weiß bis dahin jeder aufmerksame Filmzuschauer, dass dieses Vorhaben nicht wirklich nötig ist, denn Yasemin spricht im Film kaum Türkisch, dafür aber akzentfreies perfektes Deutsch, trägt kein Kopftuch, ist im Judo-Verein aktiv, will Kinderärztin werden und verhält sich, diese Attribute zusammengenommen, selbstbewusst und modern. Man könnte sie in kognitiver und struktureller Hinsicht als assimiliert bezeichnen. Dass Jan unter diesen Umständen Türkisch lernt, ist entweder als eine rein symbolische Geste gegenüber Yasemin zu verstehen oder aber hängt mit einer Form der Kulturalisierung und Folklorisierung zusammen, die auch in dieser Reflexion über die Folgen der Migration in Deutschland weit über die

277 Ähnlich zugehörig positioniert sich Günter Wallraff in seiner Dokumentation Ganz Unten, wenn er davon spricht und schreibt, dass die von ihm verwendete Erzählform »Ich (Ali)« immer in Verbindung zu anderen Schicksalen gesehen werden müsse. Siehe hierzu: WALLRAFF (1985): S. 428; vgl. auch: MERNISSI (1988).

278 HALL (2000): S. 94. 
Bedürfnisstruktur der Beziehung, aber auch über die der dargestellten türkischen Familie in YASEMIN hinausgeht - mit der Frage der Repräsentation als Frage der Vertretung.

$\mathrm{Zu}$ Anfang des Films wird der deutsche Protagonist Jan als neues Mitglied in einem Judo-Verein vorgestellt, in dem auch Yasemin trainiert und Mitglied ist. Um seinen neuen Freunden zu imponieren, schliesst Jan nach dem Training mit ihnen eine Wette ab, dass es keine »Braut« gebe, die er nicht innerhalb von zwei Tagen »auf der Matte« habe. Seine zufällige Wahl fällt auf Yasemin: Er dreht sich mit geschlossenen Augen und ausgestrecktem Arm im Kreis. Als seine Sportkollegen ihm sagen, dass Yasemin härter sei als Granit und er von ihr nicht mehr als ein »Guten Tag « erwarten könne, geht Jan nach draußen. Mit den zu einer symbolischen Pistole geformten Fingern zielt er auf den mit Yasemin und ihrem Vetter vorbeifahrenden blauen Ford Transit, und deutet damit an, dass er sie schon kriegen werde. Diese Form des überheblichen Auftritts wird Jan erst ablegen, nachdem er sich nach eigener Aussage in Yasemin verliebt hat.

Nach dieser Einstiegssequenz wird Yasemin auf dem Markt und danach in der Schule als eine selbstbewusst und souverän agierende Person gezeigt, die ihren türkischen Vetter, der in ihrer Gegenwart geradezu schüchtern wirkt, im Schlepptau hat. In diesen ersten Sequenzen des Films wird aber auch klar, dass Yasemin mit gewissen Einschränkungen leben muss. Ihre Lehrerin fragt sie, ob ihr Vater eingewilligt habe, was ihren Wunsch zu studieren betrifft, da sie noch nicht volljährig sei. ${ }^{279}$ Nach dem Schulunterricht auf dem Nachhauseweg zieht sie ihr Kleid nach unten, um ihre Beine zu bedecken, denn: Ihr Vetter wird sie gleich abholen, der sie auch auf den Markt begleitet hatte. Doch wartet noch ein anderer Mann auf sie, Jan, der ihr mit seinem Motorrad nachläuft und sie fragt, wann sie denn mal zusammen ausgehen könnten. Yasemin ist von seiner Anfrage geschmeichelt, versteckt sich jedoch bei der nächsten Gelegenheit in einem Hauseingang vor ihm. Noch nicht klar, ob aus Koketterie oder nicht, erhärtet sich der Verdacht, dass dieses Versteckspiel mit ihrem Vetter zusammenhängt, der ebenfalls auftaucht und sie sucht.

279 In der Fernsehserie UnSERE NACHBARn, DIE BALTAS des WDR von 1983 ist auch eine deutsche Lehrerin sehr darum bemüht, den Vater davon zu überzeugen, dass seine Tochter Inci weiter zur Schule gehen solle. Sie habe ihrer Ansicht nach Potential. Hinsichtlich dieser Frage ist Vater Habib sehr störrisch, denn er ist davon überzeugt, dass ein Mädchen für das spätere Leben keine sehr gute schulische Laufbahn brauche. PazARKaYA (1983): S. 9. Auch in Geierbachs Dokumentation stellt sich der Familienvater gegen die mögliche schulische Laufbahn der eigenen Tochter, allerdings nicht in Deutschland, sondern in der Türkei. Dort ist es der Schuldirektor, der Param davon überzeugen möchte, seine Tochter die weiterführende Schule besuchen zu lassen. In dieser Zeit ist Param bereits Gastarbeiter. Siehe hierzu: GEIERSBACH (1982): S. 98. 
Dieses gleich zu Anfang angelegte Spannungsfeld zwischen Familie und gestörter Kommunikation, zwischen gebundenen (Yasemin) und ungebundenen (Jan) Individuen, wird sich ab der Mitte des Films ausdehnen, wenn nach der Hochzeitsnacht von Yasemins älterer Schwester Emine (Nursel Köse) der Beweis ihrer Jungfräulichkeit ausbleibt. Bis zu diesem Ereignis ist das hier kurz skizzierte Spannungsfeld zwar vorhanden, bleibt jedoch noch verhandelbar. Denn weder der Vater noch der Vetter werden in der ersten Hälfte des Films als Tyrannen dargestellt. Sie zeichnen sich im Gegenteil in Bohms Darstellung durch eine besondere Fürsorge für Yasemin aus. ${ }^{280}$ So wird etwa Yasemins strenger und konservativer Onkel, der bei niemandem in der Familie beliebt ist, immer wieder von seinem Bruder Yusuf spielerisch beschwichtigt, wenn dieser Yasemins Engagement im Judo-Verein oder ihren Wunsch zu studieren, dem ihr Vater öffentlich auf der Hochzeit nachgibt, als für eine Frau unsittlich kritisiert. Judo lerne sie für ihre Selbstverteidigung, und daran, dass seine Tochter Kinderärztin werden wolle, sei nichts falsch, erwidert Yusuf seinem Bruder. Dieser herzliche verhandlungsoffene Raum zwischen Tochter und Vater verändert sich jedoch grundlegend, als der Nachweis von Emines (Yasemins Schwester) Jungfräulichkeit ausbleibt. ${ }^{281}$

280 In der Darstellung des türkischen Vaters und der Brüder Incis ist es Yüksel Parzarkaya hinsichtlich der Serie UnSERE NACHBARN, DIE BALTAS ebenso wie für Hark Bohm wichtig, den traditionellen türkischen Vater nicht als Bösewicht oder Tyrannen darzustellen. Habib verhält sich in der Serie »aus väterlicher Fürsorge« und besonders aus »moralischen Wertbegriffen« so, die ihn in der Türkei geprägt haben. Denn diese Traditionen »können nicht wie ein dreckiges Hemd abgestreift werden. Ebenso wenig können neue Sitten und Bräuche, neue Werte und Anschauungen wie ein neues Hemd angezogen werden.« Wie in Irene Hübners Dokumentation »... wie eine zweite Haut « Ausländerinnen in Deutschland zum Leben der türkischen Frauen in der Bundesrepublik stellen derartige Prägungen eine zweite Haut dar, die den sichtbaren Körper zum Stellvertreter der Kultur macht. Darin liegt auch ein Grund, warum Max und Aysel in Özakıns autobiografischem Roman Die Leidenschaft der Anderen nicht dazu kommen, sich als Personen zu begegnen oder einfach miteinander zu schlafen. Denn, wie gesagt, soll Max nicht denken, dass eine Türkin in der freien Zivilisation gleich mit jedem Mann ins Bett geht. Dieser kulturelle Mechanismus hat sich an die Stelle des sozialstrukturellen Mechanismus gestellt, wie wir ihn in den 1960er und 1970er Jahren feststellen konnten. Denn in Sanders-Brahms Film, in Örens Poem und Fassbinders Film haben die Türkinnen und die alte deutsche Frau Geschlechtsverkehr, ohne dass sie dabei eine kulturelle Grenze überschreiten würden. Siehe hierzu: PAZARKAYA (1983): S. 2, S. 5 und S. 9. Siehe auch: HüBNER (1985): S. 174-185.

281 Metin Gür gibt in seiner Dokumentation zu den Türken in Bergkamen ein Gespräch wieder, dass die Väter türkischer Mädchen in Deutschland nicht selten von anderen Türken beeinflusst werden, auf ihre Töchter aufzupassen, sie nicht lange zur Schule gehen zu lassen. Sie sollten besser zu Hause bleiben. Gür führte Gespräche mit 38 türkischen Mädchen im Alter zwischen 16 und 19 Jahren. Eines sagt, dass sein Vater es nicht mehr in die Schule schicken wollte. Nach den Gründen gefragt, antwortet es, dass ihre Bekannten in Bergkamen ihn beeinflusst hätten. »Mein Vater hat darauf gehört.« In der Türkei habe sie hingegen solch einen Druck der ande- 
In seiner Ehre getroffen, geht es dem Vater anschließend darum, den Rest seiner Familie vor einem weiteren Eindringen eines als feindlich verstandenen Außen zu schützen, das sich von der Lehrerin Yasemins über den Ort St. Pauli bis hin zu Jan erstreckt. Dieses neue Verhältnis zwischen Innen und Außen führt nun durch seine harte Grenzziehung zwischen der türkischen und deutschen Welt, die zuvor durchlässig, heterogen und handlungsoffen war und einen gewissen Handlungsspielraum zuließ, am Ende dazu, dass Yasemins Vater seine Tochter in die Türkei zurückbringen will, um sie zu schützen. ${ }^{282}$ Sein Versprechen, dass sie Kinderärztin werden und in Deutschland bleiben dürfe, kehrt sich ins Gegenteil. In der Schlusssequenz des Films bringen Vater und Neffe mit dem blauen Ford Transit Yasemin an einen unbestimmten Ort in Deutschland. Es ist Nacht, wir sehen türkische Männer um eine Feuerstelle tanzen; Männer, die Yasemin in die Türkei zurückbringen sollen. Doch Jan ist dem blauen Ford Transit mit seinem Motorrad gefolgt, Yasemin kann sich mit einem Messer in der Hand von den Männern entfernen und mit Jan fliehen. Mit deutlich sichtbarer Trauer, ihre Familie verlassen zu müssen, sehen wir Yasemin in der letzten Einstellung im Film in dunkler Nacht auf dem Rücksitz des fahrenden Motorrads, Jan umarmend: ein offenes, aber nicht verheißungsvolles Ende.

Der Prozess und narrative Verlauf, der nach dem ausgebliebenen Brautblut einsetzt und den Film in zwei unterschiedliche soziale Ordnungen trennt, beschreibt der Regisseur Hark Bohm selbst als eine nicht nachvollziehbare Abfolge, die ich

ren nicht erfahren. Dort seien sie eher locker gewesen, und sie hätte im Dorf auch kein Kopftuch getragen. Siehe hierzu: GÜR (1987): S. 61. Diesen Wandel stellt Alda, Params Tochter aus Geiersbach Dokumentation, besonders für ihre Mutter Rosa fest. Sie sei beispielsweise in der Türkei noch dafür gewesen, dass ihre Tochter weiter die Schule besucht. In der Türkei habe sie noch »modern gedacht «. »Erst in Deutschland ist die dann so geworden, strenger noch wie mein Vater." Geiersbach verwendet in Bruder, muß zusammen Zwiebel und Wasser essen! für alle Familienmitglieder Pseudonyme. Die Geschichte der Familie wird wie in vielen anderen Produktionen der 1980er Jahre äußerst kurz und sporadisch eingebunden. Am Anfang erfahren wir nur, dass Param 1964 allein nach Deutschland gekommen ist, damals alles in Ordnung und sein Chef mit ihm zufrieden gewesen sei; sogar so sehr, dass dieser sich wünschte, auch Params Bruder möge nach Deutschland zum Arbeiten kommen. Zwei Seiten später sind wir schon im Jahre 1974, in dem Param seine Familie nachziehen lässt und die Probleme auf einmal zunehmen. Zuvor hatte er eine Freundin in >Deutschstadt ` gehabt, was »so normal « war. Siehe hierzu: GEIERSBACH (1982): S. 22-25, S. 109.

282 Auch die sehr selbstbewusste Melek Tez möchte nicht, dass ihre Tochter wie die Deutschen wird. Sie bringt auch moralische Gründe vor, doch geht es bei ihr keineswegs darum, dass ihre Tochter ein Kopftuch tragen oder am besten das Haus nicht verlassen soll. Sie findet einfach, dass es den Menschen an Gefühlen mangelt und sie einfach nicht versteht, woher die Abneigung der Deutschen vor den Türken kommt. Ihre Tochter kehrt noch vor ihr in die Türkei zurück. Siehe hierzu: MEERAPFEL (1985). 
im Duktus dieses dritten Kapitels eine »epistemologische Gewalt« nenne. Bohm setzt dabei Jans Perspektive mit der der Mehrheitsgesellschaft gleich.

\begin{abstract}
Yasemin fühlt sich als Deutsche, denkt und handelt wie eine moderne, intelligente westeuropäische Frau. [...] Erst durch die Liebesgeschichte mit Jan erfährt Yasemin wirklich, was es heißt, eine türkische Tochter zu sein. Erst dann zerbricht das fragile Gleichgewicht zwischen türkischer Tochter und westdeutscher Gymnasiastin und wird zu einem offenbar unlösbaren Konflikt. Und wir müssen, wie Jan, staunend und hilflos mit ansehen, wie sich dieser Konflikt fast gesetzmäßig verschärft. ${ }^{283}$
\end{abstract}

Woher diese Gesetze kommen, die ein Regelwerk in diesen Film einbrechen lassen, wird für uns ebenfalls Jan herausfinden. Auf seiner Suche in Hamburg nach einem Deutsch-Türkischen Wörterbuch findet er zunächst kein Buch zu türkischer Grammatik oder zum Wortschatz, sondern einen Bildband. Das erste Bildmotiv, das wir sehen, ist die Blaue Moschee in Istanbul mit dem Wasser des Goldenen Horns im Hintergrund. Jan blättert weiter und das nächste Bild ist ein fotografisches Stillleben eines türkischen Dorflebens. Religion und Rückständigkeit gehören hier zusammen. ${ }^{284}$ Wir sehen im Vordergrund mehrere Frauen bei der Arbeit mit dem Rücken zur Kamera in traditioneller Dorfkleidung, in der Mitte links ein paar ebenfalls arbeitende Männer und im Hintergrund Häuser, die

283 Zitat aus: Bонм, Hark (1988): Yasemin, DVD, Zweitausendeins Edition 3. Identisch liest der Journalist Daniel Brunner, den ein Jahr vor YASEMIN erschienenen Dokumentarfilm ABdulLAH YAKUPOǦLU. WARUM HABE ICH MEINE TOCHTER GETÖTET?. Der Dokumentarfilmer Hans-Dieter Grabe gibt darin eindrücklich die Beweggründe des türkischen Vaters wieder, der am 22. März 1983 seine 24-jährige Tochter Perihan tötete. Daniel Brunner konstatiert in seiner Rezension zu Grabes Film am 11.10.1986 in der Frankfurter Allgemeinen Zeitung, dass man vom »behutsam dokumentierenden Film [...] zu recht erhoffen« kann, dass der Fernsehzuschauer begreift, welche Zwänge Abdullah zu dieser Handlung getrieben haben, welcher gesellschaftliche Druck von Seiten seiner Landsleute und welche »tragische Ausweglosigkeit« damit verbunden sei. »Und wie beiläufig«, führt Brunner weiter aus, »zeigt er auch die Hilflosigkeit, mit der alle Beteiligten auf diesen scheinbar unlösbaren Konflikt reagieren ...« GRABE, Hans-Dieter (2008): Dokumentarist im Fernsehen. 13 Filme 1970-2008. Beiheft. Berlin: absolut Medien GmbH, S. 23.

284 Dass der Islam oder die Religion in den 1980er Jahren keine eigene Bezugsgröße darstellt, zeigt sich nicht nur in dieser Filmsequenz. Auch in der wissenschaftlichen Forschung zur türkischen Migration nach Deutschland taucht der Islam kaum als eine analytische Kategorie auf. Siehe hierzu: Siehe hierzu: Boos-NüNNING, Ursula (1990): Die türkische Migration in deutschsprachigen Büchern 1961-1984. Eine annotierte Bibliographie. Wiesbaden: Opladen. Eindrücklich zeigt sich diese Wahrnehmung auch in der äußerst wirkmächtigen Schrift Orientalism von Edward Said aus dem Jahr 1978. Auch dort ist der Islam keine ausschlaggebende wirkmächtige Kategorie, sondern Teil des europäischen Orientalismus, der wie in der Abfolge des Bildbandes in Hark Bohms Film mit Rückständigkeit und Traditionalismus verbunden ist. Siehe hierzu auch: SAID, Edward (2003): Orientalism, London: Penguin Books. 
auf ein Dorf, höchstens auf eine Kleinstadt schließen lassen. Keine der gezeigten Personen blickt in die Kamera, alle sind mit ihrer Arbeit beschäftigt, haben ihren Ort und erfüllen ihre Funktion. Sie sind eingebunden in ein Kollektiv und stellen eine bestimmte Sozialstruktur dar - einerseits. Andererseits verbirgt sich diese rückständige Struktur hinter der türkischen Religion. Dabei dominiert im Film nicht der Verweis auf die andere Religion, sondern vielmehr auf die andere Nation, denn Jan ist, wie gesagt, auf der Suche nach einem türkischen Wörterbuch. ${ }^{285}$

Die Türkei ist in diesem Film ein Dorf, und auf diese Festlegung wird im zweiten Teil des Films immer wieder und stärker Bezug genommen: zum ersten Mal, als der Vater auf die Ehrverletzung reagierend damit droht, die ganze Familie in die Türkei zurückzubringen, falls sich Frau, Töchter und Vetter nicht mehr ehrenhaft verhalten sollten; eine Drohung, die niemanden aus der Familie erfreut. Als sich Jan und Yasemin danach heimlich auf einem Dampfer treffen, antwortet sie auf seine Frage, warum sie sich denn hier treffen würden, weil sie »das zufällige Produkt einer Kopulation zweier anatolischer Dorfmenschen« sei. ${ }^{286}$ Später wird Yasemins insgesamt eher schüchterner Vetter Dursun Jan bei einer Judo-Übung fast erwürgen, woraufhin ihn der Lehrer zurechtweist, dass er hier nicht in der Türkei sei. Diese Aussage verletzt die ebenfalls anwesende Yasemin, und sie wird auch ihr Verhältnis zu Jan beeinflussen.

Der Konnex von türkischer Gastarbeitermigration nach Deutschland und türkischem Dorf spielt in den zeitgleich entstandenen ethnologischen Arbeiten von Werner Schiffauer, besonders in seiner ersten Publikation Die Gewalt der Ehre. Erklärungen zu einem türkisch-deutschen Sexualkonflikt, eine zentrale Rolle. Wie bei Helma Sanders-Brahms' SHIRINS HochzEIT und der Studie Leben als Gastarbeiter von 1970 geht »die Gewalt der Ehre« von einem konkreten Gewaltdelikt aus, an dem Gastarbeiter beteiligt waren: Im Jahre 1978 wird eine junge Deutsche von mehreren türkischen Männern vergewaltigt. Schiffauer verweist darauf, dass diese Tat auf einem kulturellen Missverständnis zwischen der deutschen Frau und den türkischen Männern beruhe und nicht wie in den 1970ern auf unbefrie-

\footnotetext{
285 Das Dorf, die Herkunft der Türken, ist Bestandteil des Bildbandes, das in einem kulturellen Zusammenhang steht. Im Unterschied zu filmischen Aufnahmen des türkischen Dorflebens in Helma Sanders-Brahms' Film SHIRINS HochzEIT, aber auch im Unterschied zu türkei-türkischen Filmen der 1960er und 1970er Jahre, wie in Türkan Şorays Film DöNüş, sehen wir hier keine Feudalstruktur, keinen Grundbesitzer, der entweder mit einem Jeep oder auf einem Pferd zum Feld gelangt. Auch in der Familienserie UnSERE NACHBARN, DIE BaLtas gibt es wie in Yasemin keinen Großgrundbesitzer mehr, der das Leben Habibs in der Türkei erschwert und ihn mitunter zur Migration gezwungen hätte. Siehe hierzu: PAZARKAYA (1983): S. 2.
}

286 Вонм (1988). 
digten, nicht kanalisierten körperlichen Bedürfnissen oder auf den isolierten und kontaktarmen Zustand der Gastarbeiter in der Bundesrepublik zurückzuführen sei. Gehaltlos muss nach Schiffauer jede Reflexion über diese Tat bleiben und darüber hinaus jede Diskussion über Türken in Deutschland, wenn man ethnologische Kenntnisse über die türkische Dorfkultur ignoriere. Auf dieser Verbindung von türkischer Gastarbeitermigration nach Deutschland und türkischem Dorf basiert für ihn der clash of culture, dem die türkische Gastarbeitergeneration der ersten und zweiten Generation ausgesetzt war. ${ }^{287}$ Für den Ethnologen der 1980er Jahre war dieser clash vor allem ein Konflikt, der die Unterscheidung zwischen Innen und Außen, die auf dem Dorf für viele Migranten der ersten Generation üblich war, in sein Gegenteil verkehrte.

Im Dorf ist die Familie eine Produktions- und Konsumtionseinheit, die wesentlich auf den inneren Zusammenhalt angewiesen ist. Für jeden Akteur ist sie die Hauptreferenz und die politische Entität im Dorf, die es aus eigenem und sozialem Interesse zu schützen gilt. Die Struktur in der Familie im Dorf ist hierarchisch und von klaren Verhaltensregeln, besonders gegenüber dem männlichen Familienoberhaupt, geprägt. Nach außen hin ist es wichtig, dass diese Struktur der Achtung aufrechterhalten wird. Ein wichtiger Gradmesser hierfür ist die Unversehrtheit der Ehre (Namus). ${ }^{288}$ Denn im Herkunftsort Dorf weist besonders die Funktion und der Begriff der Ehre jedem Mann »einen Bereich persönlicher Integrität und Würde [zu], der die eigene körperliche Unversehrtheit wie die der Familienangehörigen umfasst «. ${ }^{289}$ So ist ein »ehrenhafter« Mann jemand, »der seine Frau zu verteidigen vermag, der Stärke und Selbstbewusstsein zeigt, politische, die äußere Sicherheit seiner Familie garantierende Fähigkeiten «. ${ }^{290}$ So

287 SCHIFFAUER, Werner (1983): Die Gewalt der Ehre. Erklärungen zu einem türkisch-deutschen Sexualkonflikt, Frankfurt a. M.: Suhrkamp, S. 103.

288 Die Funktion und die Reichweite des Begriffs `Ehre` ist im türkischen Kontext vielfältig. Dabei handelt es sich nach Başar Alabay um drei Begriffe, die semantisch ineinander greifen und das soziale Wirkungsfeld von Namus markieren. Der Begriff selbst bezeichnet einen Zustand, »der nicht erworben, sondern nur verloren werden kann«. Die Ehrhaftigkeit und Reinheit der Frauen in der Familie ist damit verbunden. Der Verlust der Ehre bedeutet nach innen wie nach außen den Verlust von sozialem Status. Sayg (Achtung, Ehre, Respekt) ist respektierendes und angemessenes Verhalten, das man "grundsätzlich älteren Personen« entgegenbringt. Sie muss immer wieder bestätigt werden, ist also eine aktive Handlung. Der letzte wichtige Begriff in diesem Zusammenhang ist Şeref (Ehre, Wert, Würde), die durch positive Eigenschaften wie »Großzügigkeit, Wissen, Reichtum, Macht und Einfluss« erworben werden kann. Sie stellt einen Wert dar. Siehe ALABAY, Başar (2012): Kulturelle Aspekte der Sozialisation. Junge türkische Männer in der Bundesrepublik Deutschland, Wiesbaden: VS Verlag, S. $96 \mathrm{f}$.

289 SCHIFFAUER (1983): S. 70.

290 Ebd., S. 64. 
ein Mann möchte auch Dursun in Başers Film 40 QM DeuTschland sein. Dieser aktiven Rolle des Mannes steht eine eher passive der Frau gegenüber, die »ehrenhaft « ist, wenn sie keusch bleibt. ${ }^{291}$ Jede Form des sexuellen Austauschs außerhalb der Ehe verletzt nicht nur die Ehre der Frau, sondern auch die der männlichen Mitglieder der Familie. ${ }^{292}$ Das Selbstverständnis des Mannes ist nach außen von der Unterscheidung zwischen stark und schwach bestimmt und die der Frau von der Dichotomie zwischen rein und unrein. ${ }^{293}$

Die Achtung, die jede Familie einer anderen zollt, erfolgt nach den Verhaltenscodes reziprok und garantiert eine friedliche und solidarische Nachbarschaft. Wenn jedoch die Grenze der Ehre und Achtung verletzt wird und es zu Konflikten kommt, werden diese entweder über die staatlichen Gerichte geschlichtet oder aber, was häufig der Fall ist, über die gemeinsame Religion, den Islam. »Die Klage, dass vom Islam nichts mehr ıgeblieben sei` (Islamiyet kalmadı burada), wird im Dorf immer dann laut, wenn das Gemeinwesen in einzelne, nur auf die eigene Ehre bedachte Gruppen zu zerfallen droht. «"294 Dieses Innen (Familie) und Außen (andere Familien), gerahmt von der Sozialstruktur des türkischen Dorfs, lässt sich als Leitunterscheidung in der Fremde nicht mehr halten, denn die Migration nach Deutschland bringt für die Familie zwei Veränderungen mit sich: »Die Familie ist nicht mehr Produktions- und Konsumtionseinheit, die anderen, gleichfalls unabhängigen Familien in Gegenseitigkeitsverhältnissen gegenübersteht, sie ist jetzt eingebettet in komplexe und funktionale Zusammenhänge«. Innen und Außen stehen nicht mehr in Korrelation zueinander, sind voneinander getrennt und das Familienoberhaupt fühlt sich nur noch der Familie verpflichtet. ${ }^{295}$

Als Yasemin nach der nicht erfolgreichen Brautwache zur Hochzeit ihrer Schwester erst einen Tag später nach Hause kommt, weil sie dem Ärger zu Hause entgehen will, ist der bis dahin herzlich dargestellte Vater ein anderer und nimmt auch das Versprechen, dass Yasemin studieren könne, zurück mit der Begründung, dass er gestern noch ein Mann mit Achtung (Şeref) und Ehre (Namus) gewesen und dies heute nicht mehr der Fall sei. Da die Frau die Ehre der Familie repräsentiert, gilt es jetzt für den Vater, Yasemin durch Beobachtung und Kontrolle zu schützen. ${ }^{296}$ Dursun soll nun überall, wo Yasemin hingeht, dabei sein. Der Raum der Verhandlungen ist nun eingeengt, denn das Außen ist in die Familie

291 Ebd., S. 72. Siehe auch: Alabay (2012): S. 98.

292 Alabay (2012): S. 96f.

293 Vgl. SCHIFFAUER (1983): S. 75.

294 Vgl., ebd., S. 68.

295 Ebd., S. 102, 104.

296 Den Aspekt der Kontrolle heben auch die Väter Abdullah Yakupoğlu und Param in Grabes und Geiersbachs Dokumentationen hervor. Siehe hierzu: GEIERSBACH (1982); GRABE (2012). 
eingedrungen, die man nun $\mathrm{zu}$ verteidigen hat, um die Ehre nicht gänzlich $\mathrm{zu}$ verlieren. Diese Einengung betrifft nicht nur Yasemin, sondern auch den Vater selbst. Er bricht den Kontakt zur älteren Tochter ab und zwingt auch die anderen Familienangehörigen dazu.

Dieser Wandel des Vaters von einer verständigen und herzlichen Person zu einem Tyrannen wird für den Zuschauer erst dann schlüssig, wenn wir den Diskurs um Dorf und Ehre mitberücksichtigen. Wenn wir sozusagen >die Türkei` nach Deutschland holen. Denn das, was im Nachhinein Jans Suche nach einem Wörterbuch andeutet - Yasemins Familie folgt anderen sozialen Ordnungen als die westlich-aufgeklärte Gesellschaft -, zeigt sich in der ersten Hälfte des Films nur unterschwellig. Auch die dargestellten deutsch-türkischen Kontakte sind zunächst keineswegs konfrontativ. Als Yasemin sich beispielsweise auch aus Koketterie heraus vor Jan versteckt und ihr Vetter sie sucht, begegnen sich Jan und Dursun, und beide verheimlichen auf eine recht schüchterne Art, wen oder was sie suchen. Sie fangen an, über Jans Motorrad zu reden. Auf der Hochzeit von Yasemins Schwester begegnen wir einer vielfältigen Lebensfreude, die einer besonders bunten Farbdramaturgie folgt. Wenige Frauen tragen Kopftuch und die, die es tun, tragen es traditionell lose am Kopf. ${ }^{297}$ Hier findet sich kein Akteur, ob Mann oder Frau, dessen Freiheit beschnitten wird, weil ein Ehrenkodex einzuhalten wäre. Im Gegenteil steht die Hochzeitssequenz in diesem Film für eine äußerst integrative Kontaktzone, die am Ende nur einen Ausgeschlossenen kennt. Denn Jan ist im Unterschied zu den nahen Verwandten, näheren Bekannten und Yasemins männlichen und weiblichen Freunden aus dem Judo-Verein nicht eingeladen. Er kommt aber trotzdem und wird auf Yasemins Wunsch hin aus der Hochzeitgesellschaft ausgewiesen. ${ }^{298}$

297 Genau so kleidet sich auch Melek Tez in DIE KüMmELTÜRKIN GEHT, als sie einmal eine »richtige Türkin« im öffentlichen Raum darstellen möchte. Siehe hierzu: MEERAPFEL (1985). Diese Art des Kopftuchtragens unterscheidet sich grundlegend vom türkischen »Turbantragen« (Türban), das Ende der 1990er Jahre Verbreitung findet. Die Haare werden dabei gänzlich bedeckt. Das Kopftuch liegt beim Turban (Türban) eng auf der Kopfhaut. In der Türkei wird diese Art der Bedeckung seit mehreren Jahren auch als tesettür giyim modası (bedeckende Bekleidungsmode) bezeichnet. Siehe hierzu: https://www.hurriyet.com.tr/aile/tesettur-giyimde-trend-modamelis-41530797 (zuletzt 12.05.2021).

298 Wie die Deutsche vom Elternbeirat der Schule in Dikmens Der andere Türke einfach ohne Einladung vor der Tür steht, taucht auch Jan ungeladen auf der Familienfeier auf. Obwohl er Yasemin noch gar nicht richtig kennt, zwingt er seine Anwesenheit auf. Nachdem er darum gebeten wurde, die Hochzeitsgesellschaft zu verlassen, sehen wir ihn draußen auf ein Fensterbrett steigen und hineinschauen. Diese herausfordernde Bewegung und Penetranz von Deutschen in türkische Wohnungen und Hochzeiten finden wir an vielen Stellen in den ästhetischen Reflexionen, Dokumentationen und mitunter soziologischen Studien. Auch in UnSERE NACHBARN, DIE 
Die Brautwache bietet Möglichkeiten, den Ehrenkodex zu umgehen. Wir sehen in dieser Filmsequenz zwei ältere türkische Damen mit Yasemin rauchend zusammensitzen. Die Damen erzählen sich selbst und Yasemin eine Geschichte, wie ein junger Mann geschickt den Blutbeweis erbringt, obwohl seine Frischvermählte nicht mehr jungfräulich ist. Er schneidet sich in den Finger, befleckt mit seinem Blut das Bettlacken und zeigt diesen Beweis der Jungfräulichkeit den draußen Wartenden. Von dieser Geschichte sind die zuhörenden Frauen angetan und empfinden sie als eine normale Strategie der kulturellen Verhandlung. Sie müssen von türkischen Mädchen von früher und heute wissen, dass diese nicht jungfräulich geheiratet haben. Man sollte diesen Umstand nur nicht öffentlich machen. Diesen Ausweg kennt Yasemins Schwager offensichtlich nicht, denn er tritt aus dem Schlafzimmer und hat nichts in der Hand. Später werden wir erfahren, dass es nicht an Yasemins Schwester lag, sie war und ist Jungfrau, sondern an der Impotenz des Schwagers, der diese `Schwäche` aus Ehrgefühl nicht zugeben kann. Im Gegensatz dazu ist Params Tochter Alda in Bruder, muß zusammen Zwiebel und Wasser essen! diese Praxis vertraut. Sie wendet sie bei ihrer ersten Hochzeitsnacht in der Türkei an. Sie heiratet dort jemanden, den sie sich selbst ausgesucht hat, weil sie ihn im Unterschied zu den Männern aus ihrem Herkunftsort als modern empfand. In Deutschland stellt sie dann fest, dass er gar nicht so modern ist, wir er sich in der Türkei gab. ${ }^{299}$

Da in den 1980ern der Blick auf `echte Türken oder auf Ausnahmen gerichtet ist, hat Bohms Film eine größere Verbreitung erfahren als Geiersbachs Analyse. Denn der Bruch zwischen der Geschichte der Umgehung und der Verhandlung über kulturelle Gesetze und der Wirklichkeiten im Film YASEMIN - der Unfähigkeit des Schwagers, strategisch zu lügen -, bringt ein neues Verhältnis zwischen Kultur und Akteur ans Licht, das die Befolgung kultureller Gesetze verlangt und die Akteure dadurch ihre soziale Fluidität verlieren lässt. Eine Fluidität, die es bei Başer und Özakın von Anfang an nicht gibt. Doch liegt der Bruch sozialer

BALTAS verhält sich der Schulfreund Incis, Bernd, ähnlich wie Jan in YASEMIN. In der zweiten von zehn Folgen der Serie mit dem Titel »Verbotenes« sitzen Inci und Bernd bei einem Schulausflug gemeinsam in einem Boot. Inci hat Angst und Bernd bringt das Boot weiter zum Schaukeln. Sie bittet ihn damit aufzuhören. »Bernd denkt gar nicht daran aufzuhören. Er schaukelt das Boot immer heftiger. Er tut so, als ob sie in einen heftigen Sturm geraten wären und er Inci retten müsste. Inci schreit auf. Bernd umarmt Inci und versucht sie zu küssen. Inci wehrt ihn ab.« Inci ist zwar ein Mädchen, das ihr Elternhaus verlassen wird, um ihren eigenen Weg zu gehen, aber Bernd ist nicht Teil dieses Weges. Siehe hierzu: PazArkaYA (1983): S. 6. Auch in der sehr interessanten, aber wenig beachteten soziologischen Studie einer türkischen Familie Bruder, muß zusammen Zwiebel und Wasser essen! von 1982 hält sich der Soziologe und Erzähler Paul Geiersbach fast durchweg in der Wohnung der Türken auf. Siehe hierzu: GEIERSBACH (1982).

299 Siehe hierzu: GeIERSBACH (1982): S. 111. 
Interaktionen in YASEMIN, der sich identitätspolitisch in der Figur des Vaters verkrustet und klare kulturelle Grenzziehungen folgen lässt, nicht allein am Ehrenkodex, sondern auch an einem clash der Narrative, an einem Mangel, wo hinein die Möglichkeiten des kulturellen Verhandelns sich bewegen sollen. Die Ehre und das Dorf als geschlossene Einheit sind die eine Seite, sie werden aber zu einem inkohärenten Problem, wenn Menschen mit ihren vielschichtigen Bedürfnisstrukturen gezeigt werden und nicht klar ist, an welchem Ort der Ankunft sie diese stabilisieren können. Hier zeigt sich Jan als emblematische Gegenfigur. Denn wenn auf der türkischen Seite detailliert ein familiärer Alltag gezeigt wird Töchter gehen in die Schule, Vater arbeitet, Mutter kocht für die Kinder, Töchter helfen dem Vater im Geschäft, sie besuchen den Judo-Unterricht usw. -, kennen wir aus Jans Welt nur den Judo-Verein. Sein sonstiger Alltag wird kaum gezeigt.

Es gibt nur eine einzige kurze Sequenz, in der Jan sich zu Hause für die türkische Hochzeit anzieht und sein Vater ihn zum Abendessen erwartet. ${ }^{300}$ Der Vater bemerkt, dass Jan seinen Anzug angezogen hat und versucht, ihm diesen abzunehmen. Jan flieht mit seinem Motorrad, der Vater folgt ihm, erwischt ihn aber nicht und stolpert beim Zurückgehen ins Haus geradezu slapstickartig. Er ist eine deutsche Vaterfigur, die vollkommen eigenschaftslos wirkt. ${ }^{301}$ Keine einzige Szene in diesem Film weist Jan, dem Deutschen, eine Zugehörigkeit oder einen stabilen Ort zu. Aber auch die anderen deutschen Protagonisten, die Lehrerin und Yasemins blonde Freundin, sind in ihrem Auftritt und in ihrer Funktion nur mit der türkischen Familie beschäftigt. Sie haben in diesem Film ebenfalls kein Alltagsleben. Das Deutsche definiert sich hier nicht, unterliegt keiner Reflexion und hat auch keinen Raum, in dem es beheimatet sein könnte. ${ }^{302}$ Und so stellt sich

300 In Literatur, Film und Dokumentation wird das Deutsche auf einer Ebene mit dem Türkischen erst ab Anfang der 2000er Jahre verglichen. Seitdem gehört es zu einem konstitutiven Bestandteil der Erzählungen.

301 In UnSere NachbaRn, DIE Baltas droht Habibs Sohn Arif die Abschiebung, weil er an einem Diebstahl mit zwei deutschen Bekannten beteiligt war. Das Mädchen Marianne, das wie Arif mit den beiden anderen deutschen Jungs zusammenhing, heiratet Arif, weil sie ihn liebt, aber auch, weil sie ihn vor der Abschiebung retten will. Mariannes Eltern sehen wir, wie Jans Vater in Bohms Film, auch nur ein einziges Mal, als sie nämlich ihren Eltern verkünden will, dass sie und Arif heiraten werden. Ihre Eltern wissen davon nichts, werden in Habibs türkisches Restaurant `Kleines Istanbuk eingeladen und entgegnen auf die Anfrage seitens von Habib, Marianne und Arif, dass sie dagegen seien, dass Türken und deutsche Frauen nicht zusammenpassten und verlassen das Lokal. Siehe hierzu: PAZARKaYa (1983): S. 20.

302 Siehe zur Darstellung und Kritik des Narrativs des entleerten und entfremdeten deutschen Alltagslebens im Neuen Deutschen Film und in der Gesellschaftskritik der 1960er und 1970er Jahre: EzLI, Özkan (2012): »Peripherien zwischen Repräsentation und Individuation. Die Körper der Minderheiten in Fassbinders Katzelmacher und ANGST ESSEN SEele AUF«. In: Prekäre Obsession. Minoritäten im Werk von Rainer Werner Fassbinder, hg. v. Nicole Colin, Franziska 
am Ende des Films auch nicht eine Erleichterung oder Freude ein, dass endlich die Liebenden zueinander gefunden haben, sondern vielmehr die Sorge, wohin dieses Paar eigentlich flüchten soll. Ähnlich drängt sich bei YASEMIN auch die Frage auf, was aus dem heterogenen sozialen Geflecht wird, das den ersten Teil des Films bestimmte und von sozialen Verhandlungsräumen und vom sguten und warmherzigen Ausländer geprägt war. ${ }^{303}$

Insgesamt sind in Bohms Film die Verhältnisse zwischen Person, Kultur und Gesellschaft unbestimmt und inkonsistent. Inwieweit ist Yasemins Vater ein Repräsentant und Vollstrecker eines Ehrenkodex, wenn wir beide Teile des Films zusammennehmen? Gleiches gilt für den Vetter, der sich in einer Szene bei Yasemin dafür entschuldigt, jetzt noch mehr auf sie aufpassen zu müssen. Die Figuren sind durchweg gespalten. Die Schwierigkeit der kulturellen Zuordnung zwischen Akteur und Gesetz zeigt sich dabei am stärksten in der Figur Yasemins, die ihre Ablehnung von Ehrenkodizes immer wieder äußert und deren Selbstbestimmung in der Aussage kulminiert, dass sie ein zufälliges Produkt zweier anatolischer Dorfmenschen sei. Dennoch ist die emotionale Bindung zwischen ihr und ihrer Familie positiv stark, nicht aber die zu irgendeiner Kultur. Ayşe Devrims widersprüchliche Diktion aus Wo gehören wir hin?, dass man gegen seine Eltern kämpfen, sie hassen müsse, auch wenn man sie liebt, um frei zu werden, scheint hier durch. ${ }^{304}$ Interessant an Devrims Aussage ist die ihr inhärente Spaltung. Die Liebe ist in ihrem Satz mit den Eltern verbunden, der Hass meint aber nicht die Eltern allein. Ein ähnliches Verhältnis zu den Eltern zeigen die Interviews mit Alda in Bruder, muß zusammen Zwiebel und Wasser essen! und die Aussagen von Perihans deutschem Verlobten in Grabes Dokumentarfilm ABDULLAH YAKUPOĞLU. WARUM HABE ICH MEINE TOCHTER GETÖTET?, wie sie von ihrem Vater zwischen Hass und Verständnis erzählte. Die Verbindung dieser widersprüchlichen Gefühlszustände gegenüber den Eltern ist nur möglich, wenn diese nicht nur einfach die leiblichen Eltern sind. Sie müssen zugleich für etwas anderes stehen und zugleich in einem Zwiespalt stecken, das sich dem Wohlbefinden im öffentlichen Raum widersetzt. Nicht nur die Frauen können nicht nach draußen gelangen, sondern ebenso wenig der Mann. In Grabes Dokumentarfilm ABDULLAH YAKUPOĞLU. WARUM HABE ICH MEINE TOCHTER GETÖTET? wird dies äußerst eindrücklich, wenn Abdullah Yapupoğlu von seinem alltäglichen Leben im rheinland-pfälzischen Andernach berichtet. Er erzählt etwa davon, wie er, nachdem

Schößler, Nike Thun, Bielefeld: transcript, S. 93-124. Siehe auch: RAUER, Valentin (2012): »Imagination des Minoritären. Terroristen in Fassbinder DiE DRITTE GENERATION «. In: Prekäre Obsession, S. 355-370.

303 Vgl. hierzu: GEIERSBACH (1982): S. 10.

304 Ayşe/Devrim (1983): S. 2. 
unter den Türken bekannt wurde, dass zwei seiner drei Töchter geflohen seien, die Jalousien in seiner Wohnung bis auf einen kleinen Spalt unten herunterließ, um zum einen nicht von draußen gesehen zu werden, um zum anderen aber selbst sehen zu können, ob Türken vor seiner Tür stehen. Nachdem er sein »Gesicht«, seine »zweite Haut« verloren hatte, machte er kaum noch die Wohnungstür auf, und er suchte nur noch türkische Kaffeehäuser auf, deren Stammkundschaft von seiner Geschichte nichts wusste. ${ }^{305}$ Er erzählt von einer Begebenheit auf der Hochzeit seiner jüngsten Tochter, die für ihn selbst äußerst schmerzhaft ist. Als ein türkischer Vater versucht, seinen Sohn von der Hochzeitsgesellschaft wegzubringen, schreitet Abdullah ein und meint, dass dieser doch seinen Sohn in Ruhe lassen solle. Der Angesprochene entgegnet, dass er sich von ihm rein gar nichts sagen lasse, von einem, dessen Töchter »deutsche Huren « geworden seien. ${ }^{306}$ Kein einziger Hochzeitsgast habe ihn auf diese Verletzung hin verteidigt. So gesehen könnte man meinen, dass Tevfik Başers Vorhaben, eine türkische Frau auf deutsche Straßen zu schicken, in den 1980er Jahren auch für den türkischen Mann gilt.

Yasemins Schwierigkeit im alltäglichen Leben zwischen privatem und öffentlichem Raum ist wiederum umgekehrt, dass sie als Assimilierte nicht ankommen kann. Denn sie lässt sich in die Leitunterscheidung der 1980er Jahre zwischen deutsch und türkisch nicht eindeutig einordnen. Diese Schwierigkeit wird jedoch in erster Linie nicht zum Problem, weil ein Ehrenkodex greift, denn dieser wird nur in Ausnahmefällen aktualisiert. Vielmehr wird die Mischung aus Assimiliert-Sein und Unbestimmtheit bei Yasemin zum Problem, weil die andere, die deutsche Seite in diesem, aber auch in den anderen Spiel-, Dokumentarfilmen, literarischen Texten und Reportagen fehlt. So nah und vertraut sich die Deutschen in den Produktionen zeigen und zeigen möchten, kippt ihr Verhältnis zu den Türken schnell zu einem sehr distanzierten, wenn die Kultur auf der anderen Seite einfach einbricht. Denn dann muss man »staunend « einfach mit ansehen, wie sich der Konflikt »fast gesetzesmäßig « verschärft. ${ }^{307}$ In all den genannten Dokumentationen sprechen Jeanine Meerapfel, Hans-Dieter Grabe und Paul Geiersbach kaum bis gar nicht. Man sieht nicht, wo sie sind oder ob sie stehen oder sitzen. Wir wissen nur, dass sie im Raum sind. Doch kann hier nicht im Sinne von einem Raum im Certauschen Sinne gesprochen werden, denn es liegt keine hybride Konstellation vor. Vielmehr geht es ausschließlich um den Ort des Türken im Raum, darum was er sagt und warum er das sagt, was er sagt.

305 Siehe hierzu: GRABE (2012).

306 Siehe hierzu: GRABE (1986).

307 Zitat aus: Boнм, Hark (1988): Yasemin, DVD, Zweitausendeins Edition 3. 
Ein Ort ist die Ordnung (egal, welcher Art), nach der Elemente in Koexistenzbeziehungen aufgeteilt werden. Damit wird also die Möglichkeit ausgeschlossen, daß sich zwei Dinge an derselben Stelle befinden. Hier gilt das Gesetz des `Eigenen`: die einen Elemente werden neben den anderen gesehen, jedes befindet sich in einem reigenen Bereich, den es definiert. ${ }^{308}$

Im Raum hingegen können zwei Dinge an derselben Stelle zugleich sein, denn er ist ein »Geflecht von beweglichen Elementen «. ${ }^{309}$ Nach Certeau ist der Raum ein Ort, mit dem man etwas macht. ${ }^{310}$ Doch in den ästhetischn Produktionen ist einfach nur klar, wo der Türke steht, aber nicht wo der Deutsche steht. Und es ist genau diese Konstellation, die Probleme der sozialen Interaktion als besondere kulturelle adressiert und damit ihre Verantwortlichkeit auch auslagert. Mit dem Dialog zwischen Shirin und Helma Sanders-Brahms in SHIRINs HochzeIT ist diese Verteilung nicht zu vergleichen. Hier greift eine andere Ordnung, andere Differenzen sind im Spiel. Paul Geiersbach weist sich beispielsweise in der Einleitung explizit als eine Vertrauensperson der Familie aus. Und tatsächlich entsteht in der Dokumentation der Eindruck, dass ihm die Familienangehörigen Geschehnisse und Ansichten schildern, die sie sich nicht einmal untereinander erzählen. Doch im Unterschied zu Aras Ören und Helma Sanders-Brahms spricht Geiersbach nicht mit. Er steht zwar metaphorisch und zugleich buchstäblich mitten in der Wohnung der türkischen Familie, achtet aber streng darauf, das Geschehen in seiner Arbeit zu kommentieren oder zu interpretieren. ${ }^{311}$ Er ist eine Vertrauensperson, die selbst nichts Vertrauliches von sich preisgibt. Er kommt einem fast vor wie der unbekannte Dritte in der Wohnung von Dursun und seiner Frau, der sie zum Sprechen bringt, aber selbst nichts sagt. Es ist dieses ein- und zugleich ausgeschlossene Deutsche, das für das komplizierte Verhältnis zwischen Türken und Deutschen in den 1980er Jahren mit verantwortlich ist und wie die Ehrvorstellungen aus der Türkei einen regelrechten Identitätsstress auslösen.

Unter den beschriebenen Bedingungen ist der Türke im öffentlichen Raum, entweder ein Türke oder ein assimilierter $>$ Nicht-mehr-Türkeく. Auch der ehemalige Berliner Bürgemeister Richard von Weizsäcker, der das erste Berliner Ausländeramt mit der Personalie Barbara John in Berlin Kreuzberg gründete, und eine offene und integrative Politik gegenüber den Ausländern verfolgte, konstatiert

308 CeRTEAU (2006): »Praktiken im Raum«. In: Raumtheorie. Grundlagentexte aus Philosophie und Kulturwissenschaften, hg. v. Jörg Dünne, Stephan Günzel, Frankfurt a. M.: Suhrkamp, S. 343353, hier S. 345.

309 Ebd.

310 Siehe hierzu: Ebd., S. 346.

311 GEIERSBACH (1982): S. 11. 
1983, dass die Ausländer sich zwischen einer Repatrierung und einem Deutscher werden entscheiden müssen. ${ }^{312}$ Dazwischen gibt es nichts. Und ebenso wenig kann es für diese Konstellation Vertreter geben. Vielmehr ist nur die Darstellung möglich, was es heißt, als Türke auf die Straße zu gehen, als Türke in Deutschland zu leben, obwohl man sowohl Türkisch als auch Deutsch spricht und obwohl man dieselben Städte bewohnt, Alltage und Orte teilt wie die Deutschen. Es ist äußerst frappierend und kaum zu glauben, dass das äußerst amateurhafte Gastarbeiterdeutsch von Ali Siğirlioğlu, alias Günter Wallraff - er bezeichnet es selbst als ein "gebrochenes Kölsch« -, in Ganz Unten von keinem Handwerksmeister, Subunternehmer oder anderen deutschen Arbeitern als ein falsches erkannt wird. ${ }^{313}$ Den türkischen Kollegen erzählt Wallraff, dass er als Türke in Griechenland aufgewachsen sei und deshalb so komisch spreche. Die Türken können unter diesen >diskriminierenden` Bedingungen entweder nur als Assimilierte auftreten, indem sie wie Französinnen aussehen oder Die Zeit lesen, oder nur als Türken, denen man ihre Rückständigkeit ansieht. Die Fragen der Zivilisiertheit und der Modernität sind nun ausschließlich Fragen der Türken geworden. Die Deutschen sind per se Bürger der Bundesrepublik, ohne dafür einen besonderen demokratisch-politischen Aufwand betreiben zu müssen. Sie stehen auf einer Seite der Modernität, die nicht beschrieben wird. Ihre Aufgabe ist nicht mehr eine explizit politische, sondern besteht darin, ihre »Lebenschancen« als Selbstbestimmungen zu nutzen, die ihnen das neue neoliberale Wirtschaftsund Gesellschaftsmodell anbietet. ${ }^{314}$ An ihre Stelle treten nun die Türken, die mit ihrer Gewalt klarkommen müssen, die nicht mehr allgemein-menschlich und humoral-körperbedingt ist, sondern nun spezifisch kulturabhängig oder als „Überreaktion psychisch gepeinigter Menschen « ${ }^{315}$ verstanden, aber nicht mehr als soziale Frage behandelt wird. Das Dazwischen, in das die Akteurinnen und Akteure hineinsprechen und in dem sie sich dann befinden, ist ein entvölkerter Bereich, der keine wirksame und entsprechende Vertretung aufbauen oder finden lässt. Anders gesagt: Die Gespräche, das Weitersprechen findet »drinnen « statt; die Türken werden so zu keinem vollwertigen Bestandteil der bundesrepublikani-

312 Aus: Soysal, Yasemin Nuhoğlu (1994): Limits of Citizenship. Migrants and Postnational Membership in Europe, Chicago: University of Chicago Press, S. 153.

313 WALlRAFF (2011): S. 12. Siehe hierzu besonders: GFöRER (1986). Der Dokumentarfilm ist auf youtube unter folgendem Link abrufbar: https://www.youtube.com/watch?v=VxMkXcypdUc (zuletzt 12.05.2021).

314 Siehe hierzu: DAHRENDDORF, Ralf (1986): Lebenschancen. Anläufe zur sozialen und politischen Theorie, Frankfurt a. M.: Suhrkamp. Ein Modell, das Anfang der 1980er Jahre in vielen Ländern weltweit Verbreitung findet, wie in Großbritannien unter Margaret Thatcher, in den USA unter Ronald Reagan und in der Türkei nach dem Putsch durch Turgut Özal.

315 GeIERSBACH (1982): S. 9. 
schen Gesellschaft. Aber auch die Türken selbst schreiben sich bewusst in dieses Modell ein. Die meisten Akteurinnen und Akteure in den analysierten Produktionen sprechen gutes Deutsch, doch kaum einer von ihnen will anerkennen, dass er oder sie in den 10 bis 15 Jahren in der Bundesrepublik auch ein wenig Deutsch geworden ist. Äußerst eindrücklich und verstörend zeigt dies Meerapfels Film. Melek selbst spricht darin durchgehend gutes Deutsch. Selbst als sie mit ihrer Tochter telefoniert, wechseln beide nach ersten türkischen Sätzen ins Deutsche. Zudem hat Melek Tez in Deutschland auch nicht wieder einen Türken geheiratet und hatte viel Kontakt zu Deutschen. Doch als Jeanine Meerapfel in der Mitte des Films eine ihrer ganz wenigen Fragen mit einer deutlich zitternden Stimme aus dem Off stellt, ob sie, Melek, in der Zwischenzeit vielleicht doch nicht ein wenig deutsch geworden sei, reagiert Melek schockiert, irritiert und auch etwas beleidigt. Sie verstehe diese blöde Frage überhaupt nicht, antwortet Melek. ${ }^{316}$ Sie habe vielleicht gewisse Erfahrungen in Deutschland gemacht, aber deutsch sei sie mit Sicherheit nicht geworden. Daraufhin schildert sie, wie ihre Verwandten sie in der Türkei als deutsch beschreiben, weil sie jetzt alles sehr schnell mache und dass früher nicht so gewesen sei. Also bist Du doch deutsch geworden, versucht Meerapfel diesmal selbstbewusster, die Identitätsfrage $\mathrm{zu}$ stellen. Melek redet zunächst weiter, bis sie wieder kurz stockt und eindringlich wiederholt, dass sie nicht deutsch geworden sei, sondern nur gewisse Erfahrungen gemacht habe. Sie beendet ihren Monolog damit, dass sie eigentlich gar nicht mehr wisse, wer sie sei. Wahrscheinlich habe sie es auch nicht gewusst, bevor sie nach Deutschland kam. In der Türkei werde sie das jetzt herausfinden und sie möchte vor allem das Land bereisen. ${ }^{317}$

Hier und an anderen Stellen in den Produktionen der 1980er Jahre zeigt sich die besondere und äußerst wirksame Referenz auf die Türkei. Sie ist das imaginierte, zugleich reale Land, in das die Rückkehr noch möglich ist und das die Diskriminierungserfahrungen kompensieren lässt. Einen der letzten Sätze äußert Meerapfel Melek gegenüber gar nicht, weil sie glaubt, dazu nicht das Recht zu haben. Er lautet, dass Melek, je mehr sie sich »in Berlin als Türkin verletzt fühlte, desto mehr [...] in ein heiles Bild der Türkei« flüchtete. Und in heute geführte aktuelle Debatten gefragt, was passiert mit Diskriminierungserfahrungen und -wahrnehmungen, wenn es ein solches Bild der Türkei und des Orients nicht mehr gibt? In der letzten Einstellung von DIE KÜMMELTüRKIN GEHT von 1985 sehen wir Melek in einer Istanbuler Straße der Kamera Meerapfels entgegenlaufen.

316 MEERAPFEL (1985).

317 Ebd. 


\subsection{Fazit zu »Wie lebt es sich als Türke in Deutschland?»}

Als der amerikanische Soziologe Milton Gordon 1964 seine Integrationstheorie vorlegt, leitet er diese mit den Worten ein, dass es ihm im Kern darum gehe, auf die "problems of prejudice and discrimination arising out of differences in race, religion, and national background among the various groups which make up the American people $« \mathrm{zu}$ reagieren. ${ }^{318}$ Nicht die Grundlagen kultureller Differenzen interessieren ihn, sondern die Akte der Diskriminierung, der Abspaltung von Gruppen mit negativen Markierungen. Die Realität und den Verlauf der »intergroup relations«, wie sie Anfang der 1960er Jahre in den Vereinigten Staaten sich für Gordon zeigen, beschreibt er als ein »race horse galloping along with blinders «. Es weiß nicht, woher es kommt, wo es ist und wohin es führt. „But he's making progress! ${ }^{319}$ Der Grund für seinen Optimismus ist, dass es Amerika als Idee und Territorium vor Ort gibt und dass sich trotz aller bestehenden Diskriminierungen in den Vereinigten Staaten, besonders gegenüber den black people, alle Gruppen am Ende darauf werden verständigen können, ein Teil dieses Amerikas zu sein. Es gibt die Projektion eines Raums und diese ist vor allem von der Idee sozialstrukturellen Aufstiegs bestimmt. Diesen Prozess und den Bedarf nach dieser Rahmung erkennt Gordon jedoch nicht allein in Amerika, sondern versteht ihn als einen allgemein-menschlichen und geschichtlichen, der besonders dort stattfindet, wo es zu Verstädterungen und Industrialisierungen kommt, wo die Kontakte unterschiedlicher Menschen und Menschengruppen rapide zunehmen. ${ }^{320}$

In den 1960er und 1970er Jahren beschreibt Norbert Elias den Zivilisationsprozess in ähnlicher Weise als einen Verlauf, der »ungeplant« und »blind« geschieht, aber doch mit einer »eigentümlichen Ordnung« einer »ganz bestimmten Richtung « folgt. ${ }^{321}$ Und ähnlich wie bei Gordon ist es auch bei Elias der Kontakt, die Begegnung und die Interaktion, aus der sich Richtung und Ordnung ergeben.

Pläne und Handlungen, emotionale und rationale Regungen der einzelnen Menschen greifen beständig freundlich oder feindlich ineinander. Diese fundamentale Verflechtung der einzelnen, menschlichen Pläne und Handlungen kann Wandlungen und Gestaltungen herbeiführen, die kein einzelner Mensch geplant oder geschaffen hat. Aus ihr, aus der Interdependenz der Menschen, ergibt sich eine Ordnung von ganz spezifischer Art, eine Ordnung,

318 Gordon, Milton (1964): Assimilation in American Life. The Role of Race, Religion, and National Origins, New York: Oxford University Press, S. 3.

319 Ebd., S. 9.

320 Ebd., S. 18.

321 ELIAS, Norbert (1969): Der Prozess der Zivilisation. Wandlungen der Gesellschaft. Entwurf zu einer Theorie der Zivilisation, Frankfurt a. M.: Suhrkamp, S. 323. 
die zwingender und stärker ist, als Wille und Vernunft der einzelnen Menschen, die sie bilden. Es ist diese Verflechtungsordnung, die den Gang des geschichtlichen Wandels bestimmt; sie ist es, die dem Prozeß der Zivilisation zugrunde liegt. ${ }^{322}$

Auch in der strukturalistisch und systemtheoretisch ausgerichteten Theorie des bekannten amerikanischen Soziologe Talcot Parsons aus den 1950 und 1960er Jahren, stehen soziale Handlungen, Begegnungen und Interaktionen im öffentlichen Raum im Zentrum seiner Gesellschaftstheorie. Dabei stellt der Begriff Inklusion eine Schlüsselkategorie dar. Mit Inklusion, einem »highly complex process«, meint Parsons die Beteiligung und Berücksichtigung von Personen oder Gruppen in sozialen Strukturen und Systemen. ${ }^{323}$ Genauer hält er in seiner bekannten Schrift Full Citizenship for the Negro American? von 1965 fest, dass die Inklusion »refers to the pattern of action in question, or complex of such patterns, and the individuals and/or groups who act in accord with that pattern coming to be accepted in a status of more or less full membership in a wider solidary social system «. ${ }^{324}$ Zwar werden durch diesen Prozess der Inklusion soziale Ungleichheiten nicht aufgehoben, jedoch ermöglicht er multiple Zugehörigkeiten nach Klassen, Ethnien und Religionsgemeinschaften in einem gemeinsamen Referenzrahmen. Die Grundlage dieses gemeinsamen Referenzrahmens sind in die jeweils eigene Lebenswelt übersetzbare Handlungsmuster und Praktiken. Seine These und zugleich Hoffnung ist, dass durch die Zunahme ähnlicher Handlungsmuster neue gemeinsame Werte entstehen (value generalization). Bei diesem zivilgesellschaftlichen Prozess müssen religiöse und ethnische Eigenheiten nicht aufgegeben werden. ${ }^{325}$ Dieser Prozess ist für Parsons deshalb von besonderer Wichtigkeit, weil moderne Gesellschaften durch Steigerungen von Komplexität, von neuen Aufgabenfeldern und Bedürfnissen, eine der funktionalen Ausdifferenzierung sind. Und dort, wo Ausdifferenzierungen zunehmen und jedes entstehende Teilsystem nur eigene Verantwortungen kennt, werden keine Vorstellungen von sozialer Einheit generiert. Inklusionsprozesse nehmen genau diese Funktion des gesellschaftlichen und solidarischen Zusammenhalts ein. Sie sind der Garant für Integration.

So unterschiedlich die genannten drei bekannten Soziologen zu Beginn der zweiten Hälfte des 20. Jahrhunderts untereinander sein mögen, in Fragen der Interaktion und der emergenten Entstehung von allgemeinen und sozialen Struk-

322 Ebd, S. $324 \mathrm{f}$.

323 PARSons, Talcott (1965): »Full Citizenship for the Negro American? A Sociological Problem«. In: Daedalus, Vol. 94, No. 4, The Negro American (Fall, 1965), S. 1009-1054, S. 1015.

324 Ebd., S. 1016.

325 Siehe hierzu: PARSONS (1965): S. 1047. 
turen in modernen Gesellschaften sind sie nah beieinander. Die Unterschiede zwischen Gordon, Parsons und Elias sind, dass ersterer mit »Amerika« der Richtung einen Namen und ein Territorium geben kann, der zweite diese Entwicklung der modernen Gesellschaft mit den Entitäten Handlungsmuster, System und Inklusion beschreibt und letzterer weder in der ersten Ausgabe seiner Theorie in den 1930er Jahren noch in der zweiten erweiterten Auflage von 1969 die Richtung eines Zivilisationsprozesses zu benennen vermag. Doch was Elias genau bestimmen kann, ist, wie Gordon und Parsons, dass jeder Zivilisierungsprozess physische wie psychische Gewalt unter den verflochtenen Menschen reduziert, im Idealfall zum Verschwinden bringt. So stehen jenseits der Differenz von Zivilisation und Amerika bei Gordon, Parsons und Elias der Kontakt, die Interaktion im öffentlichen Raum, letztlich eine Verflechtungsordnung von Aktion und Reaktion im Zentrum der Entwicklung und folgerichtig auch die Anti-Diskriminierung. Zentral sind in Gordons siebenstufigem Integrationsmodell folglich die "assimilation variables« "Absence of prejudice«, "Absence of discrimination« und schließlich die »civic assimilation" als "Assimilation in American Life». ${ }^{326}$ Der Abbau von Vorurteilen und Diskriminierungen ist also die Grundlage einer tatsächlich stattfindenden Integration, einer problemlosen Bewegung von türkischen Migranten hinaus auf deutsche Straßen. Doch wird Gordon neben der Grundlage eines gemeinsam geteilten Territoriums auch keinesfalls müde zu erwähnen, dass eine wichtige Grundlage für das Verschwinden von Vorurteilen und Diskriminierungen der sozialstrukturelle Aufstieg zuvor benachteiligter Gruppen ist. ${ }^{327}$

Wie an anderer Stelle im vorliegenden Buch bereits erwähnt, spielen die drei zuletzt genannten Variablen in Essers Theorie Aspekte der Wanderungssoziologie keine besondere Rolle im Prozess der Integration und Assimilation. Vielmehr, meint Esser, würde sich die Identifikation mit der Aufnahmegesellschaft von selbst ergeben, wenn Sprache, Beruf und soziale Kontakte zusammenkommen und soziale Mobilität gegeben ist. Kultur ist für Esser Anfang der 1980er Jahre eine private Angelegenheit. Diese apolitische Form der Integrationstheorie ist im Falle Essers mehreren - praktischen wie auch theoretischen - Faktoren geschuldet. Erstens sind die Formen der öffentlichen Diskriminierung in den Vereinigten Staaten in der Entstehungszeit von Gordons Theorie mit denen in der Bundesrepublik in den 1970er Jahren nicht direkt zu vergleichen. Denn die 1950er und 1960er Jahre waren in den Vereinigten Staaten, besonders im Süden des Landes, von unmittelbaren Diskriminierungen der Afroamerikaner geprägt.

326 Siehe hierzu: GoRdon (1964): S. 78.

327 Siehe hierzu: GoRdon (1964): S. 52f. 
Rassentrennungen in Hotels, Bussen, Park- bis hin zu Sanitäranlagen prägten die Stadtbilder. Eine öffentliche Struktur der Segregation, die auf die Entscheidung des obersten Gerichtshofs im Fall Plessy vs. Ferguson von 1896 zurückgeht. Die Entscheidung des Gerichts, dass getrennte Zugabteile für schwarze und weiße amerikanische Bürger im Bundesstaat Louisiana nicht gegen die amerikanische Verfassung verstieße, etablierte den Grundsatz »separate but equal (getrennt, aber gleich), der die Rassen im öffentlichen Raum voneinander schied und diese Politik der Segregation in der amerikanischen Gesellschaft legalisierte ${ }^{328}$ Es gab zudem für Afroamerikaner eine Liste, die sie das `Grüne Buch nannten, in der stand, in welchen Restaurants und Hotels sie essen und schlafen dürfen und welchen nicht, wenn sie durch das Land reisten. ${ }^{329}$ Gordon beschreibt eine solche Hotelsuche in seinem Buch als ein Faktum der Diskriminierung. Und dass Gordon selbst so eine Interaktionssequenz auswählt, deutet schon seine theoretische Differenz zu Esser an, dass er nämlich den Ankömmling nicht einfach nur als einen rationalen Akteur begreift, sondern auch als einen emotionalen. Was sich im Inneren der beteiligten Akteuren abspielt, interessiert Gordon genauso wie das, was draußen stattfindet. Dass es Diskriminierungen im öffentlichen Raum in der Bundesrepublik gegeben hat, habe ich bereits gezeigt.

Daher ist äußerst bemerkenswert, dass genau diese zwei Seiten in der Bundesrepublik der 1980er Jahre, die rationalen wie emotionalen Folgen der Migration, nicht zusammengedacht werden, wie in Gordons Integrations- oder in Elias' Zivilisationstheorie, in denen »Pläne und Handlungen, emotionale und rationale Regungen der einzelnen Menschen [...] beständig« ineinander greifen. Wenn allein bei Esser der rationale Akteur und sozialstrukturelle Fragen im Vordergrund stehen, sind es in Elwerts Theorie die Gefühle und das Bewusstsein des Migranten. Er empfiehlt den Migranten als Grundlage für eine gelingende Integration eine stabile Einbettung in den eigenen Communities, um dort ein stabiles individuelles Bewusstsein zu entwickeln, mit dem sich dann auf Diskriminierun-

328 HuRston, Zora Neale (2018): Barracoon. Die Geschichte des letzten amerikanischen Sklaven, München: Penguin, S. 193f.

329 Siehe hierzu: Ridderbusch, Katja (2014): »Die Aufhebung der Rassentrennung in den USA«. In: Deutschlandfunk, 02.07.2014. http://www.deutschlandfunk.de/50-jahre-gleichberechtigung-die-aufhebung-der.724.de.html?dram:article_id=290732 (27.11.2017). Im aktuellen Hollywood-Kinofilm GREEN BooK, der in den frühen 1960er spielt, steht das Grüne Buch im Zentrum der Erzählung. Bei der Oscarverleihungen 2019 erhielt es den Oscar für den >Besten Film‘. Siehe hierzu: FARRELLY, Peter (2019): Green Book. Eine besondere Freundschaft, Kinoverleih: eOne (Erstaufführung 31.01.2019). DiE WELT (2019): »Green Book als bester Film geehrt. Kein totaler Triumph für Roma«. In: Die Welt, 25.02.2019, https://www.welt.de/kultur/kino/article189342143/ Oscars-2019-Green-Book-erhaelt-den-Oscar-als-bester-Film.html (zuletzt 09.04.2019). 
gen selbstbewusst reagieren lässt. Doch ist dies eine andere Form der Reaktion auf Diskriminierungen, wie es sich Gordon oder Elias als eine endogene aus einer sozialen Verflechtungsordnung oder aus einem gemeinsam geteilten Amerika heraus gedacht haben. Elwert setzt auf ein sich emisch entwickelndes kulturelles Bewusstsein. Kultur dient hier als eine Art Schutzschild und nicht als etwas, das zusammen aus den Interaktionen heraus geschaffen werden könnte.

Es ist die Trennung von Gefühlen und Handlungen bzw. Vernunft, die auch das Verhandeln der Folgen der Arbeitsmigration in die Bundesrepublik in Dokumentation, Ästhetik und Theorie in den 1980er Jahren bestimmt. Sie begegnet uns durchgehend in den Produktionen dieser Dekade. Günter Wallraffs Dokumentation wurde beispielsweise vorgeworfen, dass sie nur »Mitleid « erzeuge. ${ }^{330}$ Tatsächlich war es aber auch ein bewusstes Ziel Wallraffs, mit GANZ UNTEN »Gefühle« in einer Gesellschaft entstehen zu lassen, »die sich sonst nur rational verhält und rein intellektuelle Abwehrmechanismen zuläßt «. ${ }^{331}$ Auf der anderen Seite hat Wallraff von vielen Türken als Reaktion auf sein Buch gehört, dass es für sie in Elwert'scher Diktion eine »Schutzfunktion « erfüllt und ihr »Selbstbewusstsein gestärkt « habe. ${ }^{332}$ Diese Diktion bestimmt auch den Film von Jörg Gförer, der auf den geheimen Aufnahmen Wallraffs basiert. Weder in Wallraffs Text noch in Gförers Film werden die Türken kaum bei der Arbeit oder bei anderen spezifischen sozialen Handlungen beschrieben oder gezeigt. Selbst die selbstbewusste Melek sehen wir in Meerapfels Dokumentation nur kurz in der Mitte des Films bei der Arbeit. Diesen besonderen Aspekt des Dramatischen und Psychischen hebt Paul Geiersbach in seiner Dokumentation ebenfalls hervor. ${ }^{333}$ Dort sehen wir auch niemanden bei der Arbeit. Wir haben gesehen, dass auch in den anderen Filmen mehr gefühlt und gesprochen wird, als die Akteurinnen und Akteure handelnd in einer interaktiven »Verflechtungsordnung « zu zeigen. Ihr Sprechen und Empfinden steht für etwas, das wir nicht sehen, nämlich für die Diskriminierungserfahrungen, für das Getrennt-Sein, das negativ markiert ist. Dieser Überschuss des Emotionalen ergibt sich nicht einfach daraus, dass die Handlungsfähigkeiten der Akteurinnen und Akteure als kulturell eingeengt skizziert werden. Im Kern

330 WALLRAFF (2011): S. 422.

331 Ebd.

332 Ebd., S. 424. Die türkische Dolmetscherin und Journalistin Yıldı El-Toukhy, die in den 1980er Jahren für das Landgericht in Hannover arbeitete und zudem ehrenamtlich für einen islamischen Verein aktiv war, übersetzte Wallraffs Buch kostenlos ins Türkische, weil viele ihrer »Landsleute um eine Übersetzung des Buches gebeten« hatten. Zudem wurde im »Türkischen Generalkonsulat [...] Ganz unten den Mitarbeitern als Pflichtlektüre verordnet«. Siehe hierzu: KuCHENBECKER, Astrid (1985): »Türken in der Stadt erkennen sich im Buch von Wallraff wieder «. In: Neue Presse, 25.10.1985.

333 Siehe: GEIERSBACH (1982): S. 9. 
geht die Unterscheidung von Gefühl und Kälte in den Darstellungen nicht auf kulturelle Differenzen zurück, sondern auf zwei erzählerische Aspekte. Zum einen findet in allen Dokumentationen eine gewisse Selbstreflexivität statt, die mit dem Faktor Wirklichkeit spielt. Denn entgegen dem Befund der Sekundärliteratur steht die Schwierigkeit der Repräsentation sehr wohl im Raum der behandelten Arbeiten. In Meerapfels Dokumentarfilm DIE KüMMELTÜRKIN GEHT sehen wir mehrere Aufnahmen, die die Gemachtheit des Films dokumentieren. Wir sehen eine Haustür, die Klappe mit dem Arbeitstitel MELEK GEHT, und wir hören, wie ein Mitarbeiter des Filmteams in die Aufnahmen hineinruft »Melek geht, die achte«, und die Klappe zugeschlagen wird. Oder Melek spielt im ersten Drittel des Films nach, wo sie die ersten Jahre in der Bundesrepublik gewohnt hat. Das Frauenwohnheim Ende der 1960er und Ende 1970er Jahre, das ihre erste Wohnstätte war, ist Mitte der 1980er Jahre ein Finanzverwaltungsbüro. Wir sehen Melek mit Meerapfel in die Büroräume und Flure gehen, in denen sie früher gewohnt hat. Dass Melek später in einer eigenen Wohnung gelebt hat, wird ebenfalls filmisch nachvollzogen. Nicht um die Dinge geht es bei dieser Nacherzählung, sondern um die Gefühle der Protagonistin, die aufkommen, wenn sie zurückblickt. ${ }^{334}$

Diese kumulative Struktur des Emotionalen interessiert auch Geiersbach, wenn er versucht $\mathrm{zu}$ erklären, warum es manchmal gewalttätig und ruppig in türkischen Familien zugeht. ${ }^{335}$ Die dafür gewählte Erzählweise erinnert an einen Roman. Und selbst in GANZ UNTEN inszeniert Wallraff am Ende darstellerisch die Wirklichkeit. Im abschließenden Kapitel »Der Auftrag oder hopp und ex - eine Inszenierung der Wirklichkeit« wird der Subunternehmer Vogel mit einem fingierten lukrativen Auftrag von Wallraffs Gruppe in eine Entscheidungssituation gebracht, in der er bewusst türkische Leiharbeiter in einen Kernreaktor schickt, ohne sie über die Lebensgefahr aufzuklären, die mit der dort zu erledigenden Arbeit einhergeht. ${ }^{336}$ Leser und Zuschauer von Buch und Film erleben diese Inszenierung der Wirklichkeit jedoch nicht als eine Konstruktion, sondern als ein Faktum der Ausländerfeindlichkeit in der Bundesrepublik, die Wallraff zuvor mit der Dastellung von Diskriminierungserfahrungen wie »Türken stinken «, »vermehren sich wie Karnikel«, »Tod allen Türken« und »Türken raus« bereits freigelegt hat. ${ }^{337}$ Die Darstellung und der Aufbau der Wirklichkeitskonstruktion dient in diesen Dokumentationen wie auch in den behandelten literarischen Texten und Spielfilmen dazu, den Empfindungen und Verletzungen der Akteurinnen und Akteure einen freien Weg nach draußen $\mathrm{zu}$ bahnen und sie nicht einfach

334 Siehe hierzu: MEERAPFEL (1985).

335 GEIERSBACH (1982): S. 11.

336 WALLRAFF (2011): S. $241 \mathrm{ff}$.

337 Siehe hierzu: ebd., S. 38-47. 
mit den sozialen Bedingungen ihres Lebens zu erklären. Anders gesagt: Turna ist vielleicht physisch nie aus der 40 qm-Hinterhofwohnung in Hamburg herausgekommen, aber ihre Gefühle schon.

Es gibt noch einen weiteren Grund dafür, warum die Gefühlsebenen sich in diesen Dokumentationen, Spielfilmen und literarischen Texten durchsetzen und die Wirklichkeit als eine zwischen Innen und Außen gespaltene wahrnehmen lassen. Denn es liegt auch an den `Zuhörern ` wie Hans-Dieter Grabe, Jeanine Meerapfel oder Paul Geiersbach, die als Teil der Aufnahmen, als Interviewer kaum mit- oder widersprechen und den anderen nur sprechen lassen. Sie senden, obwohl sie selbst mitten im Raum stehen, kaum bis gar keine Hörersignale aus. Aufgrund dieser asymmetrischen Dialogkonstellation vergessen und sehen wir in allen Filmen und Texten nicht, mit wem die Akteurinnen und Akteure sich eigentlich noch unterhalten. Letztlich dominiert der Eindruck, die dargestellten sTürken`stünden entweder in Kommunikation mit der deutschen Gesellschaft oder mit der türkischen Kultur und Community. Dass die deutsche Seite hier nicht eingreift, nicht wirklich ins Gespräch kommt und nur den Anderen zum Sprechen bringen will, gehört mit zum Problem der Integration in den 1980er Jahren, ist aber zugleich eine Stärke der besprochenen Reflexionen. Denn erst die Darstellung dieser verfangenen Dialogsituation und Begegnungsstruktur macht das eigentliche Problem der Integration in den 1980er Jahren evident. Es ist letztlich dasselbe Problem, dem wir begegnen, wenn wir uns in Bohms Film am Ende fragen, wo Jan und Yasemin jetzt eigentlich glücklich werden sollen.

Diese Zurückhaltung haben aber keineswegs allein die Deutschen zu verantworten, sondern auch die Türken selbst. Denn sie übersetzen die angefangenen Dialoge nur deshalb in Monologe, weil sie genau glauben zu wissen, was der Deutsche oder die Deutsche wirklich über sie denkt. Die Verflechtungen, die wir in den 1960er und 1970er Jahren zwischen den Frauen in SHIRINS HocHzEIT, DöNÜŞ und zwischen Arbeiterinnen und Arbeitern in Türkler Almanyada, in Was will Niyazi in der Naunynstraße kennengelernt haben, sind in den 1980er Jahren verschwunden. Wenn die Vorrangstellung von Konsum und anderen körperlichen Bedürfnissen einen Dialog vor dem Dialog in den 1960ern und 1970ern platzierte, ist mit der kulturell ausgerichteten Frage »Wie es sich als Türke in Deutschland lebt « die Kommunikation selbst zum Problem geworden. ${ }^{338}$ Dass aus solch einer Kommunikationskonstellation und Begegnungsstruktur dennoch viele ästhetische und dokumentierende Erzählungen entstanden sind, die diese

338 Selbst mein Vater, Fazlı Ezli, der 1970 als Gastarbeiter aus der Westtürkei in die Bundesrepublik gekommen war, hatte es sich zur Gewohnheit gemacht, jede Person, die nur ansatzweise ausländisch aussah, als »Türken« zu identifizieren. 
Situationen darstellen, liegt daran, dass der Bezug zur Türkei nicht allein ein imaginärer, sondern auch ein alltäglicher und ein territorialer war. Er war sowohl imaginär als auch praktisch in den eigenen Alltag eingebunden durch türkische Zeitungslektüre, türkische Filme, türkische Lebensmittelgeschäfte, die Vorstellung vom türkischen Dorf, der orientalischen Stadt Istanbul über die Vertretungen religiöser und nationaler Gemeinden bis zu den türkischen Kaffeehäusern in der Bundesrepublik. Hinzu kommt, dass trotz dieser Vermischung und kulturellen Einwanderungssituation in der Bundesrepublik klare territoriale Grenzen gezogen werden. Sie reichen von religiösen und nationalen Vereinen, deren Aktivitäten sich alle an der Türkei orientierten, bis zur Aussage Meleks zu Anfang des Films DiE KÜMMELTÜRKIN GEHT, dass das Pfeifen in der Türkei ein anderes sei als in Deutschland. Dort sei es fröhlich, hier traurig. ${ }^{339}$ Habib Balta, der Protagonist in UNSERE NACHBARN, DIE BALTAS, bezeichnet als seine »Quelle des Glücks« das Quellwasser aus seinem türkischen Heimatdorf. Der Türkeibezug in den 1980er Jahren ist sowohl Schutz als auch Grundlage der Diskriminierung. Denn das Türkische ist wie das Deutsche zugleich da und nicht da.

Auf eine besondere und leicht veränderte Weise wird der türkische Präsident Recep Tayyip Erdoğan zuerst Ende der 1990er Jahre und spätestens 2008 in seiner bekannten Kölner Rede sich in diese verfangene Konstellation der türkeistämmigen Deutschen einschreiben. ${ }^{340}$ Bekannt wurde seine Formulierung, dass "Assimilation ein Verbrechen gegen die Menschlichkeit« darstelle. Integration beschreibt er hingegen als wichtig. Doch spricht er in seiner Kölner Rede die vor ihm versammelten Menschen nicht als Bürger der Bundesrepublik, sondern als seine eigenen, als türkische Staatsbürger an. Dabei geht er noch weiter und insistiert, dass alle Anwesenden den Duft des anatolischen Bodens noch in »ihren Nasen« hätten. ${ }^{341}$ Allein hier stellt sich die Frage, was für eine Art von Integration

339 Siehe hierzu: MEERAPFEL (1985).

340 Siehe hierzu: Erdoğan, Recep Tayyip (2008): »'Assimilation ist ein Verbrechen gegen Menschlichkeitヶ. Seit Tagen sorgt die Kölner Rede des türkischen Tayyip Erdoğan für Kritik und Empörung. Doch was hat er genau gesagt? Sueddeutsche.de dokumentiert die Rede Erdoğans im Wortlaut«. In: SÜDDEUTSCHE ZEITUNG, 17.05.2010, http://www.sueddeutsche.de/politik/erdogan-rede-in-koeln-im-wortlaut-assimilation-ist-ein-verbrechen-gegen-die-menschlichkeit-1.293718 (27.11.2017).

341 Ebd. Interessant ist auch, dass das türkische Parlament unter der Führung der AKP am 13. März 2008 ein Gesetz verabschiedete, dass es den Auslandstürken zum ersten Mal ermöglichte, in der Bundesrepublik ihre Stimmen für türkische Wahlen in türkischen Konsulaten abzugeben. Zuvor konnte man nur per Briefwahl oder in der Türkei wählen. Siehe zur Gesetzesänderung: RESMî GAZETTE (2008): Kanun. Secimlerin Temel Hükümleri ve Seçmen Kütükleri Hakkında Kanunda Deǧişiklik Yapılmasina dair Kanun, Kanun No. 5749, Sayı: 26824, 22 Mart Cumartesi 2008. Äußerst interessant an dieser Wahlgesetzänderung ist der darin enthaltene Absatz 10, der Wahlwerbungen und Wahlauf- 
Erdoğan meint. ${ }^{342}$ Es kann sich, wie es auch die türkische Politik seit dem Verfassungsrefendum von 2017 zeigt, nur um eine wirtschaftliche denn werteorientierte handeln.

Den eigentlichen Hauptgrund der »diskursiven Zwickmühle« der Subalternen zwischen Moderne und Tradition in den 1980er Jahren, wie ihn Spivak zeitgleich beschreibt, kann sie selbst erst knapp eine Dekade später wirklich ausmachen. In einem Interview von 1993 konstatiert sie, dass sie damals eigentlich nur eines sagen wollte, aber nicht geschrieben hat: dass nämlich das Sprechen des Subalternen erst das Hören »vollständig macht « ${ }^{343}$, sozusagen die Reaktion des Hörenden. Und wie Dursun in 40 QM DEuTsChland und Aysel Özakın in ihren Büchern hat es Spivak Mitte der 1980er Jahre "Seelenqualen « gekostet, diesen »inneren Kampf « überhaupt darstellen zu können. ${ }^{344}$ Denn auch sie hatte sich an der »zweiten Haut« abzuarbeiten. Wir werden sehen, dass es genau die Komponente des Hörens und des Ablehnens oder Fehlens der »zweiten Haut« ist, und nicht allein die des Sprechens oder der Artikulation, die in den Produktionen von Emine Sevgi Özdamar, Feridun Zaimoğlu, Fatih Akın, Zafer Şenocak und vielen anderen in den 1990er Jahren bedeutsam wird. Wenn Norbert Elias, Talcott Parsons und Milton Gordon mit Vorstellungen von Zivilisation, allgemeiner Wertebildung oder Amerika auf Diskriminierungen reagieren und so einen Raum der Zukunft projezieren konnten, hat diese Funktion in den 1980er Jahren von türkischer wie von deutscher Seite aufgrund eines neuen emischen, von essentiellen Unterschieden anstelle von einer sozialen Verflechtungsordnung bestimmten Aktion-Reaktion-Verhältnisses die Türkei oder das Türkisch-Sein übernommen. Doch zeigen die Produktionen dieser Zeit auch äußerst eindrücklich, dass dies, die Türkei, die Herkunft, nicht die Lösung ist und auch nicht sein kann. Allein das Faktum, dass sich die Zahl der Türkeirückkehrer wie beispielsweise Melek Tez trotz der Rückkehrförderung 1983 und 1984 in Grenzen gehalten hat, stärkt den Befund der vorliegenden Analyse. ${ }^{345}$ Mit dem Verblassen des Rückkehrmo-

tritte jeder türkischen Partei im Ausland kurz vor anstehenden Wahlen und Abstimmungen verbietet. Das heißt, dass mit den geplanten Wahlauftritten in Deutschland zum Verfassungsreferendum von 2017 in der Türkei die AKP selbst gegen ihr eigens verabschiedetes Gesetz verstoßen hat.

342 Wir werden sehen, dass die Grundlage für solch ein widersprüchliches Verständnis von Integration, eine ohne Übereinstimmtung von Staatsbürgerschaft und Integration, ihre Grundlage in den Entwicklungen und Nicht-Entwicklungen der 1990er Jahre hat.

343 SPIVAK (2007): S. 127.

344 Ebd.

345 Die Ethnologin Barbara Wolbert zeigt in ihrer Studie Der getötete Pass von 1995 exemplarisch die Biografien von 17 Rückkehrinnen in die Türkei der ersten Generation auf. Dass diese auch in ihrem Herkunftsland nicht ankommen konnten, hängt nach ihren Ergebnissen besonders mit dem Umstand zusammen, dass die Rückkehr nicht als eine der Re-Integration vom 
tivs und seiner Motivation Ende der 1980er Jahre wandelt sich auch der lange als Residenz begriffene Aufenthalt der Gastarbeiter in Deutschland in eines auf Dauer abgestellten Domizilaufenthalts. Und im Unterschied zur Residenz impliziert das Domizil »some kind of legal relationship to the state«, in dem gelebt wird. ${ }^{346}$ Der »innere Kampf « in der Wohnung, im Café, im Gefängnis oder im türkischen Lebensmittelgeschäft wird zu einem äußeren und öffentlichen.

Die Verschiebung vom Territorium und der Kultur der Herkunftsgesellschaft zum Territorium der Ankunft steht auch zu Beginn der 1990er Jahre im Zentrum der theoretischen Reflexionen zu den Folgen der Gastarbeitermigration in Europa in den Arbeiten Democracy and the Nation State. Aliens, Denizens and Citizens in World of international Migration (1990) und Limits of Citizenship. Migrants and Postnational Membership in Europe (1994) von Tomas Hammar und Yasemin Soysal. Ausgangspunkt beider wissenschaftlichen Reflexionen ist, dass das Bleiben der Gastarbeiter und ihrer Nachfahren in den westlichen Gesellschaften 15 bis 20 Jahren nach der Einwanderung, ohne die Staatsbürgerschaft der Aufnahmegesellschaft angenommen zu haben, zwischen dem Ausländersein (foreign citizen) und dem Bürgerwerden in der Ankunftsgesellschaft eine hybride Zwischenposition des "permanent resident « geschaffen hat. ${ }^{347}$ Und im Unterschied zur Bürgerschaft (citizenship), unter der Parsons in den 1960er Jahren eine »full membership in a wider solidary system« verstanden hatte, bestimmt Hammar den »permanent resident« als einen »denizen«, der zur Nation der Ankunftsgesellschaft durch seine Präsenz über Wohnort (domicile) und öffentlichem Raum zwar gehört, dessen politische Repräsentation jedoch nicht existiert, da sie sich beispielsweise wegen der fehlenden Staatsbürgerschaft weder an kommunalen noch an nationalen Wahlen beteiligen können. Und da ein Ausschluss von

Herkunftsland und den Angehörigen der türkischen Frauen verstanden und inszeniert wurde. Es hat nach Wolbert eine »öffentliche Anerkennung« gefehlt. Die Rückehrenden wurden nicht als Rückkehrende aufgenommen. Denn sie werden in der Türkei als »Almancılar« oder »Almanyalılar« bezeichnet. Ihre Rückkehr ist nach Wolbert »gekennzeichnet von einer Spannung, die aus dem Nebeneinander von Bedeutsamkeit und fehlender Anerkennung, von symbolischer Aufladung und Formlosigkeit entsteht«. Siehe hierzu: WolBerT, Barbara (1995): Der getötete Pass - Rückkehr in die Türkei. Eine ethnologische Migrationsstudie, Berlin: Akademie. Siehe hierzu auch: ÖLÇEN, Ali Nejat (1986): Türken und Rückkehr. Eine Untersuchung in Duisburg über die Rückkehrneigung türkischer Arbeitnehmer als Funktion ökonomischer und sozialer Faktoren, Frankfurt a. M.: Dağyeli.

346 Hammar, Tomas (1990): Democracy and the Nation State. Aliens, Denizens and Citizens in a World of International Migration, Vermont: Avebury Gower Publishing Company Limited, S. 194. 347 7,5 Millionen der 12 Millionen Ausländer leben zu Beginn der 1990er Jahre seit über 15 bis 20 Jahren in Europa, ohne die Staatsangehörigkeit der Aufnahmeländer angenommen und die der Herkunft abgelegt zu haben. Siehe hierzu: Hammar (1990): S. 22. 
politischer Partizipation zu politischer Absenz und Passivität im Verhältnis der eingewanderten Menschen zur Aufnahmegesellschaft führe, schlägt Hammar im Gegensatz zum citizenship-Modell vor, nicht die Staatsbürgerschaft zum entscheidenden Marker der Zugehörigkeit zu erklären, sondern »the fact that a person actually lives in a certain place«. Denn »domicile is increasingly taken a basis for judicial and adminsitrative decisions and [...] within national states political rights are often tied to domicile ${ }^{348}$

Jahre später entwickelt Soysal das Konzept des auf Dauer und Wohnort beruhenden Konzepts des Denizenship auf die politische Identität eines "postnational membership« weiter. Im Kern steht bei ihr die widersprüchliche Bewegung zwischen nationalerstaatlicher Souveränität und universellen Menschenrechten. Die Anrufung von Letzterem hat nach Sosyals Ergebnissen besonders nach dem Zusammenbruch der Sowjetunion rapide zugenommen. ${ }^{349}$ Die häufende Anrufung Letzterer führt zu einer Unterminierung und regelmäßigen Überschreitung nationaler Grenzziehungen. Vielmehr wird erst durch diese globale Dialektik zwischen nationaler Territorialssouveränität und der Anrufung universeller Menschenrechte klar, dass das Reden von der Nation aus Prozessen und Akten der Grenzziehungen hervorgeht. Im Zentrum von Soysals vorgestellter Membership steht deshalb nicht ein »wider solidary system «, sondern die »personhood«, das Menschsein, denn »the individual transcends the citizen «. ${ }^{350}$ Bezeichnenderweise ist der politische Slogan »Kein Mensch ist illegal«, der auf die Aussage »No human being is illegal« von Ellie Wiesel (1988) zurückgeht, mit einer der bekanntesten politischen Aussagen der 1990er Jahre. ${ }^{351}$

So erfolgt mit dem Hören des Gesagten in den 1990er Jahren auch eine territoriale Verschiebung von der Türkei nach Deutschland, von den türkischen Residenzen in Deutschland auf die deutschen Straßen. Sie steht für eine Verbindung von deutsch und türkisch, die nicht mehr ausgelagert oder verschoben werden kann. Und weil die türkischen Wohnungen aufgelöst werden, sind aber die deutschen Straßen auch nicht einfach deutsche Straßen mehr. Doch auch wenn durch diese Verschiebung des öffentlichen Raums durch den ausländischen Mitbürger, der als Denizen bleibt, eine weitere Internationalisierng und Globalisierung einsetzt, ist

348 HAMmar (1990): S. 194.

349 Beispielsweise hat ein französisches Gericht die Gefahr der Genitalverstümmelung westafrikanischer Frauen mit Verweis auf die universellen Menschenrechte im Sommer 1993 als Grund für Asyl und Flucht anerkannt. Soysal zählt mehrere Gerichtsentscheidungen zu Beginn der 1990er Jahre in westlichen Gesellschaften auf, die in ihrer Argumentation sich auf die allgemeinen Menschenrechte beziehen. Siehe hierzu: Soysal (1994): S. 158f.

350 SoYSAL (1994): S. 142.

351 Siehe hierzu: http://nohumanbeingisillegal.com/Home.html (zuletzt 19.01.2019). 
die gesellschaftspolitische Konstellation in den 1990er Jahren in der Bundesrepublik, besonders nach der deutschen Wiedervereinigung, keineswegs einfacher als zuvor. Zwar findet mit der Änderung des Ausländerrechts 1990 im »Windschatten der deutschen Vereinigung « eine Ausweitung des Daueraufenthaltsrechts und der Einbürgerung statt, »die von der [bisherigen] Ermessensvorschrift zum Regelanspruch intensiviert wird «. ${ }^{352}$ Doch sind die Folgen der Migration kein Teil dieser Änderung. Zum einen werden bestehende juristische Regelsysteme einfach auf die Ausländerfrage angewendet. Zum anderen ist es weiterhin nicht möglich als Türke zugleich Deutscher zu sein. Wer die deutsche Staatsbürgerschaft nach acht oder fünfzehn Jahren Aufenthalt in Deutschland bekommen möchte, muss die türkische ablegen. Die Migrationsfrage und die mit ihr verbundene Migrationsgeschichte werden dadurch "gleichsam unsichtbar « gemacht. ${ }^{353}$ Nach Daniel Thym stellt das Ausländergesetz von 1990 den Höhenpunkt der Denizenship dar, das zwar aufenthalts- und sozialrechtlich Ausländer und Inländer gleichstellt, jedoch nicht als volle und gleiche Bürger anerkennt. "Deutschland erlebte eine Gleichzeitigkeit von aufenthalts- und sozialrechtlicher Gleichstellung sowie symbolischer Ausgrenzung der Ausländer. Der Übergang zu Denizenship folgte einer pragmatischen Politikgestaltung, die die identifikatorische Zugehörigkeitsfrage im geteilten Nationalstaat umging. « ${ }^{354}$ Deutschland bleibt so de facto kein Einwanderungsland. Hinzu kommt, dass das lange das Dasein der Gastarbeiter und Ausländer bestimmende Narrativ, nächstes Jahr würde man zurückkehren, in den 1990er Jahren seine territoriale Referenz verliert. Es wird zu einer reinen Vorstellung, zu einem »imaginary homeland «. ${ }^{355}$ Als Folge dessen fällt die »zweite Haut« als Herkunft, Identität und Zukunft ab, und was dann als stabilisierende Referenz übrig bleibt, ist der eigene Körper. Äußerst eindrücklich zeigt sich diese neue Kon-

352 Тнум, Daniel (2018): „Vom Fremdenrecht über die Denizenship zur Bürgerschaft. Gewandeltes Selbstverständnis im deutschen Migrationsrecht«. In: Der Staat. Zeitschrift für Staatslehre und Verfassungsgeschichte, Deutsches und Europäisches Öffentliches Recht, 57. Band Heft 1, Berlin: Duncker \& Humblot, S. 77-117, S. 95.

353 Mit einer vergleichbaren Pragmatik und Symbolarmut wurde auch die deutsche Wiedervereinigung verhandelt. Es hätte Anfang der 1990er Jahre die Möglichkeit gegeben, mit einer gesamtdeutschen Nationalversammlung oder einer Volksabstimmung eine demokratische Neugründung Deutschlands zu initiieren. Der letzte Artikel des Grundgesetzes, Art 146 GG, hat diese Möglichkeit vorgesehen. Die Wiedervereinigung wurde dagegen einfach als eine vertragliche Vereinbarung festgehalten. Der Verfassungsrechtler Christoph Möllers interpretiert diesen Vorgang heute als ein Indiz dafür, "wie schwach der Anspruch der Beteiligten war, eine wirklich gemeinsame politische Ordnung zu beginnen«. Siehe hierzu: MöLlERS, Christoph (2019): Das Grundgesetz. Geschichte und Inhalt, München: C.H. Beck, S. 84.

354 Ebd., S. 96.

355 RushdiE (1991). 
stellation in Feridun Zaimoǧlus erstem Roman Abschaum von 1997. Die Gang des deutsch-türkischen Protagonisten Ertan Ongun versucht darin, ein Kieler Stadtviertel unter ihre Kontrolle zu bringen. Nach der Hälfte des Romans hält der Erzähler zynisch und ironisch fest, dass man sich »also fremdes Territorium angeeignet und verteidigt« habe. Doch in Wirklichkeit sei »alles nur so Pseudoterritorium, is ja gar nicht deins, es gehört ja den Deutschen amina koyim. Du denkst, in diesem Territorium is ein Teil von dir, aber Scheiße is da, amina koyim. " ${ }^{356}$ Jetzt - weder deutsch noch türkisch -, sondern als »Bastard« und »Kanake« oder als deutsch und türkisch zugleich, lautet die Frage, die sich in den Raum zwängt, nicht mehr, wie es sich als Türke in Deutschland, sondern wie es sich in der eigenen Haut lebt. Dass dieser weitere Verlust nicht ein weiteres Opfernarrativ heraufbeschwört, sondern im Gegenteil tatsächlich eine Aneignung mit sich bringt, liegt an einem bestimmten Auftreten im öffentlichen Raum. Ein Auftritt, der signalisiert, dass dort, wo sie leben auch ihr Platz ist. Zudem verschiebt sich die Konstellation und die Form der Diskriminierungen. Jetzt sind es die Deutsch-Türken selbst, die diskriminieren, die diese Trennung und Wertung in Form einer Autokommunikation selbst vornehmen. Beide Aspekte zusammen führen zu einer besonderen Konfliktkonstellation der gemeinsam geteilten Gegenwart. Doch muss vor dem Übergang von einer Herkunftsgesellschaft wie in den 1980er Jahren zur Konfliktgesellschaft der 1990er Jahre aber erst die zweite Haut abfallen.

Wie in den 1980er Jahren werden wir auch im Kapitel zu den 1990er Jahren sehen, insbesondere in den Literaturen und Filmen der ersten Generation von Emine Sevgi Özdamar, Aras Ören, Tevfik Başer, Renan Demirkan und Kemal Kurt, dass diese neue politische und zugleich narrative Konstellation keineswegs allein für die zweite Generation, sondern auch für die erste gilt. Doch ist eine Unterscheidung interessant und erwähnenswert, die viele Probanden der ersten Generation dem türkischen Wirtschaftswissenschaftler Ali Nejat Ölçen im Zusammenhang des Themas »Fremdheit in beiden Kulturen« gaben. »Vielleicht sind wir heimatlos, dagegen haben unsere Kinder keine Chance mehr, weil sie weltlos aufwachsen werden. ${ }^{357}$ Tatsächlich ist Integration in den 1990er Jahren Glückssache und die Kategorie der Welt oder des »Menschseins«, wie in Soysals und anderen transnational ausgerichteten Theorien, nimmt in den ästhetischen Erzählungen ebenfalls eine äußerst entscheidende Funktion ein. Dass das Ende des Narrativs »Nächstes Jahr kehren wir zurück«, seine erzählerischen Kon-

356 ZAimoglu (1997): S. 65. »Amına koyim« steht im Türkischen für eine äußerst ordinäre Schimpfrede, die mit der ordinären Sprache in Özdamars Roman korreliert. In Das Leben ist eine Karawanserei verwenden der Kutscher, aber auch einige andere Akteure diese Formulierung recht häufig.

357 ÖLÇEN (1986): S. 130. 
sequenzen und die politische Invisibilisierung der Folgen der Migration nicht zu einer Verhärtung des Opfernarrativs in der folgenden Dekade führt, hat mit drei zentralen Modifikationen zu tun, die von der Ästhetik bis zur Sozialpolitik reichen und eine besondere Form der Aneignung dokumentieren. Erstens liegt es an einer bestimmten Form des Auftretens im öffentlichen Raum, zweitens verschiebt sich die Kommunikation der Diskriminierung. Wenn jemand jetzt diskriminiert, dann sind es nun die Deutsch-Türken selbst, die diese Trennung und Wertung in Form einer ironischen und existenziellen Autokommunikation vornehmen. Sie beleidigen die Deutschen und sich selbst. Sie sind Täter und Opfer zugleich. Als beispielsweise der Privatdetektiv Kemal Kayankaya in Dorris Dörries Film HAPPY BIRTHDAY TÜRKE von $1991 \mathrm{zu}$ Beginn vom deutschen Hausmeister diskriminierend angeschnauzt wird, weil er im Hausflur einen Zigrattenstummel findet und Kayankaya darauf in mahnendem Ton sagt, dass er hier nicht so leben könne wie in der Türkei, nimmt Kayankaya - im Unterschied zu Yasemin, ihrem Bruder und Melek Tez in Meerapfels Film - den Hausmeister nicht ernst. Er läuft mit seinem braunen Mantel im Hausflur lässig am Hausmeister mit einer Zigarette im Mund vorbei und erinnert dabei an die Coolness der amerikanischen Privatdetektivfigur Philipp Marlowe aus den Kriminalromanen der 1930er Jahre von Raymond Chandler. Er steigt in den Fahrstuhl, lässt den Hausmeister schimpfen und erwidert ihm nur, dass er, die »Putze, einfach das Maul halten soll ${ }^{358} \mathrm{Ka}$ yankaya macht klar, der Hausmeister soll seinen Job machen und er jemand ist, der auf Dauer ein Bewohner des Mehrparteienhauses ist und der Verweis auf die Türkei bei ihm überhaupt nicht mehr zieht. Zudem spricht Kayankaya akzentfreies Deutsch, kann aber kaum noch Türkisch, weil seine Eltern früh verstorben sind. Durch Stil, Auftritt und Sprache agiert Kayankaya reaktive Kräfte aus. Es ist letztlich diese ästhetische Performanz, die auf den diskriminierenden Akt des Hausmeisters reagiert. Anfang der 1980er Jahre erklärt der ehemalige Cumhuriyetzeitungsredakteur Dursun Akçam, warum die Gastarbeiter auf Beleidigungen nicht reagieren, weil sie denken, es ist nicht ihr Land und dass sie sehr bald zurückkehren werden. ${ }^{359}$ An die Stelle dieses Verweisens und auch Ausweichens treten Ästhetik und Form. Durch sie werden Affekte und Emotionen des Unbehagens ausagiert und erhalten so eine symbolische Repräsentanz.

So deutet die Szene aus Dörries Film schon auf den dritten zentralen Aspekt der Verhandlung von Migration und ihren Folgen in der Bundesrepublik an, nämlich auf die zentrale Funktion der ästhetischen Erzählung in einem globalen

358 DöRRIE, Doris (1991): Happy Birthday Türke!, Mainz: Zweites Deutsches Fernsehen. 359 Акс̧Ам, Dursun (1982): Deutsches Heim - Glück allein. Wie Türken Deutsche sehen, Berlin: Lamuv, S. 38. 
Zusammenhang und des Kommunikationsabbruchs. Was hier Marlowe ist, ist in der Kanak Sprak der amerikanische Hip Hop, in Akıns und Arslans Filmen das amerikanische und französische Kino und in Özdamars Romanen der Surrealismus und das Theater Brechts. Doch ist es in den Produktionen der 1990er Jahre keineswegs so, dass damit wieder ein Amerikaner oder Europäer werden wollen einsetzen würde. Vielmehr steht im Kern der Reflexionen nicht mehr »der Türke vom Dienst « sein zu wollen, und klar auszusagen, dass man wie jeder andere einfach ein Mensch ist. Und wenn sie jetzt keine eindeutigen Türken mehr sind, heißt das aber noch lange nicht, dass sie jetzt einfach Deutsche sind. Dass aber mit der Verweigerung, der Türke »vom Dienst« zu sein und mit Verweigerung einer kulturellen Identität auch sozialstrukturelle, ökonomische und allgemeingesellschaftliche Fragen von Positionierung verbunden sind, wird auch im Zentrum des folgenden Kapitels stehen. Doch zeigt uns allein die Änderung des Ausländerrechts von 1990, dass es für diese nicht mehr trennbare Verbindung weder eine öffentliche Anerkennung noch eine öffentliche Semantik in der Bundesrepublik gibt. ${ }^{360}$ Die Gegen-Position, die im öffentlichen Raum keinen Platz hat, bedarf eines besonderen ästhetischen Aufwands, um gegen die formelle die informelle Wirklichkeit zu setzen. So geht es im Artikulationsprozess des Hybriden in den 1990er Jahren nicht mehr einfach darum, die Grundprinzipien politischer Diskriminierung aufzudecken. Tatsächlich ist der Hausmeister in Dörries Film unwichtig, wie auch in vielen allen anderen Filmen und literarischen Texten der 1990er Jahre rechtsgesinnte und rechtsradikale Figuren höchstens Nebenfiguren sind. In den 1990er Jahren werden viele Ausländer von Rechtsradikalen ermordet, ${ }^{361}$ doch kaum ein Film oder ein literarischer Text macht diese Morde zum Thema der Erzählung.

Nach Bhabha, einem der theoretischen Wortführer der 1990er Jahre, zielt die Analyse von kultureller Differenz nicht mehr auf die Aufhebung von Diskriminierungen, wie in Gordons oder Parsons Theorie. Im Kern geht es nun darum »position of enunciation and the relations of address within « zu verändern. Es geht um eine Umformung des Ablaufs des artikulatorischen Prozesses. ${ }^{362} \mathrm{Ihr}$ Austragungsort ist die Schwelle, die Straße, der Weg, jedoch ohne eine Richtungsvorgabe wie die der Zivilisation. Die ästhetischen Figuren der 1990er Jahre sind Nomaden, die sich von Reisenden und Migranten unterscheiden, von Residenz und Einwanderung. Sie kehren weder irgendwohin zurück, noch kommen sie irgendwo an, denn sie sind aus Deutschland nie weggegangen. Anstelle von der Herkunft oder vom

360 Siehe hierzu: HAMMAR (1990): S. 14.

361 JANSEN, Frank/KLEFFneR, Heike/RAdKE, Johannes/Staud, Toralf (2012): »Tödlicher Hass. Todesopfer rechter Gewalt«. In: Der Tagesspiegel, 31.05.2012, https://www.tagesspiegel.de/themen/ rechtsextremismus/toedlicher-hass-149-todesopfer-rechter-gewalt/1934424.html (zuletzt 26.03.19). 362 Siehe hierzu: BнABHA (1994): S. 162. 
»Gang eines geschichtlichen Wandels bestimmt « zu sein, stehen im Vordergrund Performanz und Gegenwärtigkeit der Akteurinnen und Akteure und damit die Unterbrechung eingefahrener Narrative wie Moderne und Tradition, die sich auf einer entwicklungslogischen Zeitachse konstituiert. Nicht um die Übersetzung oder Aneignung von Verhaltensweisen als Entwicklung oder von Gefühlen als ein Verstehen des Anderen geht es in den 1990er Jahren, sondern um einen Bruch solcher sozial verallgemeinerbaren Praktiken, Theorien und Vorstellungen, die national oder kulturell codiert sein könnten. ${ }^{363}$ Die soziale und kulturelle Anomie ist der Ausgangspunkt der Erzählungen von Integration und Desintegration in den 1990er Jahren. Nicht nur, weil das Deutsche vom Türkischen und umgekehrt in Sprache und Auftritt nicht mehr zu trennen ist, sondern weil das einzige Innen, das es in den 1990er Jahren gibt, sich zwischen Herz und Haut im Körper bewegt und nicht mehr in Wohnungen oder bestimmten kulturellen Communities. Das Warten im Provisorium der Migration ist zu einer Suche geworden, die nicht mehr von Geduld, sondern von Ungeduld bestimmt ist. ${ }^{364}$ Integration ist in dieser komplexen Konstellation in den 1990er Jahren mehr denn je eine Frage der Erzählung und des Auftritts. Doch bevor dies alles wirkmächtig werden kann, muss zuerst die zweite Haut abfallen, das Türkischsein der 1980er Jahre. Dieser Prozess, das werden uns die Analysen des vierten Kapitels der vorliegenden Kulturgeschichte zeigen, ist unter den Bedingungen der 1990er Jahre, von Brüchen, von existenziellen und sensitiven denn von abstrakt-kulturellen Fragen bestimmt. Die einzige höhere Ordnung, die in Text und Film in den 1990er Jahren angerufen wird, ist die des „Mensch-Seins“. Wie stabil diese ist und welchen Aufwand ihr Sichtbarmachen verlangt, werden die Analysen für die 1990er Jahre ebenfalls zeigen.

Wie in den Kapiteln zuvor wird es im folgenden Einstiegskapitel 4.1. In der Gesellschaft überleben zu den 1990er Jahren darum gehen, ein Panaroma der ästhetischen Erzählungen zu präsentieren. Im daran anschließenden zweiten Teil der Einleitung zu den 1990er Jahren mit 4.2. Kultur als eine Frage des »Wohnens" werde ich prüfen inwieweit die theoretischen, politischen und gesellschaftspolitischen Debatten mit diesem Panaroma korrelieren, bevor ich mich der genauen Analyse der Erzählungen in Literatur und Film widmen werde.

363 Zur Postnational Membership konstatiert Soysal, dass sie »confers upon every person the right and duty of participation in the authority structures and public life of a polity, regardless of their historical or cultural ties to that community. A Turkish guestworker need not have a sprimordial < attachment to Berlin (or to Germany, for that matter) to participate in Berlin's public institutions and make claims in its authority structures «. Siehe hierzu: SoysAL (1994): S. 3.

364 Vgl. Leggewie, Claus/ŞENocAK, Zafer (1993): Deutsche Türken. Das Ende der Geduld, Reinbek: Rowohlt. Siehe auch: KuRT, Kemal (2000a): »Ungeduld«. In: ders, Der Chinese von Schöneberg, Berlin: Hitit, S. 18-24, S. 23. 